University of Louisville

ThinkIR: The University of Louisville's Institutional Repository

Electronic Theses and Dissertations

$5-2013$

\title{
Exploring the influence of social media on future intentions of charity sport participants.
}

Tara Q. Mahoney

University of Louisville

Follow this and additional works at: https://ir.library.louisville.edu/etd

\section{Recommended Citation}

Mahoney, Tara Q., "Exploring the influence of social media on future intentions of charity sport participants." (2013). Electronic Theses and Dissertations. Paper 889.

https://doi.org/10.18297/etd/889

This Doctoral Dissertation is brought to you for free and open access by ThinkIR: The University of Louisville's Institutional Repository. It has been accepted for inclusion in Electronic Theses and Dissertations by an authorized administrator of ThinkIR: The University of Louisville's Institutional Repository. This title appears here courtesy of the author, who has retained all other copyrights. For more information, please contact thinkir@louisville.edu. 


\title{
EXPLORING THE INFLUENCE OF SOCIAL MEDIA ON FUTURE INTENTIONS OF CHARITY SPORT PARTICIPANTS
}

\author{
By \\ Tara Q. Mahoney \\ B.A. Nazareth College of Rochester, 2005 \\ M.B.A. West Virginia Wesleyan College, 2007 \\ A Dissertation \\ Submitted to the Faculty of the \\ College of Education and Human Development \\ in Partial Fulfillment of the Requirements \\ for the degree of \\ Doctor of Philosophy \\ Department of Leadership, Foundations, and Human Resource Education \\ University of Louisville \\ Louisville, KY
}

May 2013 
Copyright 2013 by Tara Q. Mahoney

All rights reserved 



\title{
EXPLORING THE INFLUENCE OF SOCIAL MEDIA ON FUTURE INTENTIONS OF CHARITY SPORT PARTICIPANTS
}

\author{
By \\ Tara Q. Mahoney \\ B.A. Nazareth College of Rochester, 2005 \\ M.B.A. West Virginia Wesleyan College, 2007 \\ A Dissertation Approved on
}

April 12, 2013

By the following Dissertation Committee:

T. Christopher Greenwell, Chair

Karen Freberg

Namok Choi

Anita M. Moorman

Kristi King 


\section{DEDICATION}

This dissertation is dedicated to my family. Mom and Dad, you always told me I could do anything I put my mind to, and that has never rang more true than now. Thank you for your unwavering support in all of the decisions I make (as crazy as they may seem at the time). I would not have had the courage to take this leap without knowing you were there for me. Kevin, Colleen, Audrey, and Mike, thank you for your positive attitudes and support from afar. Erin, thank you for being the most amazing seester a girl could ever ask for. You always know exactly how to raise my spirits when I need it most.

I would also like to dedicate this dissertation to my Louisville family. Bill, Caitlin, and Lincoln, you have been my support system throughout the past three years and truly are family. I knew anytime I needed anything you three were there for me, and that has been such a blessing. Meg, it has been wonderful to have a roommate who understands this doctoral mayhem. Marion, I am eternally grateful for your support, encouragement, and words of wisdom from day one of this journey. Thank you for being a mentor, a researcher partner, and my best friend.

I love you all very much. This would not have been possible without the support from each and every one of you. 


\section{ACKNOWLEDGEMENTS}

I would like to acknowledge the team of individuals who provided their support and expertise to help make this dissertation idea a reality. Dr. Chris Greenwell, thank you for your patience with me over the past three years. I would not be the researcher that I am today without your guidance. Prof. Anita Moorman, thank you for encouraging me to challenge myself with legal research and teaching. I appreciate and have learned greatly from your analytical thought processes. Dr. Namok Choi, thank you so much for literally teaching me everything I know about statistics. Knowing that you care about me as a person and as a student made this process so much more enjoyable. Dr. Kristi King, thank you for being a mentor and a friend. Your professional and personal support through this process has been invaluable. Dr. Karen Freberg, thank you so much for passing along your social media expertise. I am so thankful to have you as an outside committee member and research partner. Dr. Marion Hambrick, as an unofficial member of my committee, I cannot thank you enough for your insights, advice, and always entertaining edits toward the completion of IM Diss.

I would also like to thank the other members of the Sport Administration faculty, Professor Bernstein and Dr. Hums, for always making me feel like a faculty member these past three years. A word of thanks also goes out to my fellow doctoral students and extended cohort for their research collaborations and support through this process. Thank 
you Per Svensson, Dr. JaePil Ha, Dr. Meg Hancock, Dr. Jason Simmons, Dr. Greg Greenhalgh, Chulwhan Choi, Chang-Hung Lee, Sun Kang, Maki Itoh, Jason Rice, and Matt Huml. Finally, I would like to thank my GA crew--Michael Clemons, Jennifer DeWitt, Ryan Rudman, Rich Calabrese, Alicia Cintron, Kathleen Sipe, Johanna Pfeiffer, and Sam Olson--for making the black hole a great place to work. 


\section{ABSTRACT \\ EXPLORING THE INFLUENCE OF SOCIAL MEDIA ON THE FUTURE INTENTIONS OF CHARITY SPORT PARTICIPANTS}

Tara Q. Mahoney

April 12, 2013

Charity sport participation has gained increasing popularity, with over 11.6 million individuals participating and organizations raising more than $\$ 1.7$ billion annually through charity sport participation events (Run Walk Ride Foundation, 2012). An increased number of alternatives created a competitive environment among charitable organizations to recruit and retain charity sport participants (Gladden, Mahony, \& Apostolopoulou, 2004). The use of social media provides an opportunity for organizations to efficiently and effectively raise awareness about a cause (Waters, Burnett, Lamm, \& Lucas, 2009) and build relationships with participants and alumni (Waters \& Jamal, 2011), potentially creating a competitive advantage.

The purpose of this study was to determine how charity sport organizations could leverage social media to enhance recruitment, retention, and future support of their organization. This study examined charity sport motives (i.e., cause, philanthropy, social, health and fitness, and sport), social media intensity of usage (i.e., high, moderate, and 
low), and social media consumption motivations to gain insights about maximizing future intentions (i.e., future participation intention, future support of the organization, and participants' willingness to refer). Multiple quantitative analyses were used to examine these relationships.

Data were collected from an international sample of Team in Training participants and alumni, a charity sport subset of the Leukemia and Lymphoma Society. Results yielded cause, philanthropy, social, and health and fitness-related motives as significant predictors of future intentions. Five primary motivations for social media consumption were identified (i.e., community, information, social interaction, pass time, and entertainment) and four typologies of social media users (i.e., avid, purposive, leisurely, and minimalist users) were created based on social media consumption motivations and social media intensity of usage. Further analysis revealed differences in social media typologies based on charity sport motivations and their influence on future intentions.

Results of this study confirm the primary motivations of charity sport participation as well as provide an established set of social media consumption motivations in a charity sport context. In addition, the development of social media typologies provides organizations with a more holistic view of the social media consumption habits of their users as well as differences in charity sport motives and future intentions for each typology. Results demonstrate the need for sport managers to embrace social media (e.g., Bernoff \& Li, 2008; Kaplan \& Haenlein, 2010) and engage users (e.g., King, 2013; Williams \& Chin, 2010) in order to build lasting relationships with participants and facilitate offline behaviors (Valenzuela et al., 2009). In addition, 
results yield evidence of the need for differentiated marketing and communication strategies to effectively meet the needs of users. 


\section{TABLE OF CONTENTS}

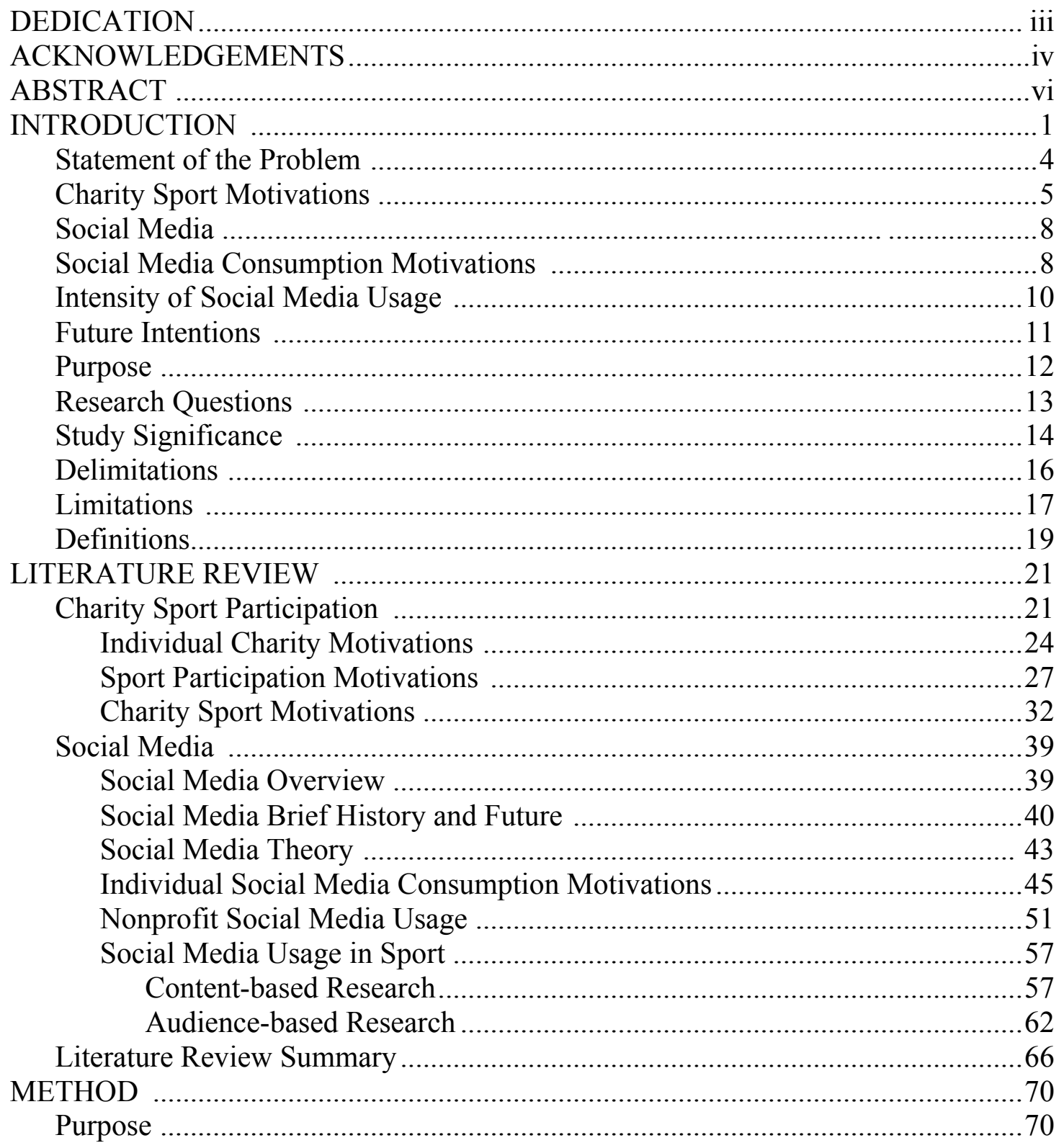




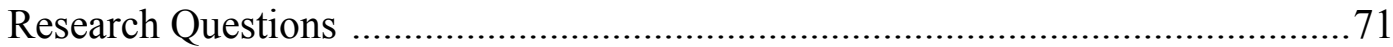

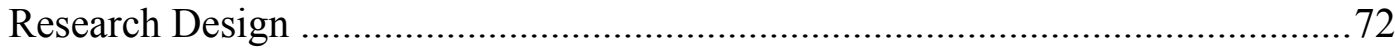

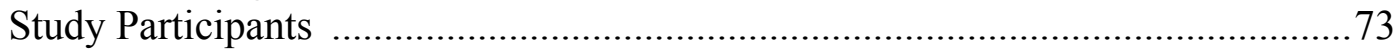

Sampling and Data Collection Procedure ......................................................... 75

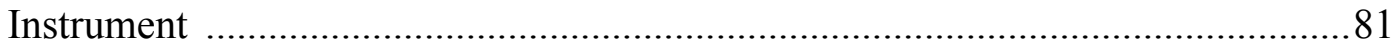

Charity Sport Motivations................................................................... 82

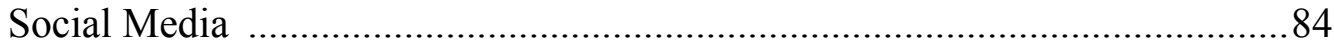

Social Media Consumption Motivations .............................................85

Social Media Intensity of Usage ..................................................... 88

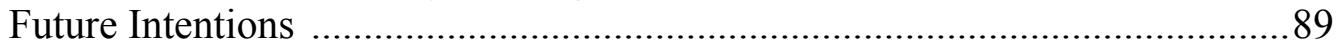

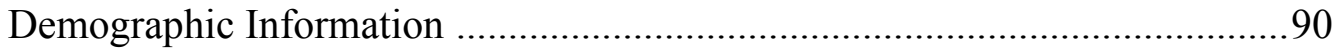

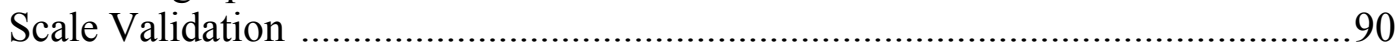

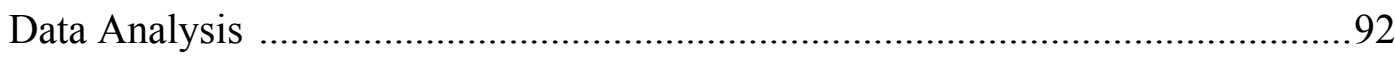

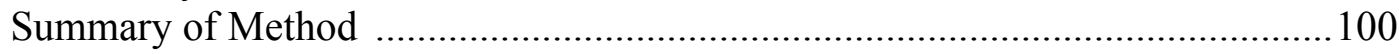

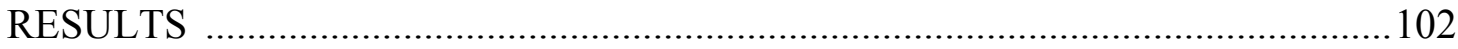

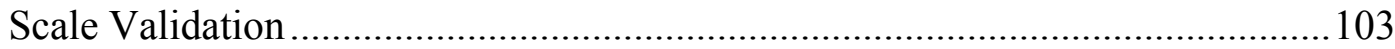

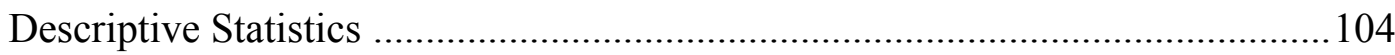

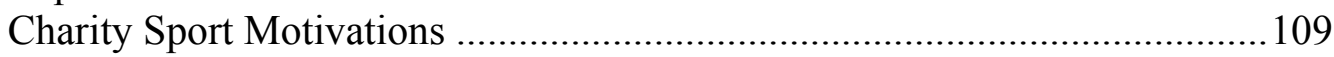

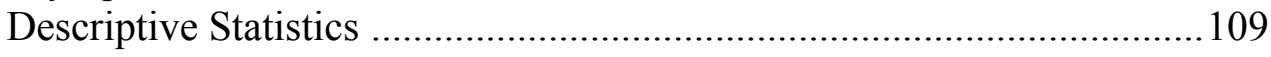

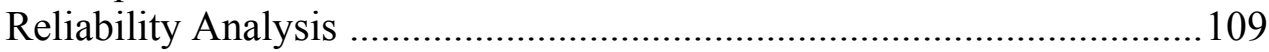

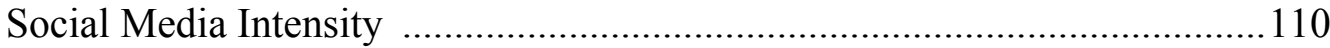

Descriptive Statistics ....................................................................... 110

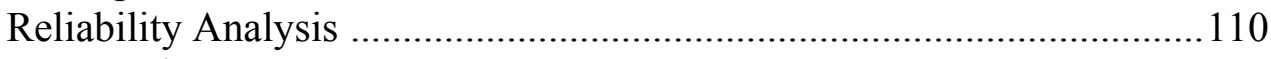

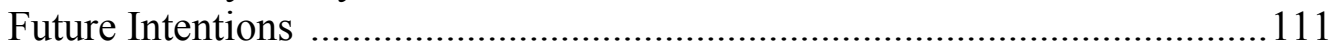

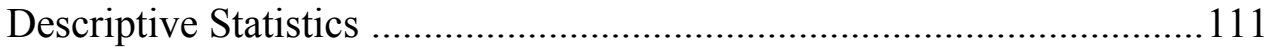

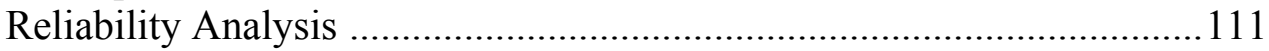

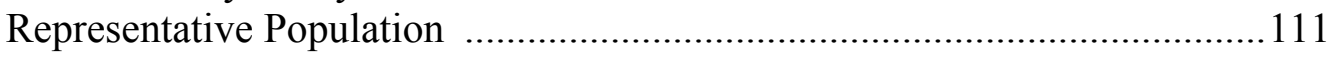

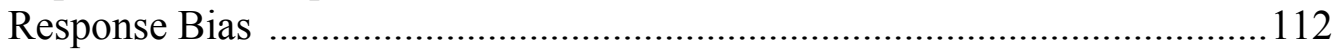

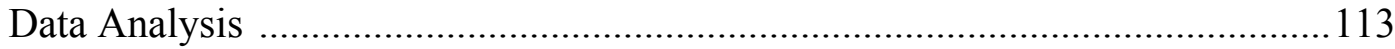

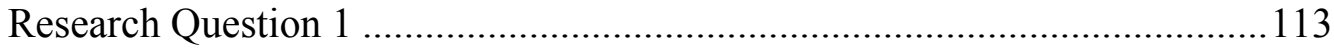

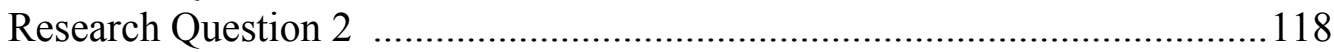

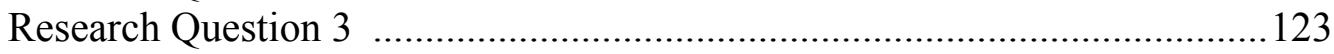

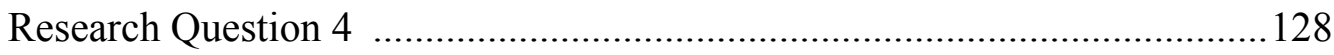

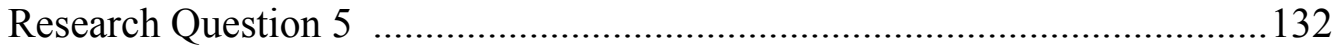

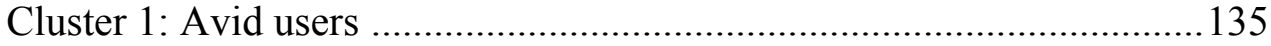

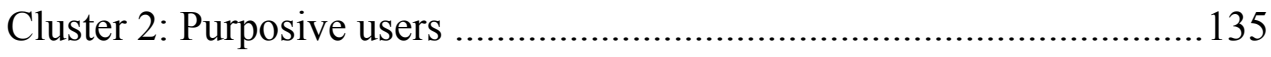

Cluster 3: Leisurely users ............................................................... 136

Cluster 4: Minimalist users .............................................................. 137

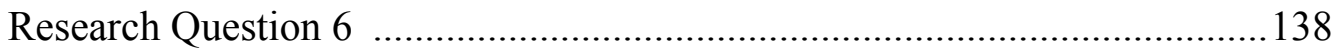

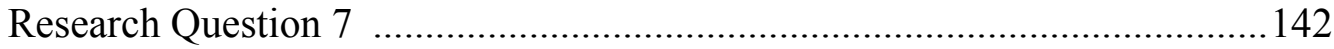

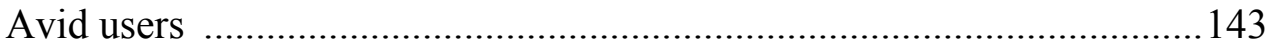

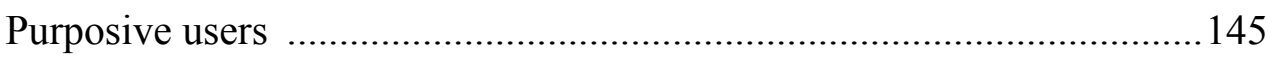

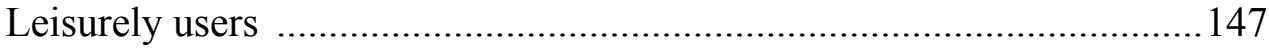

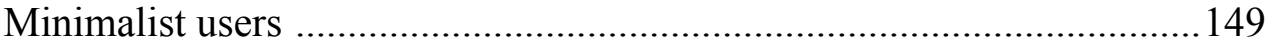

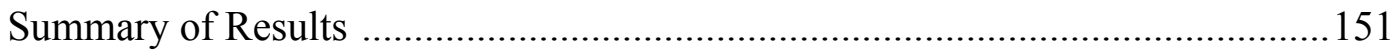




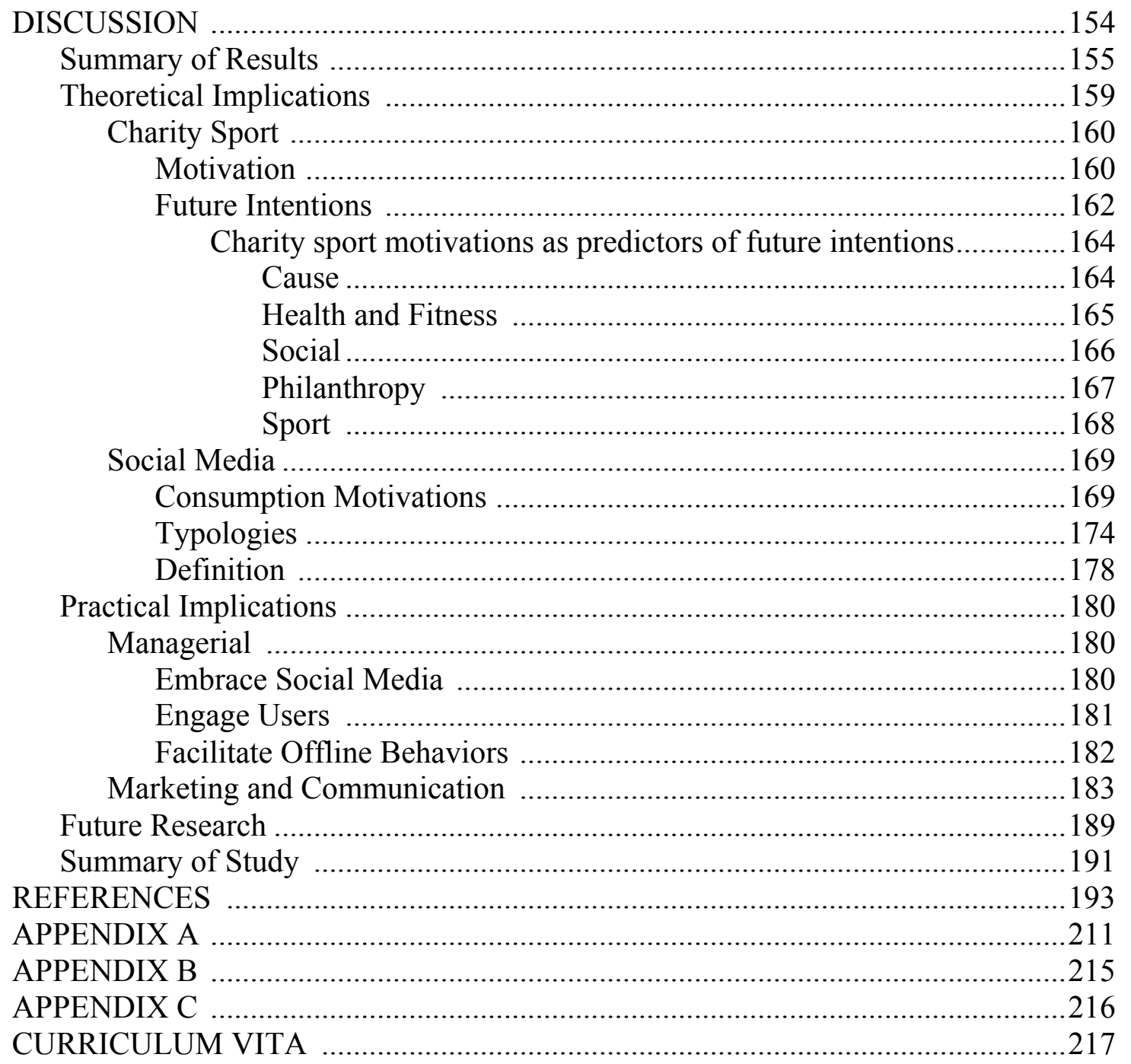




\section{CHAPTER I}

\section{INTRODUCTION}

Many charitable organizations utilize large-scale participation sporting events as communication vehicles to raise awareness about causes, reach a diverse population of individuals, and recruit supporters (Funk, Jordan, Ridinger, \& Kaplanidou, 2011). For example, the Leukemia and Lymphoma Society trained over 500,000 individual sport participants and raised over $\$ 1.2$ billion for cancer research through their sport participation program Team in Training (TNT) since its inception in 1988 (Team in Training [TNT], 2012a). Sport participation for a cause has gained increasing popularity during the past few decades, with charitable organizations raising more than $\$ 1.7$ billion annually through charity sport participation events (i.e., walks, runs, rides, swims) (Run Walk Ride Foundation [RWRF], 2012). Although some charitable organizations originally used sport training programs and mass participation events to raise funds and differentiate themselves from the competition, charity sport participation events are now commonplace.

In 2011 the top thirty charitable organizations hosted 36,422 sport participation events (RWRF, 2012). Notable charity sport participation programs include the American Cancer Society’s Relay for Life (which raised \$415 million in 2011), Leukemia and 
Lymphoma Society’s TNT (\$87 million), National Multiple Sclerosis (MS) Society’s Bike MS (\$82 million), and American Heart Association’s Jump Rope for Heart (\$61 million) (RWRF, 2011). Although the aforementioned organizations represent large-scale charitable organizations, it is important to note that thousands of smaller charity sporting events take place throughout the year in cities across the country, all raising money for a cause through sport (Wharf Higgins \& Lauzon, 2003). In addition, many individuals participate in large-scale events (e.g., Boston Marathon, Ironman Triathlon) not associated with a cause, while still raising money for the charitable organization of their choice (FirstGiving, 2010).

Charitable organizations are increasingly using sport as a medium to raise awareness about their cause and increase participation and donations. Increasing charity sport alternatives for consumers, however, has created a competitive environment among charitable organizations to recruit new and retain current charity sport participants (Gladden, Mahony, \& Apostolopoulou, 2004). Gaining a better understanding of the motivational attributes associated with participation will assist charitable organizations in enhancing future intentions such as participants signing up for other events, supporting the organization (i.e., donating funds, volunteering) in the future, and willingly referring others to the organization. Successfully enhancing these outcomes has the potential to aid charitable organizations in maximizing fundraising donations, sustaining profitability, and effectively reaching their cause-related goals.

As the world becomes increasingly interconnected, it is important to also understand the influence of social media on the future intentions of charity participants. Social media is not a new concept to nonprofit organizations (Waters \& Lovejoy, 2011). 
Charitable organizations have embraced social media platforms by building online communities and mobilizing stakeholders through Facebook, spreading news and information about fundraising campaigns through Twitter, and posting inspirational videos on YouTube (Adler, 2012). Additionally, nonprofit organizations use platforms such as Tumblr and Flickr to post event photos and Pinterest to interact with constituents and jointly create online photo and event pinboards. They also use FourSquare to team up with for-profit companies and host-giving campaigns, such as $10 \%$ off at a given retail location if supporters check-in via FourSquare and make a small donation to the charity (Adler, 2012).

Nonprofit organizations recognize the potential impact of social media on donor engagement, and a recent study found $92 \%$ of nonprofit organizations engaged in at least one social media platform (Newmark, 2012). Similarly, the 2012 Nonprofit Social Networking Benchmark Report found the number of Facebook fans at the surveyed charities grew by a median rate of 70\% from 2010 to 2011 (Nonprofit Research Collaborative, 2011). Charitable organizations use social media more frequently, because individual donors have become increasingly skeptical of nonprofit organizations, not only with how they spend the funds raised, but also the avenues chosen to raise funds. Traditional methods of fundraising such as door-to-door collections, telephone giving, and direct mailings are antiquated and not well received among consumers. A study conducted by the Charity Commission found $67 \%$ percent of respondents felt uncomfortable with some methods of fundraising, including those mentioned previously (Charity Commission, 2012). On the other hand, researchers from the Nonprofit Research Collaborative reported that Internet and online giving rose by 58\% in 2011 (Nonprofit 
Research Collaborative, 2011). The increased social media usage by nonprofit organizations and heightened skepticism of traditional fundraising methods provide an opportunity for organizations to leverage social media as an avenue to engage donors and raise funds.

Many nonprofit organizations use social media to build relationships with donors and raise awareness for their cause (Waters \& Jamal, 2011; Waters, Burnett, Lamm, \& Lucas, 2009). In the same respect, charitable organizations coordinating charity sport participation events have also leveraged social media as communication vehicles to interact with participants and assist them in their fundraising goals. For example, Team LIVESTRONG (i.e., charity sport participation subset of the LIVESTRONG Foundation) has an "Intro to Fundraising" YouTube video embedded on their homepage. They detail "How to start a social media campaign" with helpful pointers encouraging participants to reach out through their social networks (LIVESTRONG, 2012a). Team LIVESTRONG also provides links to their Facebook, Twitter, Flickr, and YouTube accounts through their website (LIVESTRONG, 2012b). Similarly, TNT has a social networking tab, asking participants to connect with the organization on Facebook, Twitter, YouTube, Flickr, LinkedIn, and their TNT community blog. The organization notes, "These tools will help you support TNT and assist you in your fundraising goals" (TNT, 2012b, para. 1). While some organizations embrace social media as part of the integrated marketing communications strategy, others are resistant to the technology (Bernoff \& Li, 2008).

\section{Statement of the Problem}

Charity sport participation provides an opportunity for individuals to simultaneously fulfill their altruistic and recreational needs (e.g., Filo, Funk, \& O'Brien, 
2008; 2011; Won \& Park, 2010). Last year over 11.6 million individuals participate in charity sporting events, volunteering to raise money for a charitable organization through their participation (RWRF, 2012). As charity sporting events increase in popularity, more charitable organizations utilize sport as a vehicle to raise money and awareness for their causes. The increase in charity sport opportunities for consumers creates a competitive environment among nonprofits to recruit and retain participants (Gladden et al., 2004). In this case, consumers and participants are the same.

One potential way to counter these competitive forces are to efficiently and effectively communicate information about fundraising events and build longstanding relationships with consumers--particularly through the use of social media. Yet, little is known about the consumption motives or intensity of social media usage as they relate to charity sport participants. Additionally, there is a gap in the literature addressing the influence of social media on behavioral outcomes of participants. Thus, the current study focuses on the influence of social media and charity sport motives on participants' future participation intention, future support of the organization, and participants' willingness to refer others. Charity sport motivations will be discussed first, then social media consumption motives and social media intensity of usage, and finally future intention variables.

\section{Charity Sport Motivations}

Sport is a unique and powerful platform to communicate messages and create social change (Smith \& Westerbeek, 2007). Individuals may not have the influence that celebrity athletes or sport organizations have; however, one way they can make a positive impact on the world and raise awareness for social change is by participating in charity 
sporting events. Gaining a better understanding of participation motives in conjunction with charity motives provides sport managers with the ability to better understand and satisfy participant needs (Wood, Snelgrove, \& Danylchuk, 2010), and build mutually beneficial long-lasting relationships with individuals (Wharf Higgins \& Lauzon, 2003).

Five major charity sport motives emerged from a thorough review of the literature: (1) Cause, (2) Philanthropy, (3) Social, (4) Sport, and (5) Health and Fitness. Cause was defined as a way for individuals to raise awareness and make a difference in the world by supporting a charitable organization they felt was important (Filo, Funk, \& O’Brien, 2009). Upon further analysis, however, cause was delineated into support of a specific charitable organization (i.e., cause) and an overall altruistic nature (i.e., philanthropy) (e.g., Won \& Park, 2010). That is, some participants may be motivated to participate in the Susan G. Komen Race for the Cure because they want to support that specific charity, whereas others participate due to a more general sense of altruism and desire to give back to society. An individual motivated for cause-related reasons participated to support a specific charitable organization (e.g., Susan G. Komen). On the other hand, someone motivated for philanthropic reason may have participated in support of any number of organizations (e.g., American Red Cross, American Heart Society, Alzheimer's Foundation).

This distinction was particularly evident in Won and Park's (2010) study, where charity sport participants identified both cause and philanthropic motives for participation. Filo, Funk, \& O’Brien $(2008 ; 2010)$ confirmed this finding, establishing differences in motives of "desire to improve the charity" and the "need to help others," similar to cause and philanthropy. For that reason, cause and philanthropy were classified 
and analyzed as separate motives of charity sport participants in this study. Therefore cause is defined as individuals motivated specifically to support a given charitable organization (e.g., Filo et al., 2010; Won \& Park, 2010) and philanthropy represents participants motivated for general altruistic reasons (i.e., make the world a better place) (Filo et al., 2010, Won \& Park, 2010).

Another highly cited motivation for participation in charity sporting events was socialization (e.g., Bennett, Mousley, Kitchin, \& Ali-Choudhury, 2007; Filo et al., 2009; 2010). Bennett et al. (2007) identified the motive as "desire to mix socially", whereas Won and Park (2010) classified it as "social interaction." In the context of the current study, social was defined as individuals motivated by social aspects participate in the charity sporting events to make new friends, interact with other participants, and share the experience with others (Bennett et al., 2007; Filo et al., 2009; Won \& Park, 2010).

In addition, many researchers identified motivation based on the physical aspects of participation in the charity sporting events. Further review of the literature, however, revealed physical competency could be further segmented into those motivated by the actual sport or activity involved (i.e., sport), and those motivated to live a healthy lifestyle (i.e., health and fitness). For example, someone who identifies as an avid runner raising money for the American Liver Foundation by running in the Boston Marathon may be motivated by the sport of running itself. Whereas, another charity sport participant running the Boston Marathon for the American Liver Foundation may be motivated to get active or lose weight. Therefore sport motivation was defined as those individuals motivated by the physical activity or sport itself (Bennett et al., 2007; Snelgrove \& Wood, 2010), while health and fitness described those motivated to live a 
healthy lifestyle (i.e., get in shape) (Bennett et al., 2007; Snelgrove \& Wood, 2010).

\section{Social Media}

One way to reach consumers and potentially motivate them to participate in future charity sporting events is through social media platforms. Increasingly, nonprofit organizations are using social media platforms in their communication strategies to connect with and build relationships with stakeholders. Practitioners and researchers across a variety of fields have debated the definition of social media, as it can be defined in various ways (e.g., Bernoff \& Li, 2008; Blackshaw \& Nazzaro, 2004). For the context of this study, social media was defined as online communities built through communication platforms, whereby individuals collectively create, share, and improve information and user generated content while interacting with others (Blackshaw \& Nazzaro, 2004; Mangold \& Faulds, 2009; Williams \& Chin, 2010).

Social media platforms break down geographic borders (e.g., Dittmore, Stoldt, \& Greenwell, 2008) and create a virtual community of individuals interacting and supporting each other without the limits of time or space (Kietzmann, Hermkens, McCarthy, \& Silvestre, 2011). They facilitate a place for individuals to build relationships and socialize with each other and the organization through two-way communication (e.g., Kaplan \& Haenlein, 2010). Social media platforms are unique from traditional communication platforms in that they create a virtual community (e.g., Anderson, 2011) and space for individuals to share their experiences and tell their stories digitally (Gleason, 2012).

Theoretically, researchers identified many frameworks to classify social media platforms and gain insights about consumption behaviors (Clavio, 2011). In terms of 
usage, many researchers turned to the uses and gratifications framework when trying to identify motivations for usage of social media (e.g., Raacke \& Bonds-Raacke, 2008; Shao, 2009). Uses and gratification, the mass communication-based theory, provides a framework to gain a better understanding of an individual's use of a particular platform (i.e., motives of consumption) in comparison to the gratifications (i.e., benefits) they receive from doing so (Katz, Blumler, Gurevitch, 1974). Assuming there are always alternative communication platforms for an individual to use, continuation or discontinuation of usage is based on the gratifications sought and gratifications received from that usage (Katz, et al., 1974). Additionally, uses and gratifications is often used to understand an individual's motivations to use emergent communications (e.g., the introduction of the newspaper; television; social media) (Ruggerio, 2000).

\section{Social Media Consumption Motivations}

Nearly two billion people worldwide are online, and $66 \%$ of those individuals are on at least one social media platform. Previous research identified many motivations for consumption of social media of those 1.3 billion users (Internet World Stats, 2012). The Pew Research Center found that staying in touch with current friends, connecting with old friends, making new friends, gathering information, and finding potential romantic/dating partners were the main motivations for individuals to consume social media (Smith, 2011). In addition, a more recent study conducted by Rainie, Brenner, and Purcell (2012) at the Pew Research Center, found 56\% of Internet users to be either creators (i.e., post original photos or videos) or curators (i.e., repost/share photos or videos) of photos or videos online. This increase in usage from previous years shows the rise in photo and video platforms such as Pinterest, Instagram, Tumblr and Ptch, as well 
as the influence of mobile phones (Isaac, 2012). Many individuals have mobile phones with both camera and Internet capabilities, which creates increased accessibility and ease of use for both photo and video social media platforms (Dube, 2012).

Primarily using the uses and gratifications framework, academic researchers conducted extensive research regarding the motivational constructs of social media consumption and have broadly identified them as information sharing (e.g., Johnson \& Yang, 2010; Shao, 2009), information seeking (e.g., Dunne, Lawlor, \& Rowley, 2010; Hanson \& Haridakis, 2008), friendship/socializing (e.g., Bonds-Raacke and Raacke, 2010), connection (e.g., Chen, 2011), entertainment (e.g., Haridakis \& Hanson, 2009), self-expression and self-presentation (e.g., Lampe et al., 2010), sense of community (e.g., Anderson, 2011), social support (e.g., Sanderson, 2010), interaction (e.g., Clavio \& Kian, 2010), and escape (e.g., Haridakis \& Hanson, 2009). As evidenced by examination of the previous studies, researchers identified a diverse set of motivational constructs. The current study expanded the literature by identifying motivations of social media consumption. The integrated concept of social media usage provided insights about individuals' overall social media motivations. Due to the continuous emergence of social media platforms, there is a need to understand broad social media consumption motivations (Hanna, Rohm, \& Crittenden, 2011). A greater understanding of social media consumption motives would provide organizations with a road map of how to effectively tailor their communication messages and marketing campaigns to best reach their audience amidst the social media 'noise'.

\section{Intensity of Social Media Usage}

In addition to the motivations of social media consumption, it is also essential for 
organizations to know the intensity of usage among individuals. For example, the top social media platforms claim to have millions of users, but analysts note that a much smaller percentage of those users are daily active users, accessing the platforms on a frequent and continuous basis (Isaac, 2012). Practitioners commonly define daily active users as registered social media users who logged in and visited the site, or took an action (e.g., post content, comment, like, tweet) on a given day (Reisinger, 2012). Daily active users are the individuals who advertisers, developers, investors, and marketing managers target (Devol, Edelman, \& Serrazin, 2012) therefore it is important to know participants' level of intensity of social media usage. Motivations for social media consumption answer the question of why individuals are using social media; however, intensity of usage provides an understanding of how individuals are using social media.

Intensity of usage combined frequency of usage with attitudinal measures of social media, such as the importance social media has in your daily life (Ellison, Steinfield, \& Lampe, 2007). Gaining an increased knowledge of the intensity of usage and motivations of consumption provide marketing managers with a more holistic view of their audience. This additional information could aid in segmenting consumers based on intensity of usage and more effectively communicating with consumers via social media platforms to build relationships to facilitate future participation, support, and referral intentions with the organization.

\section{Future Intentions}

As previously discussed, organizations leveraging charity sport participation face an increasingly competitive environment. Therefore, identifying how participants' motivations and social media usage impact their future intentions can be vital information 
relative to an organization's success. Within the context of this study, future intentions included (1) future participation intention, (2) future support of the organization, and (3) participants' willingness to refer. Future event participation is the likelihood of charity sport participants' intention to continue their participation with an organization or charity sporting event in the future (Filo et al., 2010). Similar to the for profit realm, it costs an organization less money to retain a customer than it does to attract a new one (Hightower, Brady, \& Baker, 2002). Charity sport organizers should aim to build lasting relationships with participants and retain them in their fundraising programs each year. Future support of the organization is the likelihood a charity sport participant will donate to or volunteer with the organization in the future. For instance, even if a charity sport participant chooses not to participate in the future, it would be beneficial for the nonprofit organization if that individual continued to volunteer at events and support the organization financially. Finally, participants' willingness to refer is the likelihood a charity sport participant would recommend the training program or event to family and friends. Recruitment of new participants through positive word of mouth behaviors is essential for nonprofit organizations, especially considering the limited marketing and advertising budgets available to the typical non-profit organization (Adler, 2011).

\section{Purpose}

The purpose of this study was to determine how charity sport organizations could leverage social media to enhance recruitment, retention, and future support of their organization. Gaining a better understanding of charity sport participant motives, intensity of social media usage, and consumption motives of social media usage provides sport managers with valuable insights into the types of marketing and communication 
campaigns they could employ in order to maximize future intentions. There were seven main purposes of the current study: to (1) examine which charity sport participation motives were likely to predict future intentions, (2) determine which levels of social media intensity of usage predicted future intentions, (3) establish a set of social media consumption motivations within a charity sport context, (4) determine which social media consumption motivations best predicted future intentions, (5) develop social media user typologies based on consumption motives and intensity of usage, (6) provide profiles of social media typologies based on their motives of charity sport participation, and (7) understand which charity sport participation motives predict future intentions for each social media typology. The results of this study will assist researchers in developing strategies for charity sport organizations in leveraging social media to enhance recruitment, retention, and future support of their organization.

\section{Research Questions}

The following seven research questions will address the purpose:

RQ1: Are the charity sport motives of cause, philanthropy, social, health and fitness, and sport significant predictors of future intentions (i.e., future participation intention, future support of the organization, and participants' willingness to refer)?

RQ2: Are the different levels of social media intensity of usage (i.e., low, moderate, and high) related to future intentions (i.e., future participation intention, future support of the organization, and participants' willingness to refer)? RQ3: What is the factor structure of social media consumption motivation? RQ4: Are the social media consumption motives significant predictors of future 
intentions (i.e., future participation intention, future support of the organization, and participants' willingness to refer)?

RQ5: What typologies of social media users exist based on intensity of usage and consumption motivations?

RQ6: Are there differences in social media typologies related to charity sport motivations (i.e., cause, philanthropy, social, sport, health and fitness)? RQ7: Are charity sport motives (i.e., cause, philanthropy, social, sport, health and fitness) significant predictors of future intentions (i.e., future participation intention, future support of the organization, and participants' willingness to refer) for each social media typology?

\section{Study Significance}

Individuals participating in charity sporting events collectively raised over $\$ 2$ billion in 2011 for charities (RWRF, 2012). Charity sport participation has proven to be a lucrative fundraising technique, which is precisely the reason many other nonprofits adopted this strategy in recent years (Filo et al., 2010). In an increasingly competitive market, an enormous opportunity exists for nonprofit organizations to leverage social media to engage stakeholders, yet minimal research has explored this area. Over 1.3 billion people actively use social media platforms (Smith, 2012), and $92 \%$ of nonprofit organizations use at least one social media platform (Newmark, 2012). Results from this study add to the current body of literature in an under-researched area.

From a charity sport perspective, previous research examined motivations of charity sport participants (e.g., Filo et al., 2009), developed market segmentation based on motivational profiles (e.g., Nettleton \& Hardy, 2006) and demographic profiles (e.g., 
Won, Park, \& Turner, 2010), identified the role of sponsor image (Filo, et al., 2010), and created marketing strategies for the recruitment and retention of participants (e.g., Filo et al., 2011). There is a lack of research, however, identifying future intentions of participants based on their charity sport motivations. It is crucial for sport managers to have a full understanding of which motives effectively predict behavioral outcomes such as participant retention, future support of the charitable organization, and participants' willingness to refer. In a competitive industry, charitable organizations require a full understanding of participant motivations and behavioral outcomes in order to remain successful (e.g., Filo et al., 2011). The current study looked to fill that gap by identifying which charity sport motives predict future participation intention, future support of the organization, and participants' willingness to refer.

In the same respect as charity sport motives, charitable organizations may benefit from knowing which social media consumption motivations and intensity levels effectively predict future intentions. From a practical perspective, this information provides charitable organizations with a better understanding of the type of social media consumers participating in their events use and how they could craft their communication strategies accordingly. For instance, if the majority of participants had low social media intensity of usage, an integrated communication strategy using both traditional and nontraditional methods to communicate to consumers would be appropriate. On the other hand, if the majority of respondents had high intensity of usage, an increased organizational presence on various social media platforms may be deemed appropriate. In addition, based upon the social media motivations for consumption, charitable organizations could effectively tailor the content and goals of social media messages to 
fit the motivations of participants, and increase future intentions.

\section{Delimitations}

Delimitations refer to external validity or issues that threaten the ability of the researcher to generalize findings from sample data to other sample settings or the population (Creswell, 2009). Several delimitations exist within the current study. First, charity sport participants are classified as anyone participating in a sporting event or activity while raising money for a cause (Filo et al., 2009). Charity sport events range from a walk-a-thon to an Ironman, from a jump-roping event to a marathon. The diversity in charity sporting events also yields diversity in motives for participation in those events. TNT was chosen specifically due to the serious leisure and endurance nature of the events they coordinate. The events take a considerable amount of training time in preparation for the event, and have fairly high fundraising objectives. Results should be extrapolated only to include other serious leisure events requiring a significant commitment to both the training and the cause. In addition, TNT offers a program which trains participants for approximately five months before a given endurance event (TNT, 2012a). Not all charity sport events coordinate training programs for their participants. This study will be limited to those organizations that build relationships and communicate with participants over a longer period of time.

Second, although the current study used an international sample, TNT is based in North America (i.e., United States, Canada, and Puerto Rico). Participants of the study were residents of North America therefore results should be interpreted to other charitable organizations in the same region. Future research could examine charitable organizations with a broader international scope. 
Third, the current study conducted outcome-based research by examining the future intentions of participants. In order to better understand the future intentions (i.e., future participation intention, future support of the organization, and participants' willingness to refer) of participants, the current study sampled individuals that were already participating with TNT. The focus of this study was on the decisions of current participants and alumni to participate in future events, continue to support the organization, and refer others to the training program. Therefore, those individuals who have not participated with TNT previously were not included in the scope of this study.

Fourth, similar to the previous delimitation, this study focused on individuals already using social media platforms. The goal of the study was not how to recruit people to use social media, but to better reach those participants and alumni using social media platforms. The current study aimed to assist organizations in better understanding who is using social media and how to effectively target those users through marketing and communication strategies.

\section{Limitations}

Limitations refer to the internal validity issues threatening the ability of the researcher to draw correct inferences due to the experimental procedures, treatments, or experiences of participants (Creswell, 2009). Some commonly cited threats to internal validity are history, maturation, selection bias, instrumentation, and mortality (Creswell, 2009). While most of these threats only concern experimental design, some of these threats can be applied to cross-sectional survey design.

Selection bias refers to an error in choosing the individuals to take part in a study. In the current study, the researcher collected data from one specific charitable 
organization, in turn the sample may not adequately represent the target population. In addition, although the researcher tested the reliability, validity, and readability of the instrument used in the study, it was impossible to control for all extraneous variables. The researcher thoroughly reviewed the literature to formulate sound theoretical and empirical evidence for the variables chosen to include in the study, however extraneous variable may impact results.

Also, this study used an international sample of TNT participants. Among TNT members, the geographic location of where they live and participate may affect their charity sport motivations as well as their social media consumption motivations and social media intensity of usage. For example, the organizational usage and emphasis on social media usage may vary from regional chapter to chapter depending upon location, and potential familiarity by its leaders. So while the study yielded a representative international sample of participants, it did not control for geographic region.

Additionally, this study focused on the future intentions of charity sport participants as they relate to social media and motivations for participation. Future participation intention, future support of the organization, and participants' willingness to refer, all rely on participants' stated intentions, instead of their actual behaviors. Therefore, there may be a disconnect between what charity sport participants say they will do in the future and what they actually do.

Finally, the social media intensity of usage variable was modified from the Facebook intensity of usage scale created by Ellison et al. (2007). Although this variable yielded sufficient Cronbach's alpha coefficients in the current study $(\alpha=.878)$ and prior research (Steinfield et al., 2008; Valenzuela et al., 2009), the variable incorporated both 
frequency of usage and attitudinal measures in one unstandardized construct. This variable was chosen since it was the most complete measure of social media intensity, however, future research should explore a more statistically sounds method of measurement.

\section{Definitions}

Charitable Organizations: "Organizations created for the purpose of philanthropic rather than pecuniary pursuits...designed to benefit society or a specific group of people" (Legal Dictionary, para. 1)

Charity Sport Participation: Individuals who take part in a sporting event or activity while simultaneously raising money for a cause (Filo et al., 2009)

Charity Sport Participation Motives:

Cause: Motivated specifically to support the mission of a given charitable organization (i.e., Susan G. Komen--increase breast cancer awareness) (Filo et al., 2010; Won \& Park, 2010)

Philanthropy: Motivated for general altruistic reasons (i.e., make the world a better place) (Filo et al., 2010, Won \& Park, 2010)

Social: Motivated to make new friends and interact with others (Filo et al., 2009) Sport: Motivated by the physical activity itself (i.e., runner wants to participate in Chicago Marathon) (Bennett et al., 2007; Snelgrove \& Wood, 2010)

Health and Fitness: Motivated to live a healthy lifestyle (i.e., get in shape)

(Bennett et al., 2007; Snelgrove \& Wood, 2010)

Future Intentions:

Future participation intention: The likelihood a charity sport participant will take 
part in a future event with the organization (Filo et al., 2010).

Future support of the organization: The likelihood a charity sport participant will donate to or volunteer for the organization in the future.

Participants' willingness to refer: The likelihood a charity sport participant will recommend the training program or event to family and friends (Hightower et al., 2002).

Non-profit organization: "generally intended to include all organizations with federal tax-exempt status" (Sherlock \& Gravelle, 2009, p. 2)

Social media: Online communities built through communication platforms, whereby individuals collectively create, share, and improve information and user generated content while interacting with others (Blackshaw \& Nazzaro, 2004; Mangold \& Faulds, 2009; Williams \& Chin, 2010).

Social media consumption motives: The decision as to why individuals choose to use social media platforms.

Social media intensity of usage: The number of social media platforms an individual uses, frequency of usage (i.e., number of times logged on each day, week), the amount of time spent on such platforms each day (Zuniga, et al., 2012), and their attitudes about the importance of social media in one's life (Ellison et al., 2007).

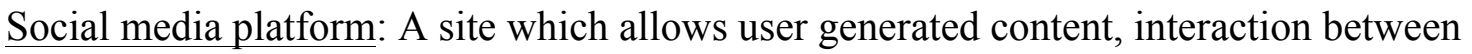
individuals, and two-way communication. Examples include (but are not limited to) Facebook, Twitter, Pinterest, LinkedIn, Google+, YouTube, Flickr, Tumblr, FourSquare, and blogs. 


\section{CHAPTER II}

\section{LITERATURE REVIEW}

One way in which individuals can make a positive impact on the world and raise awareness for social change is through participating in charity sporting events (Wharf Higgins \& Lauzon, 2003). Large-scale charity sporting events can be used as communication vehicles to reach a diverse audience and recruit supporters. The following literature review will be broken down into two main sections: (a) charity sport participation and (b) social media.

\section{Charity Sport Participation}

The popularity of charity sport participation events has garnered more attention in recent years, with the top 30 charitable organization using sport as a platform to recruit 11.6 million people and raise \$1.7 billion in 2011 alone (RWRF, 2012). It is essential for charity sport organizers to gain a better understanding of both the participation and charitable donation motives of individuals to maximize efficiency in recruiting and retaining participants (Wharf Higgins \& Lauzon, 2003). Previous charity sport research identified motivations of charity sport participants (e.g., Filo et al., 2008; Won et al., 2010), established market segmentation based on motivational and demographic profiles (Bennett et al., 2007; Nettleton \& Hardy, 2006; Wood et al., 2010), identified the role of 
sponsor image (Filo et al., 2010), and created marketing strategies for the recruitment and retention of participants (Filo et al., 2011; Nettleton \& Hardy, 2006). Charity sporting events have evolved into common communication and development tools for nonprofits. The following studies provide greater information into the unique characteristics of charity sport participation events and individuals participating in such events.

One of the first attempts to explore the increasing occurrence of physical activity events to raise money for charitable organizations was Wharf Higgins and Lauzon (2003), in their exploratory analysis of the purpose of charity sporting events. The researchers examined 50 charity sport events of various sizes and intensity levels, and identified two distinct themes of 'cause' and 'event.' They found the main purposes of charity sporting events were to celebrate a cause and offer an event that satisfied the physical needs of participants. In addition, they found nonprofit organizations used the event as a promotional tool to increase awareness about the cause and raise funds to support the organization. Results also indicated nonprofit organizations hosted events to develop long-term relationships with participants and supporters. Additionally, participants preferred to be a part of a community experience and social activism. Organizations also saw the importance of a long-term relationship and the retention of participants in order to remain successful.

Wharf Higgons and Lauzon (2003) focused on the purpose of charity sporting events, whereas Nettleton and Hardey (2006) aimed to gain a better understanding of the individuals participating in events raising money for a cause. The researchers created theoretical classifications of participants based on their orientation toward the charity and their identification with the sport of running. They identified four participant 
classifications: (a) leisure runners, (b) purist runners, (c) runners for charity, and (d) fun runners. Leisure runners were those individuals who had a low orientation towards the charity and the sport of running. Purist runners had a low orientation toward the charity but a high orientation towards running. Fun runners had a high orientation toward the charity and a low orientation toward running. Finally, runners for charity had both a high orientation toward the charity and running. Both runners for charity and fun runners were termed "charitable bodies," or participants motivated by the simultaneous benefits felt by the interrelationship between charitable organizations, the sport, and their individual performance in the participation events. The findings revealed the prevalence of active citizens looking to give back to society by raising money for those in need. Through an examination of the literature, the researchers established theoretical motivational profiles of runners in a charity sport marathon.

Similarly, Wood et al. (2010) aimed to empirically create and test classifications of charity sport participants at the Multiple Sclerosis (MS) Bike Tour in 2007. The results yielded four emergent segments. Consistent with Nettleton \& Hardey (2006), Wood et al. classified the categories as (a) non-identifiers, (b) cause fundraisers, (c) road warriors, and (d) event enthusiasts. Non-identifiers reported no connection to either the sport or fundraising for a cause. Cause fundraisers identified only with fundraising for the cause, whereas road warriors reported a connection only with the sport. Event enthusiasts reported connections to both the cause and the sport. The researchers found event enthusiasts raised on average more money than participants in all other categories combined, and reported a longer history with the event. These findings stress the 
relationship between sport and the charity on participation rates, since participants are attracted for different reasons.

Charity sport participation events are commonly used to host a social gathering and raise awareness for the cause (Wharf Higgins \& Lauzon, 2003). Participants are often identified with both the cause itself and the sport or event (Nettleton \& Hardey, 2006; Wood et al., 2010). In addition, participation in charity sporting events simultaneously meet the sport participation and altruistic needs of individuals (e.g. Filo et al., 2008). To maximize efficiency by recruiting and retaining participants, it is essential for charity sport organizers to gain a better understanding of the charitable donation motives of individuals, the sport participation motives, and their intersection in charity sporting events. The following section will review the charity sport participation literature; first taking a deeper look at individual charity motivations literature, then examining existing sport participation literature, and finally synthesizing previous literature on charity sport motivations.

\section{Individual Charity Motivations}

The issue of why individuals offer their support to others is a topic that has "puzzled philosophers and economists since the dawn of antiquity" (Sargeant, West, \& Ford, 2004, p. 27). Approaches from the economic, clinical psychology, social psychology, anthropology, and sociology fields have emerged to address the multidimensional construct of charity motivation (e.g., Guy \& Patton, 1989; Sargeant, Ford, \& Hudson, 2008). The following studies go beyond the simple demographic profiles and consider the role of intrinsic and extrinsic variables as motivating factors of charitable behaviors. 
Guy and Patton (1989) conducted an extensive literature review to examine the motivations of giving behavior, the decision-making process, and factors that may enhance or inhibit these behaviors. A recurring theme found in the literature was the intrinsic motivations of altruism. By in large the need to help others satisfied the intrinsic needs of individuals and outweighed extrinsic needs such as tax benefits, increase in social status, or admission to special events. Gaining a better understanding of the motives in the donor decision process yielded five strategies for implementation by management: (a) provide need satisfaction (i.e., donor's intrinsic need to help others), (b) generate awareness that needs exist, (c) instill a sense of personal responsibility, (d) demonstrate the ability/competency to help, and (e) remove barriers. The researchers urged marketers to leverage the aspects of charity (i.e., intrinsic variables) that most resonate with the target market in order to remain successful in the increasingly cluttered nonprofit environment.

Dawson (1988) conducted one of the first empirical analyses to determine the motivations of donors associated with monetary giving to medical research charities. The author identified four common charitable giving motivations found in the literature: motives of (a) reciprocity, (b) self-esteem, (c) income or tax, and (d) career. The researcher sought to determine the influence of these motives on the monetary donations of individual's to medical research charities. Reciprocity was a significant predictor of monetary donations, whereas career and self-esteem motives were not significant predictors. In addition, demographic variables of age, annual income, and assets were significant predictors; however, education was not. The results support Simpson's (1986) 
findings that the younger demographic donates less than the older demographic and those with a greater amount of assets donate more than those without (Dawson, 1988).

Previous work identified motivational factors for giving, but not how perceptions affect a consumer's decision to choose a charity amongst an overabundance of alternatives. Sargeant et al. (2004) created a conceptual model to analyze the perceptions of givers and the outcomes related to their donations. The researchers aimed to identify which perceptual determinants influenced charity giving behavior (i.e., amount given to charities, amount given to specific charity, number of gifts given to specific charity, giving lifetime to specific charity). The confirmed model contained five main constructs: (a) demonstrable utility (i.e., benefits received from donations), (b) familial utility (i.e., personal connection to cause), (c) effectiveness, (d) professionalism, and (e) service quality. The constructs have the capacity to influence the amount given to charity, which charity an individual chooses, and the longevity of the giving relationship.

Gladden et al. (2004) expanded the literature on the motives of giving to a sportspecific context. In their analysis of individual motivations to donate to athletic support groups, the researchers found that the most common motivational factors were to support and improve the athletic program, to receive benefits related to tickets, and to help student-athletes. The researchers identified two emergent motives through this analysis: (a) entertainment via enjoyment and interest in the sport and (b) commitment to the program, team, and school. The findings suggest schools should take care not to overemphasize the tangible benefits of donations, since doing so places more importance on the team performances and could affect the long-term giving behaviors of individuals. 
Instead, managers should focus on the intangible and altruistic motivations to donors (e.g., supporting athletic programs, provide opportunities for student-athletes).

Analyzing research studies identifying motives of donations to an athletic program (e.g., Gladden et al., 2004) in conjunction with individual motives for charity giving (e.g., Dawson, 1988; Guy \& Patton, 1989) provides a set of motives that could be used to recruit and retain participants and fundraisers in a charity sport participant context. From a motivational standpoint individuals donated because they felt there was a need and their efforts would make a difference (Gladden et al., 2004; Guy \& Patton, 1989; Sargeant et al., 2004), to support programs they previously received benefits from (Dawson, 1988; Gladden et al., 2004), and to fulfill their altruistic needs (Dawson, 1988; King, 2001). Additionally, individuals were more likely to donate to organizations that had transparent accounting practices (Kottasz, 2004). Clarity in the motivations of individuals (Dawson, 1988; Gladden et al., 2004; Sargeant et al., 2004) provides charitable organizations with greater insights about donors, which aids in effectively creating marketing strategies and potentially increasing fundraising amounts.

\section{Sport Participation Motivations}

The above studies demonstrated the range of factors influencing individual donor motivations. The next section focuses on the motivation of individuals to participate in sporting events. Over 860 million Americans participated in a variety of sports in 2011 (National Sporting Goods Association, 2012). Sport participation is a highly saturated market, where consumers have extensive opportunities to participate in various sport and recreational activities, making it crucial for managers and organizations to understand the motives of individuals in order to attract and retain participants (Ko, Park, \& Claussen, 
2008). Knowledge of participation motives in conjunction with charity motives will provide managers with the ability to understand and satisfy participant needs (Wood et al., 2010) and build mutually beneficial long-lasting relationships with individuals (Wharf Higgins \& Lauzon, 2003).

Motivation is a multifaceted concept interrelated with constructs from many other fields of research, and researchers to date have identified over 100 motivational factors regarding individuals' participation decisions and behaviors (Ko et al., 2008). Motives of participation have been researched across gender (Hardin, Andrew, Koo, \& Bemiller, 2009; Ko et al., 2008; Rohm, Milne, \& McDonald, 2006; Swanson, Colwell, \& Zhao, 2008), types of sports (Hardin et al., 2009; McDonald, Milne, Hong, 2002), skill level (Rohm et al., 2008; Swanson et al., 2008), experience (Hardin et al., 2009; Ko et al., 2008; Rohm et al., 2006; Swanson et al., 2008), age (Hardin et al., 2009; Rohm et al., 2006; Swanson et al., 2008), and academic performance (Hardin et al., 2009). Since the complexity of motivation is incredibly deep, broad generalizations about consumer typologies are often ineffective. The most successful analysis and strategies are created through individualized research on specific consumers, sports, and events. Consumer motivations for participation are complex; however, it is essential for marketers to understand the underlying reasons for participant motivation in order to develop effective market segmentations and communication strategies (e.g., Havenar \& Lochbaum, 2003; Rohm et al., 2006).

Multiple studies address participation motives in detail and can be used to understand sport participation more fully. Recours, Souville, and Griffet (2004) created a Sports Motivation Scale to measure four kinds of sport motivations: (a) exhibitionism, (b) 
competition, (c) sociability and emotion, and (d) playing to the limit. The Sports Motivation Scale examined four dimensions of participant motivations, including two extrinsic (i.e., exhibitionism and competition) and two intrinsic (i.e., sociability and emotion and playing to the limits). Researchers found that intrinsic motives (i.e., a combination of risk, adventure and inner strength) were more important to participants than other extrinsic motives. The most important motive identified by both males and females was sociability, although females ranked this variable higher than males. Males were motivated significantly more than females by extrinsic motives. The findings confirmed the importance of intrinsic motives over extrinsic motives in participant's decision-making behaviors.

Kilpatrick, Hebert, and Bartholomew (2005) examined differences in motivations of participation in sports versus exercise. They also investigated motivational differences of participants across gender. The results showed competition, affiliation, enjoyment and challenge were the highest rated factors for motivation of sport participation. On the contrary, health and appearance related factors emerged as the primary motives of exercise. Analysis of gender-based differences revealed that men reported higher levels of motivation than women in challenge, competition, and strength and endurance, while women rated weight management significantly higher than men. Findings from this study provide evidence that intrinsic motives (i.e., challenge, social recognition, enjoyment) are more influential in regards to sport participation, while extrinsic reasons (i.e., appearance, health pressures, stress management) are linked more closely with motivations of exercise. 
Tsorbatzoudis, Alexandris, Zahariadis, and Grouios (2006) investigated the relationship between sport motivation and the frequency of participation as well as future participation intentions. Similar to previous research, they examined intrinsic (i.e., knowledge, accomplishment, experience) and extrinsic motivations (i.e., social recognition, guilt, and value), as well as amotivation. The researchers found the group with the most frequent sports participation were motivated by knowledge, stimulation, accomplishment, and introjection regulation (i.e., people who act in a certain way because they feel a self-obligation to do so). In addition, introjected regulation, knowledge, and accomplishment were the strongest predictors of behavioral intentions. The findings from this research provide greater insight to the effect motivational dimensions have on frequency of sport participation and future behavioral intentions.

Havenar and Lochbaum (2003) examined the motivational differences between first time marathon finishers and dropouts, both of which participated in a training program. The researchers used the Motivation of Marathons Scales (MOMS), which measured motives in psychological, physical health, social and achievement categories. The researchers found that participants who are motivated by weight concern and social recognition in the beginning of the training program were more likely to drop out than participants motivated for other reasons. Sport managers should tailor their marketing strategies accordingly, leveraging intrinsic motives to retain participants in training programs. The findings from this study are applicable considering the prevalence of training programs used by nonprofit organizations in charity sport participation context.

Next, Funk et al. (2011) analyzed the ability of mass participant sport events (MSPE) to promote physically active leisure among a diverse population of individuals. 
The researchers addressed the overwhelming problem of physical inactivity and the potential of MPSEs to (a) motivate individuals to participate in events, and (b) sustain physically active leisure through activity commitment and future exercise intentions. The researchers found eleven sport participation motives (i.e., challenge, enjoyment, strength and endurance, positive health, competition, weight management, ill-health avoidance, appearance, stress management, social affiliation, and health pressures) as predictive for running commitment and future exercise intention. The results revealed MPSEs can influence attitudes towards physically active leisure; however other factors such as event satisfaction and prior physical activity involvement can play a role in attitudinal development. The researchers concluded that MPSEs have the potential to encourage active citizens and influence attitudes about physically active leisure.

In addition, Allender, Cowburn, and Foster (2006) conducted a meta-analytic review to determine the overarching motives for adults participating in sporting events and physical activities. The researchers identified seven primary motivations of adults commonly found in the literature including: (1) sense of achievement, (2) skill development, (3) medical sanction, (4) support networks, (5) enjoyment, (6) social support, and (7) health benefits. The most commonly cited motives were be physically active were for enjoyment and social purposes. The motivations identified are similar to those of previous studies, highlighting intrinsic motivations as opposed to extrinsic.

As evidenced by the previous studies, individuals are motivated to participate in sports and physical activities to fill psychological or physical needs in their lives. "While many activities outside of sport can, and do, fulfill mental well-being, social, and personal needs, sport is a unique and valuable outlet for needs which often go unfulfilled" 
(McDonald et al., 2002, p. 111). Researchers commonly identified competition (e.g., Kilpatrick et al., 2005), socialization (e.g., Recours et al., 2004), skill development (e.g., Tsorbatzoudis et al., 2006), enjoyment (e.g., Allender et al., 2006), weight management (Funk et al., 2011), and health pressures (e.g., Kilpatrick et al., 2005), as motives of participation. Most importantly, researchers found intrinsic motivations more commonly cited by participants than extrinsic motives (e.g., Kilpatrick et al., 2005; Recours et al., 2004; Tsorbatzoudis et al., 2006). Intrinsic motives were also more likely to predict behavioral intentions such as continued exercise and future participation (Funk et al., 2011; Havenar \& Lochbaum, 2003; Tsorbatzoudis et al., 2006)

Charity sport participation events provide an opportunity for individuals to simultaneously fulfill a multitude of needs they may have in order to feel that they are living a well-balanced, socially responsible life (e.g., Filo et al., 2009). Charity sport researchers have effectively combined the motivational constructs of giving behavior and sport participation as underlying motivations for participation in charity sporting events (e.g., Filo et al., 2008; Won \& Park, 2010). The next section will discuss motivations specific to charity sport events.

\section{Charity Sport Motivations}

Filo et al. (2008) analyzed factors that motivated individuals to participate in charity sporting events, investigating the influence of charity on participant motives and how they impact individuals' development and attachment to the events. The researchers found reciprocity, self-esteem, need to help others, and desire to improve the charity by participants in the focus groups as charitable motives influencing participation. In addition, the researchers reported an interaction between core motives (i.e., recreational 
motives--intellectual, social, competency) and contextual motives (i.e., charitable giving motives--reciprocity, self-esteem, need to help other, desire to improve the charity), both contributing to participation in charity sporting events. The study results provided evidence supporting the symbiotic relationship between the motives for sport event participation and motives for charitable giving in that individuals are motivated to fulfill both altruistic and physical needs through charity sport participation. For example, participants may be run a marathon with Team Fox because they feel the internal need to support the Fox Foundation for Parkinsons' research and also want to improve their own physical health and well being through training.

Similarly, Filo, Funk, and O’Brien (2009) explored the meaning behind individual's experiences and participation in charity sport events, and identified three common themes, (a) camaraderie, (b) cause, and (c) competency. The researchers described camaraderie as the emotional meaning--the bond they felt with other participants and the community atmosphere created at charity sport events. Cause was defined as the symbolic meaning the event takes on--the inspiration and self-expression they felt through participating in the charity sport event for a good cause. Competency addressed the functional meaning participants attribute to a charity sport event-participants took pride in the health and well being they establish through participation in the event. The themes of camaraderie, cause, and competency were linked to the meaning of attachment, which guided decision-making in participation of events and future behavioral intentions. In addition, Filo et al. identified camaraderie, cause, and competency as motivations for participation in charity sporting events. 
Bennett et al. (2007) also examined the motives related to participation in charity sporting events. They found that the primary motivating factors for participation were "personal involvement with a good cause supported by an occasion," "opportunities to lead a healthy lifestyle provided by the event," "an individual's involvement with the sport in question," and "the desire to mix socially with other attendees." They also reported that people who felt intrinsically compelled to make a difference and those who wanted to experience a fun atmosphere were more likely to frequently participate in charity sporting events. Individuals who had taken part in a greater number of events were primarily motivated by "fun and enjoyment" and/or "felt a duty to participate." The findings provide evidence of a variety of participation motives in charity sport events and the need for organizations to tailor marketing strategies to reach their target markets. Additionally, the researchers found that charity sporting events tend to attract less competitive participants than non-charity sporting events. The researchers highlighted the need for a community experience and a positive social experience to encourage retention.

Won and Park (2010) also examined the motivating factors of participation in charity sport events; however, they specifically explored motives of college students. Young professionals represent a large market for potential donors, yet charitable organizations generally avoid marketing to younger individuals. Kottasz (2004) found one of the main reasons young professionals do not donate to charity is because they have never been asked. Won and Park found females reported greater motivation on philanthropy, cause, and social interaction, whereas males considered the sport and event more important than females. In addition, students with previous charity sport event experience were more motivated by the cause than other participants. Overall, results 
showed that college students were primarily influenced by philanthropic motives, followed by desire to enjoy the sport or special event, supporting the cause, desire for social interactions, reference group influence, and benefits. The findings from this study provide greater insights in to the motivating factors of college students to participate in charity sport events, as well as differences based on demographic information.

Filo et al. (2011) extended the charity sport literature by comparing the role of charitable giving motives and the role of recreation motives in participant's attachment across two different charity sport contexts. The researchers surveyed participants at the LIVESTRONG Challenge and 3M Half Marathon and Relay to examine charitable giving and recreation motives between two charity sport event contexts (i.e., prominence of charity and non-prominence of charity). In the charity prominence event (i.e., LIVESTRONG Challenge), data yielded the social recreation motive and the charitable motives of reciprocity, self-esteem, need to help others, and desire to improve the charity were significantly predictive of event attachment. In the non-prominence of charity event (i.e., 3M Half Marathon) data yielded that intellectual, social, physical, and escape recreation motives, and charitable motives of reciprocity, self-esteem, and desire to improve the charity significantly contributed to event attachment. The motives for charitable giving were stronger when the charity was prominent, whereas the motives for recreation were stronger when the charity was less prominent. Additionally, the social motive created event attachment in both contexts and could be leveraged to increase the sociability of participants.

Filo et al. (2010) further expanded on existing studies by examining the role of sponsor image and future participation intent. The researchers investigated the 
relationship among participant motives, sponsor image, event attachment, and future behavioral outcomes (i.e., purchase intent toward event sponsors, and participation intent). The researchers examined relationships between the variables and found (a) charity and recreational motives contribute to event attachment, (b) charity motives and event attachment contribute to sponsor image, (c) sponsor image and event attachment contribute to purchase intent for event sponsors' products, and (d) sponsor image does not influence future participation intent while event attachment does. The study was the first to examine sponsor image at charity sporting events and behavioral outcomes from participation. The results provide evidence to the positive effects sponsorship could have on corporate image and purchase intentions.

The previous studies highlighted the importance of including both individual giving behaviors and sport motivations to gain a better understanding of participant's charity sport motivations (e.g., Filo et al., 2008). Filo et al.'s (2009) qualitative study is considered a foundational study in the charity sport context, which identified three primary motivations of charity sport participants including cause, camaraderie, and competency. Further quantitative analysis of charity sport participants confirmed these findings; however, the literature suggests there may be motivational differences in some of the original charity sport motives identified (i.e., Bennett et al., 2007; Filo et al., 2010; Won \& Park, 2010). Using the charity sport motives identified by Filo et al. (2009) as a framework, the next section will discuss the affirmation and expansion of those three original motives into the five that will be utilized in the current study: (1) Cause, (2) Philanthropy, (3) Social, (4) Sport, and (5) Health and Fitness.

Filo et al. (2009) described cause as a way for individuals to raise awareness and 
make a difference in the world by supporting a charitable organization they felt was important. Upon further analysis, however, researchers identified a distinction between individuals motivated to participate in charity sporting events to support a specific charitable organization (i.e., cause) and those participants with general altruistic motivations (i.e., philanthropy). The difference between individuals motivated for cause and philanthropic reasons was particularly evident in Won and Park's (2010) study. Additionally, Filo et al. $(2010 ; 2011)$ confirmed these findings, establishing differences in motives of "desire to improve the charity" and the "need to help others", similar to cause and philanthropy. For that reason, cause and philanthropy will be classified and analyzed as separate motives of charity sport participants.

Next, an overwhelming amount of research identified socialization as a motive of charity participants (e.g., Bennett et al., 2007; Filo et al., 2010; 2011; Won \& Park, 2010). Providing opportunities for participants to socialize and celebrate their accomplishments will effectively create a community atmosphere and potentially increase identification levels and brand loyalty (Chalip, 2006; Green, 2001). Chalip (2006) suggests enabling sociability, creating event related social events, facilitating informal social opportunities, producing ancillary events, and theming as effective strategies to increase retention. Establishing a fun atmosphere, where participants can build relationships and feel like they are a part of something bigger than themselves, assists organizations in creating economic and social value around their events (Chalip, 2006). Filo et al. (2009) established camaraderie as a motive of charity sport participants, addressing the social aspects of the event as well as the sense of community and belonging the participants felt toward each other. This motive was confirmed by other 
researchers (e.g., Bennett et al., 2007; Won \& Park, 2010) and will be identified as social in the current setting.

Furthermore, researchers identified the physical aspects of a charity sporting event as a motivation for participation (e.g., Bennett et al., 2007; Filo et al., 2010; Won \& Park, 2010; Won et al., 2011). Filo et al. (2009) used the term competency to encompass the motivations to participate in charity sporting events for physical reasons. Upon further analysis, the motivations involving the physical nature of charity sporting events can be further segmented. Bennett et al., (2007) identified the differences in these motivations through two variables "involvement with the sport" and the "desire to pursue a healthy lifestyle," whereas Snelgrove and Wood (2010) labeled them "cycling identity" and "physicality." Therefore, the competency motive will be separated into two motives, sport and health and fitness, to accurately identify those motivated by the actual sport or activity involved (i.e., sport), and those motivated to live a healthy lifestyle (i.e., health and fitness).

Additionally, there is a limited amount of research conducted on participant retention (Filo et al., 2010). Considering the increasing number of nonprofit organizations and their competition for participants, further research should address future participation intentions. On the other hand, there is an overwhelming amount of research supporting the positive influence of socialization as a motive of participation (e.g., Bennett, 2007; Filo et al., 2008), an avenue to create attachment to an event (Filo et al., 2009; 2011), and potentially contribute to retention. 


\section{Social Media}

Charitable organizations and individuals participating in charity sport events have the potential to utilize social media platforms to promote their fundraising efforts and increase awareness. Leveraging social media platforms and increasing the interactions between participants, before and after the events, has the potential to increase attraction and retention to events (Filo et al., 2010; 2011). The following section will be divided into four subsections. First, an overview of social media will be provided, then an analysis of individual social media consumption motivations, followed by a review of nonprofit social media usage, and a discussion of social media in a sport context.

\section{Social Media Overview}

Social media is a term defined in many different ways. Kaplan and Haenlein (2010) described social media as "a group of Internet-based applications that build on the ideological and technological foundations of Web 2.0, and that allow the creation and exchange of User generated content” (p. 61). Blackshaw and Nazzaro (2004) characterized the term as "a variety of new sources of online information that are created, initiated, circulated and used by consumers intent on educating each other about products, brands, services, personalities, and issues” (p. 2). Similarly, Williams and Chinn (2010) termed social media as "the tools, platforms, and applications that enable consumers to connect, communicate, and collaborate with others" (p. 422). Based on the definitions of social media previously established by researchers, social media in the context of this study will be defined as: Online communities enabled through communication platforms, whereby individuals collectively create, share, and improve information and user generated content, while interacting with others (Blackshaw \& Nazzaro, 2004; Kaplan \& 
Haenlien, 2010; Williams \& Chin, 2010). The focal point of the provided definition is placed on communities. Social media platforms enable virtual communities of individuals to interact and support each other.

Social media platforms are constantly evolving and new platforms emerge at an exponential rate. Currently, some of the most popular platforms include, Facebook, Twitter, Pinterest, LinkedIn, Google+, YouTube, Flickr, Tumblr, FourSquare, and blogs. Social media platforms differ from traditional media platforms in their ability to break down geographic borders (e.g., Dittmore et al., 2008), facilitate two-way communications (e.g., Kaplan \& Haenlein, 2010), provide instant access to content (e.g., Kietzmann et al., 2011), offer cost-effective communication mediums (e.g., Mangold \& Faulds, 2009), create a virtual community for likeminded individuals to interact with one another (e.g., Anderson, 2011), and allow users to generate content (e.g., blogs, photos, videos) and tell their stories digitally (Gleason, 2012). The present definition of social media is appropriate for the 2012 landscape; however, as the platforms and uses of those platforms continue to evolve, the definition of social media will evolve accordingly.

Social Media Brief History and Future. Technological advances have, and will continue to have, great influence on trends in social media usage. One of the first sites classified as a social network was SixDegrees.com where individuals created their own profile page and listed other individuals they were friends with who also had profile pages. Individuals could view each other's friends lists, send messages, and make posts on bulletin boards (boyd \& Ellison, 2008). Although the premise was very similar to Facebook, the multi-billion dollar company and most widely used social network currently, SixDegrees.com failed to attract new users and successfully make a profit; 
therefore shut down in 2001. boyd and Ellison (2008) argued the site was simply created before its time. Although some people were online and connecting through this network, by in large, the population did not have extensive Internet access. Therefore connections and friendships were limited due to technology.

Friendster, another social networking site with a similar premise, was created in 2002, and floundered a few years later (but has since been rebranded as a social gaming site currently popular in Asia). Some researchers note the lack of technology and the platform's inability to support the enormous amount of site traffic it received (boyd \& Ellison, 2008), while others explained that the site did not have enough social features for individuals to interact with each other to be sustainable as a social media platform (Pachal, 2011). Since their emergence in the late 1990's, other social networking sites such as LunarStorm, BlackPlanet, and AsianAvenue have seen a similar rise and fall. Conversely, some successful social media platforms have focused on niche markets, such as LinkedIn targeting business professionals and MySpace rebranding itself into a platform for music artists and their fans. While others such as Facebook, Twitter, and YouTube have seen success with broad-based, all-inclusive strategies to recruit participants (boyd \& Ellison, 2008). Facebook is an interactive friendship and connection site. The micro-blogging site Twitter, on the other hand, markets itself more as a source of information, while YouTube provides a platform for video dissemination and sharing (boyd \& Ellison, 2008).

As previously mentioned, the popularity and sustainability of social media platforms is closely tied to the technology available to users. Two major features that will be prevalent in the future of social media platforms are visual and mobile applications. 
Pew Internet Research documented the prominence of photo and video uploading and sharing via social networking sites (Rainie et al., 2012). The social bookmarking (i.e., virtual pinboard) site Pinterest saw has the all-time fastest growth rate of any social media outlet since its introduction in 2010, with some researchers ranking it as the third most visited social media platform behind Facebook and Twitter (Wasserman, 2012). Pinterest relies on users uploading and sharing photos. Similarly, Instagram, a photo based social media platform, reportedly has more active users, who spend more time, on average, on the site than Twitter (Isaac, 2012). Other social media platforms focusing on photos and videos which are making a mark are Viddy and Ptch. Viddy is marketed as the Instagram for videos, allowing users to easily format, style, and upload videos set to music; while Ptch combines photos, videos, and music into a multimedia slideshow which can be easily uploaded and shared with friends (Bissram, 2012). Although the previously mentioned platforms may never become "the next Facebook," they highlight the significant rise in social multimedia platforms--one that may continue in the upcoming years.

From a mobile perspective, the increase in photo and video sharing can partially be attributed to the prevalence of mobile phone usage around the world (Dube, 2012), where more consumers have photo and video cameras as well as Internet capabilities in the palm of their hand. There is a marked increase in the number of individuals accessing social media platforms via mobile devices. A recent study found Facebook and Twitter users spent more time accessing those sites through their mobile phone than computers, and four of five users accessing social media platforms from their mobile devices did so through an application (Dube, 2012). There are currently 110 million smartphone users in 
the United States (Isaac, 2012). As this number continues to increase, the trend of users veering away from websites and toward mobile applications will become ever more prominent.

The previous section defined and explained social media, primarily from a practical standpoint. The following section will explore theoretical and managerial perspectives of social media.

Social Media Theory. Social media is researched across many different fields of study including psychology (e.g., Raacke \& Bonds-Raacke, 2008), communication (e.g., Anderson, 2011), information technology (e.g., Chen, 2011), business (e.g., Kaplan \& Haenlein, 2010) public relations (e.g., Lovejoy, Waters \& Saxton, 2012), and sport administration (e.g., Clavio, 2011). The extent of research in different fields of study also facilitated the use of many different frameworks and theories used to classify social media platforms and help explain the social media phenomenon. For example, Kaplan and Haenlien (2010) combined elements of social presence and media richness theories (i.e., commonly used the communication field), with self-presentation and self-disclosure theories (i.e., commonly used in the sociology and psychology fields) to categorize social media platforms. Social networking sites such as Facebook were also classified as high in self-presentation and self-disclosure while medium in social presence and media richness. Content communities such as YouTube were classified as low in categories of selfpresentation and self-disclosure, yet medium in social presence and media richness (Kaplan \& Haenlein, 2010).

From a theoretical perspective, many researchers have utilized the uses and gratifications theory to explain social media consumption motivations (e.g., Bonds- 
Raacke \& Raacke, 2008; Clavio \& Kian, 2010; Johnson \& Yang, 2010). Others however used the Unified Theory of Acceptance and Use of Technology (UTAUT; Venkatesh, Morris, Davis \& Davis, 2003), framing theory (Sanderson, 2011), theory of planned behavior (Schultz \& Sheffer, 2010), social network analysis (Hambrick, 2012), and parasocial interaction (Kassing \& Sanderson, 2010) to name a few. To properly identify motivations of social media consumption, the uses and gratifications will be used as a theoretical framework.

Simply put, uses and gratifications theory provides a framework for identifying the rationale of individuals to use a particular platform (i.e., motives of consumption) and the gratifications (i.e., benefits) they receive from doing so (Katz, Blumler, Gurevitch, 1974). The benefits the individual perceives from their usage then dictates their continuation or discontinuation of usage in the future, assuming that there are always alternative choices for users to fulfill their needs (Katz, et al., 1974). Ruggerio (2000) noted the theory of uses and gratifications was particularly useful when trying to understand motivations of emergent communication vehicles, including social media.

Many researchers across a multitude of fields have embraced the uses and gratifications theory as a theoretical model to frame their research. For example, Raacke and Bonds-Raacke (2008) used uses and gratifications to understand motivations of consumption of Facebook and MySpace by college students, whereas Park, Kee, and Valenzuela (2009) used the theory to examine the relationship between gratifications and offline civic engagement behaviors. Additionally, in the sport realm, Clavio (2008) used uses and gratifications to understand sport fans participation on message boards, while Hambrick, Simmons, Greenhalgh, and Greenwell (2010) used it as a framework to 
analyze the tweets of professional athletes. To gain a better understanding of social media usage; particularly identifying consumption motivations of individual users, uses and gratifications was deemed appropriate and will be utilized as a theoretical framework for

the current study. The following section will detail various studies examining individual's social media consumption motives, most of which utilize the uses and gratifications framework (e.g., Johnson \& Yang, 2010; Haridakis \& Hanson, 2009; Raacke \& BondsRaacke, 2008).

\section{Individual Social Media Consumption Motivations}

In one of the first studies to examine social media users, Raacke and BondsRaacke (2008) conducted an exploratory study to (a) create a profile of the typical user of friend-networking sites, (b) determine why individuals use these sites, and (c) understand what uses and gratifications they fulfill by doing so. They found most respondents had a Facebook or MySpace account and on average spent three hours per day on these social networking sites. Demographically, users were significantly younger than non-users. Men, more often than women, used the social networking sites for dating purposes and to learn about events. In general, however, both sexes primarily utilized Facebook and MySpace to share pictures as well as keep in touch with current friends, make new friends, and locate old friends (54\%). The researchers highlighted the prevalence of Internet and social media usage as an emergent and popular form of communication, especially among the younger demographic (Raacke \& Bonds-Raacke, 2008). In a follow up study, Bonds-Raacke and Raacke (2010) used the uses and gratifications theory as a theoretical framework and exploring the underlying dimensions of social network usage. They identified three major dimensions: Friendship, Information, and Connection. Many 
of the uses and gratifications previously identified in research are interconnected (e.g., keeping in touch with friends, locating old friends), and the results of this research show evidence of these dimensions and interconnections.

In a theoretical piece, Shao (2009) created a model describing the interdependence of consumption motivations of user-generated media (i.e., social media), and identified seven motivations: (a) information seeking, (b) information sharing, (c) entertainment, (d) social interaction, (e) community development, (f) self-expression, and (g) self-actualization. He also identified differences between individual's motives in consuming, participating, and producing user-generated media. The researcher explained that users typically consume user-generated media for information and entertainment purposes, while they participate to be a part of a virtual community and have social interactions with others. In addition users produce user-generated content to have an online identity and express themselves through a different format. Although this study was conceptual in nature, it provides valuable information about social media consumption motives and a potential model for variations of usage.

As opposed to user-generated content, Lampe et al. (2010) identified motivations for participation in online communities. The researchers employed uses and gratifications as an underlying framework, and identified six motivations for participation in online communities: (1) get information, (2) provide information, (3) self discovery, (4) maintaining interpersonal connectivity, (5) social enhancement, and (6) entertainment. The researchers found entertainment value, getting information, and satisfaction from providing value through the site as respondents' main uses of social media. The more social elements were not predictive of use or future use of the site. Implications from the 
current study reveal that information based motives (i.e., seeking and providing) and entertainment were important motivations for consumption, while social motives were less important to respondents. Considering the nature of the sample (i.e., user-generated encyclopedia platform), it is not surprising that information-based motives were prevalent.

Similarly, Johnson and Yang (2010) utilized uses and gratifications theory to gain a better understanding of social media user motives; however, they looked specifically at Twitter users. The researchers examined potential motives and found two emergent factors, social motives and information motives. Social motives included nine items: to have fun, be entertained, relax, see what others are up to, pass the time, express myself freely, keep in touch with friends and family, communicate more easily, and communicate with many people at the same time. Information motives included six items: get information, give/receive advice, learn interesting things, meet new people, and share information with others. Findings from this study reveal both informational and social motives were prevalent through Twitter usage. Similar to Lampe et al. (2010), information based motivations were consistent; however, although Twitter is primarily considered an information communication platform, elements of socialization were present. Findings from the current study provide greater insight into the various motivations of individuals and how they differ depending on the type of social media platform they are using.

In a similar study, Haridakis and Hanson (2009) examined the uses and gratifications of YouTube users. The researchers surveyed individuals to determine the motivations that predict viewing and sharing YouTube content. The researchers 
uncovered six major motives of YouTube use: (1) convenient entertainment, (2) interpersonal connection, (3) convenient information seeking, (4) escape, (5) co-viewing, and (6) social interaction. Additionally, the researchers found convenient entertainment, convenient information seeking, co-viewing, and social interaction as significant predictors of YouTube viewing, while social interaction, convenient entertainment, and co-viewing motives significantly predicted YouTube sharing. Results from this study provide evidence to the social nature of YouTube and the television-type qualities the platform possesses. Additionally, greater information is gained about the motives of social media usage in relation to YouTube and potentially other platforms.

Park et al. (2009) also utilized the uses and gratifications framework to gain a better understanding of Facebook usage; however, they focused specifically on Facebook group usage. The researchers examined the relationship between social media usage and civic and political participation. They found four social media motives with socializing, entertainment, self-status seeking, and information seeking, and their results indicated that information seeking positively predicted civic participation. Respondents engaging in Facebook groups for informational purposes were more likely to participate in civic and political activities offline, whereas those simply using social networking sites for entertainment purposes were less likely to do so. These findings provide greater insight to social media group usage and their ability to facilitate action.

Similarly, Valenzuela, Park, and Kee (2009) examined the relationship between social media usage and social capital. The researchers analyzed the intensity of college students Facebook usage in comparison to social capital variables such as life satisfaction, social trust, civic engagement, and political participation. The researchers 
found evidence in the results to the positive relationship between college students Facebook use and social capital; meaning the intensity of Facebook use is related to greater life satisfaction, trust, as well as civic and political participation. This study contributes to the field of communication literature by providing evidence to the fact that a technological medium such as Facebook can facilitate intrapersonal relationships and influence college students' attitudes and behaviors.

Chen (2011) examined the uses and gratifications of Twitter and the ability of the social media platform to enhance connections with others. They found a significant relationship between variables such as the number of active months on Twitter, total tweets, and @ replies and the need to connect with others. Results from this study show the ability of social media platforms to fulfill sociability needs of individuals, specifically examining the need to connect with others through Twitter. Additionally, this study shows the greater amount of time and effort a user places in the usage of Twitter, the more likely they are to fulfill their need to connect with others. This finding confirms previous research identifying the connection people feel from their use in social networks (Valenzuela et al., 2009).

Similarly, Anderson (2011) examined the uses and gratifications of online care pages. The researcher sought to understand why individuals were using the social media platform CaringBridge and the gratifications they felt from that usage. The researcher discovered four main constructs: (a) networking, (b) convenience, (c) spiritual support, and (d) psychological support. The participants identified providing information to others, encouragement, convenience, and psychological support factors as the major benefits they received from using CaringBridge. The results of this study support the 
notion that social support can be achieved through new media usage. Additionally, the researcher documented a social media platform's ability to raise awareness about a cause.

Previous researchers identified primary motivations of social media consumption as: information sharing (Bonds-Raacke and Raacke, 2010; Johnson \& Yang, 2010; Lampe et al., 2010; Park et al., 2009; Shao, 2009), information seeking (Hanson \& Haridakis, 2008; Johnson \& Yang, 2010; Lampe, et al., 2010; Shao, 2009) friendship (Bonds-Raacke and Raacke, 2010; Park et al., 2009; Raacke \& Bonds-Raacke, 2008;), social (Hanson \& Haridakis, 2008; Johnson \& Yang, 2009; Shao, 2009), connection (Bonds-Raacke and Raacke, 2010; Chen, 2011; Haridakis \& Hanson, 2009), entertainment (Haridakis \& Hanson, 2009; Lampe et al., 2010; Park et al., 2009; Shao, 2009), self-expression and self-presentation (Lampe et al., 2010; Park et al., 2009; Shao, 2009), sense of community (Anderson, 2011; Chen, 2011; Lampe et al. 2010; Sanderson, 2010; Shao, 2009), social support (Anderson, 2011; Lampe et al., 2010; Sanderson, 2010), interaction (Clavio \& Kian, 2010; Dunne et al., 2010; Shao, 2009), and escape (Dunne, et al., 2010; Haridakis \& Hanson, 2009). Additional research provided evidence of online motivations to enhance or facilitate offline motivations (Valenzuela et al., 2009; Park et al., 2009).

Overall, many motivations for social media consumption have been previously identified; however, most of those are platform specific examining motivations for the usage of Twitter (e.g., Chen, 2011; Johnson \& Yang, 2009), Facebook (e.g., BondsRaacke and Raacke, 2010; Raacke \& Bonds-Raacke, 2008), YouTube (Haridakis \& Hanson, 2009) or other platforms (e.g., Anderson, 2011; Sanderson, 2010). Although understanding the motivations of usage for a specific platform is important, it also would 
be beneficial to have insights to social media usage as an integrated concept. In addition, there is limited information addressing the social media consumption motivations of charity sport participants. Therefore, there is a need to analyze generalized social media consumption motivations specific to the charity sport context. The following section examines social media usage in a nonprofit setting.

\section{Nonprofit Social Media Usage}

As previously discussed, social media platforms are an efficient and cost-effective avenue to reach consumers. Nonprofit organizations typically have smaller budgets in terms of advertising, marketing, and promotional campaigns than for-profit businesses (Adler, 2012). Social media presents itself as communication channel that may offer various benefits to nonprofit organizations in regard to development, recruiting and coordinating volunteers, reaching other news media outlets, and engaging stakeholders (Briones, Kuch, Liu, \& Jin, 2011). The following studies discuss social media usage specific to nonprofit organizations.

Curtis, Edwards, Fraser, Gudelsky, Holmquist, Thornton, and Sweester (2010) explored the adoption of various social media platforms by nonprofit organizations using the Unified Theory of Acceptance and Use of Technology (UTAUT) (Venkatesh et al., 2003) as a theoretical framework. The researchers conducted an exploratory study examining public relations practitioners' social media usage within a nonprofit setting, specifically analyzing their, familiarity with social media, level of participation, behaviors regarding emerging communication outlets, and tendencies to adopt such mediums. The researchers found eight factors: (1) performance expectancy and attitudes-the perceived usefulness and potential to increase productivity, (2) social influence-- 
apprehension and influences to adopting social media, (3) effort expectancy--ease of use, (4) behavioral intention--likelihood of adoption in the future, (5) facilitating conditions-resources and knowledge of the organization, (6) voluntariness of use--whether social media was required or not, (7) anxiety--hesitation toward social media, and (8) self efficacy--the comfort level individuals felt with using social media. Major study implications include the determination of factors effecting public relations adoption of such platforms. Additionally, social media represents a beneficial communication channel that nonprofit organizations can use to reach their stakeholders.

On the other hand, Waters et al. (2009) analyzed nonprofit organization Facebook profiles, one of the first studies examining social networking usage by nonprofit organizations. The researchers explored how organizations engaged stakeholders and fostered relationship growth through organizational disclosure (e.g., page administrator, official logo), information dissemination (e.g., news links, press releases), and involvement (e.g., volunteer opportunities, calendar of events), all of which have been previously identified in the literature as strategies for relationship cultivation in virtual communities. The researchers found disclosure was the most common strategy implemented. Information dissemination items were used infrequently, and involvement strategy even less often. The researchers concluded that the capabilities of social networking sites, specifically Facebook, were underutilizing by most nonprofit organizations. Nonprofits were transparent by disclosing information about the organization, yet did not effectively interact with stakeholders, encourage involvement with the organization offline, or disseminate information. The researchers emphasized the 
social nature of Facebook and encouraged nonprofits to strategically craft messages in order to make the most out of their efforts.

Waters and Jamal (2011) also examined the use of social media in a nonprofit context, specifically looking at Twitter. They explored nonprofits use of public relations strategic communication models to build relationships with followers. Press agentry and public information are both information-based models that use one-way communication to disseminate information. Press agency uses truthful messages that may include a sentiment of emotion, whereas public information rarely communicates any sort of emotion within the message. Two-way asymmetry and two-way symmetry are forms of two-way communication that reflect a dialogue and interactivity between the organization and individuals. The researchers found that nonprofit organizations were more likely to use Twitter to communicate via one-way communication with public information and press agency. Public information was used most frequently by organizations with tweets providing updates and announcements about the organization, research and reports, and upcoming dates of events. Additionally, the vast majority of tweets included a hyperlink to other resources. The results of this study provide evidence suggesting the underutilization of social media as a two-way communication tool in relationship building, with organizations using platforms primarily to disseminate informational messages.

In a similar study, Lovejoy et al. (2012) examined Twitter usage among nonprofit organizations; however, they extended the previous research by not only examining tweets but various other communication methods such as hyperlinks, hashtags, public messages (i.e., those that include @), and retweets. The researchers analyzed nonprofit 
organizations use of communication tools available through the social media platform Twitter over a month. They found the vast majority of organizations to be active users (i.e., tweet at least 3 times per week). Most of their tweets included hyperlinks to external sources, while a small percentage of all tweets were public messages, representing interactivity between the organization and followers. The researchers concluded again that organizations are continuing to use Twitter as a one-way, information dissemination platform, regardless of recommendations to embrace two-way dialogues to engage followers and build an online community.

Lovejoy and Saxton (2012) also analyzed Twitter usage of the largest nonprofit organizations in the United States to determine the primary organizational uses of this micro-blogging platform. They, however, distinguished their research from the former study, by creating typologies for organizational uses. Three major functions emerged from the data: Information, Community, and Action. Information included tweets that shared information about the organization, its events, and activities with followers-primarily a form of one-way communication. Community aimed to build communities on Twitter by fostering relationships and promoting interactivity--promoting two-way communication. Action encouraged followers to take action and 'do something' on behalf of the organization. This function urged followers to buy products, attend events, volunteer, donate and get involved in any way possible. The results revealed that most nonprofit organizations primarily use Twitter to share information with constituents. A smaller number effectively engage followers by sharing information, strengthening ties in the community, and encouraging action. The researchers proposed the three functions be used as a ladder to increase engagement among stakeholders. 
Muralidharan, Rasmussen, Patterson, and Shin (2011) examined Facebook and Twitter usage of nonprofit organizations and media organizations after the Haitian earthquake in 2010. The majority of tweets and posts by both nonprofit organizations and media organizations during this time period were 'updates on relief efforts in Haiti,' providing information through a one-way communication method. The researchers also examined the data for relationship development strategies (i.e., disclosure, information, and involvement), finding that nonprofits used disclosure on Facebook pages, particularly more so than media organizations. Nonprofit organizations used disclosure techniques in order to promote transparency and gain trust with constituents. Both nonprofit organizations and media organizations effectively used Facebook and Twitter to disseminate information, while both were lacking in encouraging involvement through the communication platforms. Additionally, nonprofit organizations used positive emotions to increase awareness and readership, whereas media organizations primarily used negative emotions. Similar to the previous studies, the study affirmed the use of social media as an information dissemination tool, and showed the apparent underutilization of interactive elements within the platform.

Conversely, in a study examining relationship-building techniques of nonprofits, Briones, Kuch, Liu, and Jin (2011) found organizations primarily used social media to foster two-way communication dialogue with constituents. The researchers interviewed American Red Cross employees to determine the uses, barriers, and opportunities of social media use by nonprofit organizations. Strategically, employees discussed building relationships with stakeholders, listening to stakeholders as to how they could improve their organization, spreading awareness about the organization, and engaging with current 
and potential volunteers. Tactically, employees used social media to distribute information, engage with local media, and connect with the community. Although the employees noted the importance and many benefits of social media, they also identified barriers such as time and staff limitations and limited support from their executive boards. Finally, the employees managing social media accounts suggested the headquarters of the American Red Cross assist local chapters to adapt to the new form of technology. The interviewees spoke of opportunities to engage donors, inform the community about the organization, and increase involvement; however, they requested additional information from the national headquarters about how they could achieve these goals through social media. Findings from this study yield evidence of the benefits and opportunities for nonprofit organizations to cost-effectively engage their constituents through social media.

In a recent article in the Chronicle of Philanthropy, Wallace (2012) stated, "It's not about the number of likes your page has but rather what you do with them" (para. 7). As many researchers noted through the prior studies, simply creating a social media presence is not enough; nonprofit organizations are urged to embrace the technology and all of the benefits that come along with it. Nonprofits effectively use social media for information distribution, but many continue to use the platforms for one-way communication, and fail to engage and interact with stakeholders (Lovejoy et al., 2012; Muralidharan et al., 2011, Waters et al., 2009; Waters \& Jamal, 2011). Previous research also identified the opportunity to build relationships with constituents and facilitate offline action (Briones et al., 2011; Lovejoy et al., 2012), yet Lovejoy and Saxton (2012) found only a small number of organizations studied actually used social media for those 
purposes. Briones et al. (2011) interviewed American Red Cross employees and found they were leveraging social media for relationship building; however, previous social media research also identified a disconnect between how individuals say they are using social media, and how they are actually using social media (Schultz \& Sheffer, 2010; Sheffer \& Schultz, 2010). For example, through interviews Schultz and Sheffer (2010) found journalists used social media platforms primarily to break news, offer personal opinions, promote their media outlet, and connect with the readership. A follow-up content analysis of the journalist's tweets, however, revealed the majority of the tweets offered commentary on the news, as opposed to breaking news, or the other uses mentioned.

\section{Social Media Usage in Sport}

The previous studies provided insights to the uses and gratifications as well as potential outcomes that could be leveraged through social media usage. The following studies will discuss social media usage in a sport specific context. This section will be segmented into two sections, one addressing content-based research (i.e., what are people saying and why), and audience-based research (i.e., who is the audience and why are they using social media).

Content-based Research. Mainly through content-based inquiry, previous research analyzed the messages disseminated by athletes (Kassing \& Sanderson, 2010; Hambrick et al., 2010, Pegoraro, 2010), teams (Waters, Burke, Jackson, \& Buning, 2010), and sport organizations (Schoenstedt \& Reau, 2010; Wallace, Wilson, \& Miloch, 2011) through social media platforms. The following studies will discuss content-based research on social media found within the sport realm. 
Specifically focusing on the use of Twitter as a communication tool by athletes, Kassing and Sanderson (2010) conducted an exploratory study using case study design and parasocial interaction as a theoretical basis. Using grounded theory to detect emergent themes, the researchers examined tweets from eight cyclists during the Giro d'Italia, a 27-day cycling tour in Italy. The data revealed three emergent themes: (a) sharing of commentary and opinion, (b) fostering of interactivity, and (c) cultivating of insider perspectives. The researchers found through the results of the content analysis that Twitter is a unique form of communication providing fans with the opportunity to directly interact with the athletes they admire, and gain access to an unprecedented insiders perspective to the sport, organization and athletes they admire. Athletes use of this unfiltered communication tool allows increased fan interaction as well as promotion their sport and products they endorse. The authors suggest sport organizations and athletes can use this social media platform as a communications strategy to have dialogues with fans, and build and maintain relationships over time. Sports managers must recognize, however, that this two-way communication opens the door to both positive and negative feedback from consumers.

In a similar study, Hambrick et al. (2010) conducted a content analysis professional athletes tweets to gain a better understanding of the communication exchange through social media. The researchers placed the athletes' tweets into six categories based on previous communications literature, (a) interactivity (i.e., direct communication with fans or other athletes), (b) diversion (e.g., where they had lunch, favorite movie), (c) information sharing (i.e., information about their sport) (d) content (i.e., provide links to other websites), (e) fanship (i.e., discussion of other athletes or 
teams accomplishments), and (f) promotion (i.e., promotion of products and events). Results yielded celebrity athletes used Twitter as a communication tool primarily for interactivity and diversion, and again emphasized two-way communication as athletes traded tweets with friends, family members, and fans...

Pegoraro (2010) also analyzed the content of professional athlete's tweets to better understand how they engage fans through this social medium. Similar to the methodology in Hamrick et al. (2010), the researcher categorized tweets into one of seven categories: (a) relating to personal life, (b) relating to business life, (c) relating to another sport or athlete, (d) relating to their sport, (e) responding to fans, (f) responding to other athletes, and (g) relating to pop culture. The majority of tweets were direct messages with a very small number containing a link or picture. The top content category in most leagues was players responding to fans, indicating the importance of social media tools in direct interactions with fans. Although the analysis revealed that most athletes did not mention business life, Pegoraro emphasized the marketing potential of social media tools, including exposure, publicity, and potentially even recruiting sponsors due to their media presence.

To further investigate the untapped potential of Twitter as a promotional tool, Hambrick and Mahoney (2011) analyzed two celebrity athletes, Lance Armstrong and Serena Williams, and their lifetime of tweets. They found a limited number of tweets designated as promotional, where the athletes discussed products they endorse, charitable organizations they support, as well as other athletes, sports, and family and friends. Although the majority of messages communicated by the athletes were interactive in nature similar to previous research (Kassing \& Sanderson, 2010; Hambrick et al. 2010; 
Pegoraro, 2010), promotional tweets were intermixed amongst a broader range of messages. This could represent strategic message dissemination by the celebrity athletes, dispersing promotional tweets in limited amounts as to not overwhelm their followers (Hambrick \& Mahoney, 2011).

The previous studies examining the content of professional athlete tweets found similar results across the board. Athletes were primarily using Twitter to interact with followers (Hamrick et al., 2010; Pegoraro, 2010) and increase two-way communication (Kassing \& Sanderson, 2010). This interactivity provides fans with unprecedented insights and access into the professional athletes they follow, potentially increasing attachment (Kassing \& Sanderson, 2010; Hambrick et al., 2010; Pegoraro, 2010). Additionally, the previous studies found despite the marketing and promotional potential of Twitter, very few athletes communicated messages promoting their sponsors or products they endorse (Hambrick \& Mahoney, 2011; Hambrick et al., 2010; Pegoraro, 2010).

On the other hand, from an organizational perspective of social media in a sport context, Wallace et al. (2011) analyzed the NCAA organizational Facebook pages as well as athletic department Facebook pages for teams in the Big 12 Conference. They used content analysis and descriptive statistics to determine differences in communication types, marketing strategies, and branding techniques used by the organization. Although they examined two distinct types of organizational Facebook pages (i.e., NCAA and athletic departments), the results yielded similar management strategies of the social media platform. Both organizational groups used Facebook to cultivate engagement with fans, facilitate relationship building, and disseminate content to build their brands and 
interact with fans via two-way interactions. In a similar study of organizational social media usage, Waters, et al. (2010) examined National Football League (NFL) teams use of websites and Facebook pages to engage fans. The authors found organizations used relationship-building techniques (i.e., reciprocity, responsibility, reporting, and relationship nurturing) more prominently through the team website as opposed to connecting with fans through various online communication channels.

Schoenstedt and Reau (2010) examined social media within a sporting event context. They conducted a case study, taking an in-depth look at running a social media newsroom (e.g., YouTube, Twitter, Facebook, Twitpics, blogs) for a large-scale endurance event, the Cincinnati Flying Pig Marathon. The race organizers created a social media campaign in conjunction with traditional marketing campaigns to generate positive media attention and track digital participation for marketing, sponsorship, and sales purposes. The social media newsroom was a year-round initiative that targeted different audiences, highlighted varying sponsorships, and provided helpful information and special opportunities to followers. Organizers promoted social media platforms through each of the email and print newsletters, and Tweetdeck was used to post and organize tweets, monitor conversations, and engage runners. The social media newsroom was a huge success with over 300 updates, 150 Twitpics, 14 YouTube videos, and more than 1,300 people following the event on Twitter, making it the second most tweeted marathon in the country after Boston. The case study provides a template for other organizations that may want to utilize similar technologies to engage potential customers in an efficient and cost-effective manner. 
Audience-based Research. A considerable amount of social media research has addressed the content of messages (e.g., Kassing \& Sanderson, 2010; Hambrick et al., 2010) and social media usage from an organizational standpoint (e.g., Waters et al., 2010; Wallace et al., 2011); less has addressed the users. It is important for sport managers to have an understanding of who their social media consumers are, the frequency with which they consume, as well as their motivations for doing so. The following studies provide insights into the social media audience in a sport context.

One of the first studies to examine Web 2.0 technologies within a sport setting was Dittmore et al. (2008). The researchers surveyed blog users of a Major League Baseball team and analyzed components of conversational human voice (CHV) and communicated relational commitment (CRC) measures as well as points of attachment (sport, team, players), media consumption, game attendance and basic demographic information. Researchers found high mean scores for $\mathrm{CHV}$ and $\mathrm{CRC}$, indicating that a sport organization weblog is an effective relationship-building tool. The blog readers were voracious media consumers of Dodger games and frequent ticket customers. The researchers found the majority of customers surveyed were highly identified with the team and sport, but not the players. Overall, the researchers found the Dodgers official blog was perceived favorably in communicating $\mathrm{CHV}$ and $\mathrm{CRC}$ objectives. From these results, the authors emphasize the responsibility an organization has in building and maintaining long-term relationships with its consumers, as well as the potential of weblogs and other social media platforms to reach a diverse population of individuals efficiently and effectively. 
Similarly, Williams and Chinn (2010) explored the managerial uses of social media to build relationships and engage an audience in a sport context. The researchers created a conceptual relationship-marketing framework model to address the emerging market of online social media in marketing as well as the proactive consumer, which tends to be commonplace in today's society. The researchers describe today's prosumers (i.e., proactive consumers) as actively engaged in Web 2.0 technologies and social media tools, whereby they exchange knowledge and information with fellow consumers. The researchers use concepts presented in Gronroo's (2004) model on the relationship building process (i.e., communication, interaction, and value) and modified it to include the needs of a prosumer and the interactions that are heavily present within social media platforms. Organizations may continue to send out planned messages; however the prosumer is looking for a more interactive way of communicating with fellow fans, athletes and the organization on the whole. The researchers suggest that embracing the prosumer and actively engaging this new type of customer through social media platforms may enhance relationship building with fans over time.

In a study of social media usage among a college football audience, Clavio (2011) found significant differences between demographic factors and traditional and new media consumption behaviors. An online survey of FBS-division football ticket buyers revealed significant differences between age and the consumption of social media. The researcher found a negative relationship with Facebook and YouTube usage, such that as age increases usage decreases. Facebook was the most popular platform, followed by YouTube. Twitter and podcasts had the lowest new media usage scores. Results of this study yield important distinctions in the use of social media platforms by demographic 
groups. From the given sample of college football ticketholders, college athletic departments should focus on Facebook and YouTube for information dissemination, considering Twitter and podcasts were significantly less popular among the fanbase. Additionally, college marketing managers should integrate social media along with traditional forms of communication in order to effectively reach their diverse range of fans and potential ticketholders in the future.

Clavio and Kian (2010) also examined demographic information; however, they specifically analyzed followers of a retired female athlete. The researchers found a retired Ladies Professional Golf Association player's Twitter followers to be primarily 40 to 59 years old with an almost even distribution of males and females. Follower motives included 'I think the athlete is an expert at her sport,' 'I like what the athlete writes,' 'I get information on what the athlete is doing that I can't get elsewhere,' and 'I have always followed the athletes career.'. The researchers also identified three underlying dimensions of Twitter follower uses and gratifications: Organic fandom (i.e., perceived entertainment value of the athlete, athlete as a role model), Functional fandom (i.e., affinity for the athlete's products, business relate purposes), and Interaction (i.e., interacting with the athlete, camaraderie with other fans via Twitter). The findings mirror the uses of professional athletes, focusing on interaction and providing an insider perspective to followers (Kassing \& Sanderson, 2010; Hambrick et al., 2010; Pegoraro, 2010). Results could also be interpreted as athlete specific, considering the personal and functional affinity could change drastically depending on the athlete using Twitter.

Sanderson (2010) took a different route to audience-based social media research, by examining the social support garnered through social media platforms. He analyzed 
responses to Boston Red Sox pitcher, Curt Schilling's (38pitches.com) blog posts addressing the "the public questioning of his integrity" and "his apology for critical comments he made toward fellow baseball player Barry Bonds" (Sanderson, 2010, p. 189) to gain a better understanding of social support manifestation on a social media platform. Through a thematic analysis of the blog posts and comments, the researcher found unwavering support for Schilling and common themes of fans. Implications from this study provide evidence of the social support achieved by celebrity athletes through their blogs and other such non-traditional media outlets. Professional athletes can utilize blogs to avoid sport journalists and have direct communications with their fans, clarify controversies, create positive public relations, and indirectly receive social support from the masses. In turn, this blog is an example of readers uniting through a social media platform to show their support for a cause, in this case support of Curt Schilling as a Red Sox hero. Findings validate the use of social media as an avenue for like-minded individuals to band together and show collective action.

Researchers across multiple disciplines have addressed the concept of social media as it relates to individual (e.g., Bonds-Raacke \& Raacke, 2009) and organizational usage (e.g., Waters \& Jamal, 2012). With social networking sites such as Facebook now having over 1 billion users (Ortutay, 2012), it is important for organizations to use social media platforms to communicate and build relationships with consumers. Although there has been an extensive amount of research conducted on the content of information (e.g., Hambrick et al., 2010; Pergoraro, 2010) less research addresses the audience itself (e.g., Clavio, 2011; Clavio \& Kian, 2010). Particularly in a sport context, social media platforms provide an opportunity for individuals to interact directly with athletes 
(Hambrick et al., 2010), sport organizations (Wallace et al., 2011), other fans and likeminded individuals (Clavio \& Kian, 2010). Researchers have identified the social aspects of participants and fans interacting on social media platforms to show collective action (Sanderson, 2010). Although much research has identified the role of social media in a sport context (e.g., Kassing \& Sanderson) there is a lack of literature addressing social media in a charity sport context, particularly examining participants of events.

\section{Literature Review Summary}

Previous literature on sport philanthropy, charity sport participation motivation, and social media analyzed the growing phenomenon of charity sporting events and the emergence of social media. Research on charity sport participation thus far aided in gaining a better understanding of the motives (e.g., Won et al., 2010), and perceived meaning individuals attribute to participating in charity sporting events (e.g., Filo et al., 2009; Won \& Park, 2010), however, is lacking in terms of behavioral outcomes, such as participant retention, future support of the organization, or participants' willingness to refer.

One of the common themes seen throughout the literature is the prevalence of intrinsic motives of individuals to participate in sports (e.g., Recours et al., 2004; Tsorbatzoudis et al., 2006), donate to charity (e.g., Guy \& Patton, 1989), and participate in charity sporting events (e.g., Filo et al., 2008; 2009). Charity sporting events provide a unique opportunity for consumers to simultaneously participate in two meaningful activities, charitable giving and sport participation (e.g., Filo et al., 2008, Filo et al., 2009; Wood et al., 2010). 
Another commonality found is the importance of social aspects within the context of sport participation needs (Recours et al., 2004; Tsorbatzoudis et al., 2006) as well as donor behavior (Dawson, 1988; Guy \& Patton, 1989). Charity sporting events form the perfect medium for participants to make a difference in the world, while embracing an altruistic community (e.g., Chalip, 2006; Green, 2001; Nettleton \& Hardey, 2006; Wood et al., 2010). Establishing a sense of community and camaraderie at events assists organizations in creating greater economic and social value as well as increasing brand loyalty (Chalip, 2006; Filo et al., 2008).

Communicating the message of the cause was another common theme found within numerous charity motivation and charity sport motivation studies (Sargeant et al., 2008; Smith \& Westerbeek, 2007; Walker \& Kent, 2009; Wharf Higgins \& Lauzon, 2003). One of the major benefits of utilizing charity sport participation for development is reaching a diverse audience of individuals in one event (Bennett, 2006; Green, 2001; Peloza \& Hassay, 2007). Peloza and Hassay (2007) identified the uninvolved supporter as a market segment ignored by most charitable organizations. Sport events, however, represent an ideal opportunity for charitable organizations to communicate their mission and the severity of the cause to a captive audience and potential supporters (Peloza $\&$ Hassay, 2007).

One of the major gaps in the literature identified from this review is the intersection of charity sport participation and social media. Previous social media research provided evidence of the power of social media platforms to promote products and events (Hambrick \& Mahoney, 2011), recruit participants (Valenzuela et al., 2009), and create a social support system (Sanderson, 2010). Charity sporting events represent 
an ideal opportunity for charitable organizations to communicate their mission and the importance of the cause to a captive audience and potential supporters (Funk et al., 2010). Social media, used as a marketing, fundraising, and recruiting tool, could assist nonprofit organizations in their quest to raise awareness and funds through charity sport events. Additionally, organizations could use social media to build long-lasting relationships with participants (Waters \& Jamal, 2011), facilitate socialization before and after events (Filo et al., 2009), and encourage collective action through offline behaviors (Park et al., 2009; Valenzuela et al., 2009). In an increasingly competitive nonprofit environment, the use of social media could be an effective avenue to enhancing future outcomes of participants.

There is a clear gap in the literature addressing the intersection of social media and charity sport events. In fact, much of the social media research conducted lacks a multidisciplinary approach. Social media researchers tend to examine the use or users of social media, but leave out how that affects consumer behaviors or offline behaviors. The focus of this study is on the outcomes themselves, bridging the gap between on and offline behaviors, and incorporating literature from many fields (i.e., sport philanthropy, development, sport participation, charity sport, and social media) to accomplish that goal.

In addition, this study creates a clear definition for social media for the current time frame, as well as insights as to the future of social media. As technology continues to evolve, so will social media and the way in which researchers define the term. The established definition in this study embraces the sense of community, which may be unique to a sport and particularly charity sport setting. Finally, the majority of social media studies up until this point have used content analysis as a research method (e.g., 
Clavio, 2009; Hambrick et al., 2010; Waters et al., 2010). Content analysis is an appropriate method for analyzing data in the beginning stages of social media research; however, at this point in time, in order to expand the research base other methodological designs should be implemented. The current study uses various statistical procedures through survey design to produce empirical results and expand the literature on social media. Therefore, the purpose of this dissertation is to examine the influence of social media on future outcomes of charity sport participants. 


\section{CHAPTER III}

\section{METHOD}

This chapter will discuss the methodology used to address the study's purpose and research questions. Specifically, the chapter will examine the research design, study participants, sampling procedure, data collection and sampling procedure, instrumentation, and data analysis.

\section{Purpose}

The purpose of this study was to determine how charity sport organizations can leverage social media to enhance recruitment, retention, and future support of their organization. Gaining a better understanding of charity sport participant motives, intensity of social media usage, and motives of social media usage will provide sport managers with valuable insights into the types of marketing and communication campaigns they could employ in order to maximize important outcomes.

There were seven main purposes of the current study: to (1) examine which charity sport participation motives were likely to predict future intentions, (2) determine which levels of social media intensity of usage predicted future intentions, (3) establish a

set of social media consumption motivations within a charity sport context, (4) determine 
which social media consumption motivations best predicted future intentions, (5) develop social media user typologies based on consumption motives and intensity of usage, (6) provide profiles of social media typologies based on their motives of charity sport participation, and (7) understand which charity sport participation motives predict future intentions for each social media typology.

\section{Research Questions}

To address the purpose, the researcher developed seven major research questions: RQ1: Are the charity sport motives of cause, philanthropy, social, health and fitness, and sport significant predictors of future intentions (i.e., future participation intention, future support of the organization, and participants' willingness to refer)?

RQ2: Are the different levels of social media intensity of usage (i.e., low, moderate, and high) related to future intentions (i.e., future participation intention, future support of the organization, and participants' willingness to refer)? RQ3: What is the factor structure of social media consumption motivation? RQ4: Are the social media consumption motives significant predictors of future intentions (i.e., future participation intention, future support of the organization, and participants' willingness to refer)?

RQ5: What typologies of social media users exist based on intensity of usage and consumption motivations?

RQ6: Are there differences in social media typologies related to charity sport motivations (i.e., cause, philanthropy, social, sport, health and fitness)? RQ7: Are charity sport motives (i.e., cause, philanthropy, social, sport, health and 
fitness) significant predictors of future intentions (i.e., future participation intention, future support of the organization, and participants' willingness to refer) for each social media typology?

\section{Research Design}

To achieve the study purposes and research questions, the researcher used a cross-sectional survey research design. Employing a survey research design allowed the researcher to gain a better understanding of the trends of the population by examining attitudes, opinions, behaviors, and characteristics (Creswell, 2008). Survey research was appropriate for this study since it is primarily used to explore the characteristics of a population from a sample selected for the study by asking the study participants a series of questions (Creswell, 2008). Specifically, survey design was used for the following reasons: (a) it helps explain the characteristics of a large population; (b) it allows for the gathering of sufficient amount of data at a relatively inexpensive cost in a short period of time; (c) it is useful in collecting data from large samples; and (d) it can be easily modified if necessary (Ary, Jacobs, Sorensen, \& Razavieh, 2010). Survey design, however, has also some disadvantages such as the chance of some items being misinterpreted and the limitation of obtaining a low rate of return (Ary, et al., 2010). Additionally, survey design is used to analyze trends in a population as opposed to determining a cause and effect relationships, or predicting outcomes; therefore, results should be interpreted as such (Creswell, 2008).

Survey design has been used extensively across the sport management field in examining the motivations and attitudes of participants (Funk et al., 2011), spectator behaviors (Robinson \& Trail, 2005), athletic donor motivations (Gladden et al., 2004), 
and social media motivations among football fans (Clavio, 2011). In addition, the majority of studies in the charity sport context used survey research designs (e.g., Bennett et al., 2007; Filo et al., 2010; Won \& Park, 2010; Won et al., 2011).

\section{Study Participants}

The aim of the current study was to assess the motivations of charity sport participants and the influence social media usage has on future intentions. To address this purpose, TNT was the study population. TNT participants were selected for several reasons. They (1) are a well-established charity sport organization, (2) offer events which require a significant athletic and financial commitment, and (3) embrace social media as part of their communication strategies. The rationale for using TNT will be discussed further in the following paragraphs.

TNT is one of the major fundraising campaigns of the Leukemia and Lymphoma Society, which supports cancer research and programs for blood cancers. The training program is among the oldest and most reputable charity sport organizations in the world. TNT prides itself on being "the world's largest and most successful endurance sports charity training program” (Leukemia and Lymphoma Society, 2012, para. 1). The organization consistently ranks among the top charity sport programs (i.e., by gross revenue) and was ranked fifth in 2010 (RWRF, 2011). TNT is a unique program that hires coaches and mentors to help train and prepare participants over approximately five months prior to the event. The training program was established in 1988 when Bruce Cleland asked 38 of his friends to run the New York City Marathon with him to raise money for his daughter who had leukemia. The original group of runners raised $\$ 322,000$, and TNT found its beginnings. Throughout the past 25 years, TNT has trained 
over 500,000 runners, cyclists, triathletes, and hikers, while raising $\$ 1.3$ billion for cancer research (TNT, 2012c).

In addition TNT was chosen for this study based on the type of charity participation events it offers. Charity sporting events of all kinds (e.g., walk-a-thon, jump rope for a cause, etc.) have become extremely popular; however, the focus of this study was on serious leisure events (Heo, Lee, Kim, \& Stebbins, 2012) that require participants to make a significant commitment to the sporting event and the charitable organization, in this case Leukemia and Lymphoma Society. All of the training programs coordinated through TNT last between four and five months long, and have fundraising goals ranging from $\$ 800$ to $\$ 5,000$, depending on the event (TNT, 2012a). Therefore, participants in the current study were either training to compete, or had previously competed in a halfmarathon, marathon, century bike ride, or triathlon. Consistent with serious leisure events, these standards differentiate participants in TNT from other charity sport participation events that require less sport and cause involvement and commitment (Heo et al., 2012).

TNT was also selected because of its adoption of social media at the organizational level. TNT promotes social media usage and encourages participants to use these technologies to help them achieve their fundraising and participation goals. TNT has a national Facebook page with over 61,000 likes and approximately 2,000 active users as of September 2012 (Facebook, 2012). The organization also has a presence on Twitter, YouTube, Flickr, LinkedIn, and maintains three blogs called the 'TNT Community,' which allow users to interact with each other and create a virtual community where discussion topics include anything from fundraising strategies and 
training techniques to cancer treatments and grief counseling. At the same time, the organization uses these platforms to build lasting relationships with participants, provide information to assist them in their sport and fundraising goals, and inspire them to continue supporting the organization in the future (TNT, 2012b).

As previously mentioned, TNT is one of the major development programs coordinated by the Leukemia and Lymphoma Society to support the ongoing fight against blood cancers. The Leukemia and Lymphoma Society currently consists of 64 regional chapters in the United States, Canada, and Puerto Rico, and each chapter coordinates a TNT program. The researcher selected an international sample of participants through purposive and snowball sampling.

\section{Sampling and Data Collection Procedure}

The following section will detail sampling and data collection procedures. The preferred method of sampling is probability sampling (e.g., simple random sampling, cluster sampling, stratified sampling, or systematic sampling) to achieve a sample representative of the population (Ary et al., 2010). However, if there is a situation where enumeration of the population is impossible, Ary et al. (2010) suggests that nonprobability sampling, such as purposive sampling, convenience sampling, or snowball sampling can be effectively utilized. Considering the extensive scope of the population of TNT participants, the current study utilized a combination of purposive and snowball sampling of TNT participants and alumni.

The purpose of this study was to determine how charity sport organizations could leverage social media to enhance recruitment, retention, and future support of their organization. A purposive sample of charity sport participants is not an uncommon 
technique, and has been used in previous sport management literature. Researchers have commonly sampled charity sport participants at the LIVESTRONG Challenge (Filo et al., 2009; 2010; 2011), Lance Armstrong Ride for the Roses (Filo et al., 2008), MS Bike Tour (Snelgrove \& Wood, 2010, Wood \& Snelgrove, 2010), and TNT informational meetings (Havenar \& Lochbaum, 2003).

Considering the research purpose and previous studies that used similar data collection methods, electronic dissemination through social media platforms was deemed an appropriate data collection technique for the current study. In recent years researchers have effectively used social media platforms to gather data. For example, Chen (2011) used snowball sampling through social media platforms to obtain a sample in her research regarding users 'need to connect' with others on Twitter. The researcher recruited participants by posting the link to the survey on her Twitter feed, Facebook profile, and blog, asking users to take the survey and forward it to others. She also sent direct messages to users with large followings and asked them to post the survey link to their social networks (Chen, 2011). Using a broader surveying technique, Lindqvist, Cranshaw, Weise, Hong, and Zimmerman (2011) posted links to their online survey on craigslist to solicit participants and gain a better understanding of FourSquare users. On the other hand, Lampe et al. (2010) posted a link to their survey on the Everything2.com site, a user-generated encyclopedia similar to Wikipedia, asking users to voluntarily participate in their survey when they logged onto the site.

The previous studies detailed commonly used data collection and sampling techniques through social media. Sport management researchers also adopted similar data collection techniques using social media platforms. For example, Clavio and Kian (2010) 
used the social media platform Twitter to reach potential participants in their research study. The researchers gained access to a retired athlete's Twitter page, and posted a short message and link to the online survey. Similarly, Johnson and Yang (2010) sent a direct message, which included the electronic survey link, to a few key individuals with many followers on Twitter. The key individuals tweeted that link to their followers and asked them to retweet the message to their respective networks. The researchers effectively used snowball sampling to collect their data through Twitter. Clavio (2011) examined the social media usage characteristics of football fans by posting a link on the athletic department website homepage as well as distributing it through email. Based on the wellestablished social media data collection methods, the current survey used a combination of purposive and snowball sampling techniques. Specific data collection procedures and methods to increase response rate will be discussed next.

Each participant received a survey with four main sections: (a) charity sport, (b) social media, (c) future outcomes, and (d) demographic information. The estimated time to complete the survey was approximately 15 minutes. The survey was hosted on surveymonkey.com, and the link was distributed electronically via various social media platforms. First, the researcher contacted the TNT Director of all 64 regional chapters in the United States, Canada, and Puerto Rico. The researcher requested TNT Directors to post the survey on their respective Facebook pages, Twitter accounts, and email it to participants and alumni of their programs. The researcher crafted message language describing the nature and purpose of the study (Appendix B). Next, the researcher posted information about the survey on various sport specific forums to recruit additional survey participants. The researcher specifically targeted message boards with high volumes of 
users across a divers spectrum of sports. A complete list of sites where the survey was posted can be found in Appendix C. In addition, the researcher requested all participants of the survey share it with their friends, family, and social networks, further disseminating the survey. As an incentive for voluntary participation, the messages also contained information about two $\$ 50$ Visa gift cards that would be randomly awarded to two survey respondents. Reminders were posted on the same social media platforms seven days after the initial dissemination to encourage further participation.

Some concerns regarding nonresponse bias, low response rates, or a nonrepresentative sample may exist with this data collection process. However, the nature of this study was examining social media usage of charity sport participants and alumni, and leveraging social media platforms in order to recruit participants as a valuable strategy. Additionally, the focus of this study addressed the individual uses of social media platforms, intensity of usage, and the effects on future intentions. Thus, it was necessary to sample respondents who use social media platforms. The study's objective was not how to get people to use social media, but how to tailor messages to influence behaviors for those currently using social media platforms.

While online surveys represent a popular format, one major disadvantage of online surveys is low response rates in comparison to traditional (e.g., intercept, paper and pencil) forms of survey dissemination (Dillman, 2007). In fact, the average response rate for online surveys is often below 20\% (e.g., Dillman, 2007; Funk et al., 2011). In order to obtain a sample size large enough to attain statistical power, the researcher targeted a large international sample of charity sport participants, including current participants and alumni. The decision to distribute the link to the survey through multiple 
platforms helped increase the number of individuals who had the opportunity to participate in the survey, in turn, increasing responses. Additionally, posting the link on sport related forums and social media platforms, potentially increased the diversity of the sample.

To combat low response rates commonly found in online surveys, the researcher implemented various tactics cited by Dillman (2007) to effectively increase response rates. First, the survey was distributed from a recognized TNT official employee account and posted on official Facebook pages. The researcher crafted the language in the text; however, the actual email and posts came from a verified employee of the organization. Second, the researcher used two $\$ 50$ gift cards as incentives for participation. Two participants' names were randomly selected for the giveaway, through a feature available on surveymokey.com. The use of incentives to increase participation rates is a commonly used (e.g., Valenzuela, et al., 2009) and accepted practice to increase response rates (Dillman, 2007). Third, the researcher asked TNT employees to send a reminder email and Facebook post seven days after the initial distribution date, and the researcher reposted the survey link on the social media platforms a week later as well.

The current study employed a combination of multiple regression equations, multivariate analysis of variance (MANOVA) and cluster analysis. There are statistical and inferential requirements necessary for the sample size in order to assure the results will be sound. To determine adequate sample size for multiple regression, Stevens (2009) suggested that 15 participants were needed per predictor variable. For the multiple regression analyses, the researcher used a maximum of five predictor variables, dictating a minimum sample size of 75 participants. Similarly, for MANOVA Stevens (2009) 
recommended a minimum of 15 participants for each independent variable. For the MANOVA the researcher used five independent variables, for a minimum sample size of 75. For cluster analysis, there are no generally accepted sample size requirements, however, Mooi and Sarstedt (2011) recommend a sample size of at least $2^{\mathrm{m}}$, where $\mathrm{m}$ is the clustering variables. Cluster classification was based on the underlying constructs of social media consumption motivations (i.e., 5 variables) and social media intensity of usage (i.e., 1 variable). Following the recommendations of Mooi and Sarstedt (2011), the required sample size for cluster analysis was 64 (i.e., $2^{6}=64$ ). For exploratory factor analysis, Tabachnik and Fiddell (1996) suggested a minimum sample size of 150 participants to produce a reliable solution. In order to generalize to the population, the inferential requirement is based upon sampling error. Dillman (2007) suggested a sample size of 245 respondents to attain a 95\% confidence interval, and less than 5\% sampling error, for a population of 50,000 (i.e., the number of TNT participants last year) (TNT, 2012). The usable sample in the current study was 277 participants, thus meeting all of the statistical and generalizability requirements discussed.

To ensure the sample was representative, the researcher employed sound data collection and sampling procedures along with statistical techniques examining the representative nature of the sample. First, the researcher disseminated the survey through multiple platforms (e.g., forums, social media sites) with the aim of reducing nonresponse bias, particularly from those who are infrequent social media users. Second, the researcher encouraged users to share the survey link with their networks (through email or social media) to increase the number of individuals who had the opportunity to take the survey. Third, the researcher employed multiple strategies previously discussed to 
increase response rate and facilitate an adequate sample size. Fourth, the researcher compared sample demographics to the demographics of the TNT membership to ensure the sample is similar to that of the population. The researcher used chi-square analysis and one sample $t$-tests to compare the sample demographics (i.e., gender, age, household income) to that of the population (i.e., TNT national membership). Fifth, the researcher also used one-way analysis of variances (ANOVA) to compare survey responses of early and late respondents, since previous researchers identified late respondents to have similar results to non-respondents (Groves, 2006; Siebert, 2008). Although the sample may not be representative of all charity sport participants, the researcher took additional efforts to ensure it was representative of TNT participants. Therefore, the results should be generalizable to TNT participants and interpreted with caution beyond that scope.

Prior to data collection the researcher had all methods of sampling and data collection approved by the University of Louisville Institutional Review Board (IRB). Although the compiled results of the data were shared with TNT, individual responses will remain anonymous. Additionally, results of the survey were stored on a passwordprotected computer at all times to ensure anonymity. The first page of the electronic survey (hosted on surveymonkey.com) included appropriate IRB information detailing the purpose of the study, the voluntary nature of participation, and respondent's option to discontinue participation at any time. Survey respondents read and agreed to the IRB requirements prior to taking the survey.

\section{Instrument}

The survey contained four major sections, (1) charity sport participation motivations, (2) social media usage, (3) future intentions, and (4) demographic 
information. Survey items and rationale for usage will be discussed in that order. The full survey can be found in Appendix A.

\section{Charity Sport Motivations}

Although many sport management researchers examined charity sport participation events, to date no established scale exists. Previous researchers combined scale items from sport, health and fitness, and donor literature, and saw success with valid and reliable results (e.g., Bennet et al., 2007; Filo et al., 2009; Won \& Park, 2010). This study followed the lead of other researchers in this field, and modified existing charity sport scale items to fit the sample of TNT participants.

A thorough review of the literature identified five dimensions of charity sport participation motivation: (1) Cause, (2) Philanthropy, (3) Social, (4) Sport, and (5) Health and Fitness. Scale items were primarily adopted from three quantitative studies examining motivations of charity sport participants (Bennett et al., 2007; Filo et al., 2010; Won et al., 2010). Participant responses were measured on a 7-point Likert-type scale from 1 (strongly disagree) to 7 (strongly agree).

Four items were adopted to measure cause. Two items were taken from Bennett et al. (2007), and they were "A major reason I participate with TNT is to help enhance the status of the Leukemia and Lymphoma Society" and "My decision to participate with TNT was mainly determined by my desire to help support the Leukemia and Lymphoma Society." Two additional items were adapted from Won et al. (2010) with "I participate in TNT to raise money for research and programs of the Leukemia and Lymphoma Society" and "I am proud to contribute to the Leukemia and Lymphoma Society through my participation with TNT.” These four items were chosen because they effectively 
communicated the definition of cause as a motivation for participation based on support of the charity and the cause itself--in this case, the Leukemia and Lymphoma Society.

An additional five items measured charity sport participants' philanthropic motives. These items were "I participate with TNT because I believe philanthropy is everyone's responsibility" (Won \& Park, 2010), "I participate with TNT so that I can help out others in some small way" (Won \& Park, 2010), "Supporting a charity gives me an inherent sense of satisfaction" (Bennett et al., 2007), "I participate with TNT because I think that it is important to give back to a nonprofit organization" (Won et al., 2011), and "I participate with TNT because I feel a need to help others" (Filo et al., 2010). These items captured participant motives based on their altruistic nature and support of philanthropic behaviors in general.

Next, four items were adopted to identify individuals motivated to participate in the charity sporting events for social reasons (i.e., to make new friends, interact with other participants, and share the experience with others). Three of these items were adopted from Bennett et al. (2007), including, "Participating in TNT programs gave me a chance to meet new people with similar interests," "I enjoy sharing the experience of participating with other TNT participants," and "I like the social interaction I have through my participation with TNT." One additional item was adopted from Won \& Park (2010) "Participating with TNT makes me feel like I belong to a group or community." The four items chosen measured the social aspects of events and motivations for participating.

To gain a better understanding about individuals motivated for reasons relating to the sport in question, four items were adapted with three from Bennett et al. (2007) and 
one from Filo et al. (2010). The items were "Participating in this particular sport event with TNT is an important part of my life" (Bennett et al., 2007), "I am a true enthusiast of running/biking/triathlon (i.e., the sport in which you participate with TNT)" (Bennett et al., 2007), "My deep interest in running/biking/triathlon (i.e., the sport in which you participate) sparked my interest in TNT" (Bennett, et al., 2007), and “One of my reasons for engaging in TNT is to challenge my running/biking/triathlon (i.e., the sport in which you participate) abilities" (Filo et al., 2010).

Health and fitness motives identify those individuals that participated in charity sporting events in order to promote a healthier lifestyle. Four items were adopted from previous studies to capture this motivation. They are "I participate with TNT to stay active" (Bennett et al., 2007), "I participate with TNT to keep me in shape physically" (Filo et al., 2011), "Participating with TNT helps me live a healthy lifestyle" (Bennett et al., 2007), and "Participating with TNT aids in developing my physical fitness" (Bennett, et al. 2007).

\section{Social Media}

There are established scales for online consumption (e.g., MSSOC, Seo \& Green, 2008); however, scales focused on the motivations of social media consumption have yet to be established. Considering the emergent nature of social media research, the lack of an established scale is not surprising. Therefore, to determine motives of social media consumption, items from numerous scales were compiled, and an exploratory factor analysis was conducted to establish social media consumption motivations specific to participants in this context.

Unlike the well-defined charity sport motivations, the motives for social media 
consumption are much more indistinct. A thorough review of interdisciplinary literature (e.g., public relations, communications, psychology, sport) assessing social media consumption motivations aided the researcher in compiling a comprehensive list of 25 items previously established by researchers (e.g., Chen, 2011; Haridakis \& Hanson, 2009; Park et al., 2009). The wide variety of motives across multiple fields of research and social media platforms provided evidence for the need to employ an exploratory factor analysis. A further discussion of exploratory factor analysis and other data analysis techniques are included in the data analysis subsection. The social media section of the survey was split into two sections, one identifying social media consumption motivations, and the second capturing the social media intensity of usage.

Social Media Consumption Motivations. Previous research identified a diverse set of motivations for social media consumption. Consumption motivations vary from information-based motives, including information sharing (Bonds-Raacke \& Raacke, 2010; Johnson \& Yang, 2010; Lampe et al., 2010; Park et al., 2009; Shao, 2009), and information seeking (Dunne, et al. 2010; Haridakis \& Hanson, 2009; Johnson \& Yang, 2010; Lampe et al., 2010; Shao, 2009) to more social motives, such as friendship/socializing (Bonds-Raacke and Raacke, 2010; Dunne, et al., 2010; Haridakis \& Hanson, 2009; Johnson \& Yang, 2009; Park et al., 2009; Raacke \& Bonds-Raacke, 2008; Shao, 2009), connection (Bonds-Raacke and Raacke, 2010; Chen, 2011; Haridaksi \& Hanson, 2009), sense of community (Anderson, 2011; Chen, 2011; Lampe et al. 2010; Sanderson, 2010; Shao, 2009), social support (Anderson, 2011; Lampe et al., 2010; Sanderson, 2010), and interaction (Clavio \& Kian, 2010; Dunne, et al., 2010; Shao, 2009). 
Other researchers identified social media use for entertainment purposes (Dunne, et al., 2010; Haridakis \& Hanson, 2009; Lampe et al., 2010; Park et al., 2009; Shao, 2009) and as an escape and distraction from everyday life (Dunne, et al., 2010; Haridakis \& Hanson, 2009). While still other researchers identify individuals' need to express themselves and affirm an online identity (Dunne et al., 2010; Lampe et al., 2010; Park et al., 2009; Shao, 2009). Because there are so many motives that are not well defined, the next section will detail the items chosen from the previous literature which will be used to identify underlying social media consumption motivations specific to the context of charity sport participants.

In total the researcher identified 25 items commonly used as motivational items in social media consumption literature, and these items were included in the instrument. The items were prefaced with the statement, "The primary reason I use social media is" in conjunction with one of the following 25 motivational items: "To get peer support from others" (Park et al., 2009), "To meet interesting people” (Park et al., 2009), “To talk about something with others" (Park, et al., 2009), "To stay in touch with people I know" (Park, et al., 2009), "To communicate with friends and family" (Haridakis \& Hanson, 2009), “To feel like I belong to a community" (Park et al., 2009), “To feel connected to other users on social media" (Chen, 2011), "To make connections to other people on social media sites" (Chen, 2011), "To belong to a group with same interests as mine" (Haridakis \& Hanson, 2009), "To participate in discussions" (Haridakis \& Hanson, 2009), "Because it is entertaining” (Park et al., 2009), "Because it is funny" (Park et al., 2009), "Because it is exciting" (Park et al., 2009), "Because it is easier to get information" (Park et al., 2009), “To learn about events” (Park et al., 2009), "To get 
useful information about product/services/events" (Park et al., 2009), "To search for information” (Haridakis \& Hanson, 2009), “To keep up with current issues and events (e.g., news)" (Haridakis \& Hanson, 2009), “To share information about myself (e.g., personal interests, profile)" (Bonds-Raacke, Raacke, 2010), “To share information with others (e.g., content-- links, news, ideas)” (Johnson \& Yang, 2009), “To express myself freely" (Johnson \& Yang, 2009), “To pass the time” (Johnson \& Yang, 2009), “To escape from boredom" (Johnson \& Yang, 2009), "So I can get away from family, friends or others" (Haridakis \& Hanson, 2009), "Because it gives me something to occupy my time" (Haridakis \& Hanson, 2009). The previous items listed represent items from interdisciplinary research on multiple social media platforms, including a wide-range of items covering everything from escape and boredom to socialization and making new friends.

This study addressed social media consumption as an integrated concept, measuring individual's social media consumption across various platforms and the motivations to do so. Social media platforms themselves, however, are very different from one another. Considering this difference, the survey included four open-ended response questions asking respondents "My primary motivation for using Facebook is: _," “My primary motivation for using Twitter is: ___ _ _ _." Facebook and

Twitter are the most widely used social media platforms which is why they are identified by name in the survey. In addition, video sharing platforms such as YouTube, viddy, and Ptch, as well as photo sharing platforms such as Pinterest, Instagram, Flickr have been gaining increased popularity recently (Raines et al., 2012) and will be assessed through the items, "My primary motivation for using video social media platforms is: 
" "My primary motivation for using photo social media platforms is: ." This additional information aided in gaining a better understanding of motivations of usage for the individual platforms in addition to social media consumption in general.

Social Media Intensity of Usage. Traditional communication literature measures usage through duration and frequency; however, that approach "fails to account for the richer user experience provided by interactive online sites" (Valenzuela, et al., 2009, p. 886). Ellison et al. (2007) created the Facebook intensity scale to obtain a better measure of intensity of usage, above and beyond frequencies and duration of usage. Since its creation, other social media researchers used this scale, supporting its validity and reliability (Steinfield et al., 2008; Valenzuela et al., 2009). In order to yield acceptable internal consistency and reliability of the items, Nunnally and Bernstein (1994) suggest Cronbach's alpha levels to be greater than .70. Ellison et al. (2007) reported a Cronbach's alpha of .83, while Valenzuela et al. (2009) reported .89, and Steinfield et al. (2008) reported .88 , all of which exhibit acceptable measures of internal consistency, and reliability of the scale.

Accordingly, the Facebook intensity scale (Ellison et al., 2007) was modified to measure social media intensity of usage. The Facebook intensity scale, and now modified social media intensity scale, used five items to measure social media intensity of usage. First, the frequency of usage was analyzed through the item "How many times per day do you use social media platforms?" measured on a 1 (not at all) to 7 (all the time) scale. Next, four attitudinal items measuring the intensity of usage were adopted from Ellison et al.'s (2007) Facebook intensity scale. These items were measured on a 7-point Likerttype scale where $1=$ strongly disagree and 7 = strongly agree: "Social media usage is part 
of my everyday life," "Using social media platforms has become part of my daily routine," "I feel out of touch when I have not logged on to social media platforms in a while," "Using social media makes me feel like I am part of a virtual community." The original scale included two other items (i.e., "I am proud to tell people I am on Facebook" and "I would be sorry if Facebook shut down") that were not easily adapted to the broader social media context and were left out of the current survey. The previous five items were combined to form the social media intensity of usage variable.

\section{Future Intentions}

In addition to charity sport motivations, social media consumption intentions, and social media intensity of usage, the survey also included items measuring participants future intentions, including (1) future participation intention, (2) future support of the organization, and (3) participants' willingness to refer.

Future participation intention was measured by three items adopted from Filo et al. (2010). They were "It is likely that I will participate with TNT programs in the future," "The probability is high that I will participate in future seasons of TNT programs," and "The likelihood of me participating with TNT is very high." These items aimed to measure the intention of respondents to participate in TNT programs in the future.

Future support of the organization was measured by three items, "It is likely that I will donate to the Leukemia and Lymphoma Society in the future," "The probability is high that I will volunteer with TNT or the Leukemia and Lymphoma Society in the future," and "I plan to support the Leukemia and Lymphoma society in their programs and events in the future." The previous items aimed to identify participants' intention to 
support the Leukemia and Lymphoma Society through volunteering and financial support in the future.

Participants' willingness to refer was measured through three items, adopted from Hightower et al. (2002). These items included, "I say positive things about participating with TNT to other people," "I recommend participating with TNT to someone who seeks my advice," and "I encourage my friends and family to participate with TNT." All of the previously mentioned items measuring future intentions of participants were measured on a 7 point Likert-type scale.

\section{Demographic Information}

Additional demographic information was also collected in order to better understand the profiles of charity sport participants and social media behaviors. The researcher collected gender, age, level of education, and average income.

\section{Scale Validation}

Since both of the major research areas in this study were relatively new and under-researched, additional measures were taken to ensure reliability and validity of the instrument. A series of pretests were conducted to ensure the reliability, validity, and readability of the instrument. This study followed three stages of pretesting as outlined by Dillman (2007). First, the instrument was distributed to a panel of experts in the field to examine the readability and overall quality of the scale plus identify any mistakes or confusing wording. Second, the researcher conducted a field test with approximately ten master's and doctoral students across various disciplines. The field test specifically targeted individuals outside the scope of this research content area to provide insights into the readability and interpretation of the survey items. Dillman (2007) also 
encouraged "think-aloud" interviews during this stage, where respondents of the survey reflect upon their experience taking the survey, furthering the readability of the instrument and eliminating any potential problems. The researcher conducted "thinkaloud" interviews with all of the field test participants.

The third step of pre-testing included a pilot study. This pilot study served three main purposes: (1) establish internal consistency of the subscales within the instrument, (2) determine which items, if any, are being left unanswered consistently, and (3) check for readability, making sure the items make sense. The pretest assisted the researcher in eliminating or adding items from the survey, and in improving response rates. The pilot study was emailed to two groups of former TNT participants that created their own independent nonprofit organization and charity sport group called the Road Warriors and Team Believe. The survey was posted on their Facebook group walls and emailed to members of each group. The sample was chosen to mimic the sample of TNT participants and methods of distribution used for the actual study. The researcher aimed to collect approximately 50 responses from the Road Warriors and Team Believe groups in order to effectively analyze the reliability and validity of the instrument and make changes accordingly prior to sending out the survey. The researcher ran preliminary results to check the internal consistency and reliability of the scale by examining Cronbach's alphas. The researcher used cut off values of .70, established by Nunnally and Bernstein (1994), and eliminated items as needed.

The fourth step in the pretest process was what Dillman (2007) classified as a "final check." In this stage of the pretest, the researcher distributed the survey to a small group of experts in the field, who have not previously viewed the survey. This panel of 
experts completed and examined the survey for any errors or mistakes within the survey that were not previously detected by the first three stages of the pretest. The panel of experts' review of the survey was used as the first and final steps of the pretest processes to ensure the quality of the instrument. The emergent nature of charity sport participation motivations and social media consumption patterns and lack of established scales warrants the extensive pretests listed above.

\section{Data Analysis}

The researcher conducted a combination of multiple regression, multivariate analysis of variance (MANOVA), and cluster analysis to address the seven research questions. Prior to conducting further statistical procedures, the researcher examined Cronbach's alphas to confirm the reliability of the subscales of the instrument. The researcher followed recommendations of Nunnally and Bernstein (1994) in which Cronbach's alpha levels were greater than .70 for items to yield acceptable internal consistency.

To address the first research question, [i.e., Are the charity sport motives of cause, philanthropy, social, health and fitness, and sport significant predictors of future intentions (i.e., future participation intention, future support of the organization, and participants' willingness to refer)?] the researcher used a series of three multiple regression equations. Multiple regression was deemed an appropriate statistical analysis when trying to determine the predictive nature of a set of independent or predictor variables on dependent or outcome variables (Field, 2009; Stevens, 2009). In this case, the researcher regressed the dependent future intention variables of future event participation, future support of the organization, participants' willingness to refer on the 
independent variable set of philanthropy, cause, sport, health and fitness, and social charity sport motives.

In this context, the researcher used multiple regression for explanatory research, with a goal of understanding the combined relationships of all charity sport motives with each future intention variable. For that reason, the simultaneous entry method of multiple regression was used, where all predictors were forced into the model simultaneously. This simultaneous analysis was used to understand the combined relationships of all charity sport motives with each dependent variable, effectively showing the amount of variance in the relevant outcome variable explained by the entire set of charity motives (Field, 2009).

Prior to conducting multiple regression, six assumptions must be met, and they are as follows: (1) independence, (2) linearity, (3) homoscedacity, (4) normality of residuals, (5) multicollinearity, and (6) outliers (Field, 2009; Stevens, 2009). The assumption of independence implies that the respondents are responding independently of one another, and will be satisfied through a sound research design and sampling technique. The researcher ensured independence of responses by including specific directions in the email messages and Facebook posts asking participants to complete only one survey each and to do so independently of any other respondents. Next, to check the assumption of linearity and homoscedacity, the researcher examined residual plots, looking for a random scatter around zero, to adequately fulfill the assumption. Normality of residuals examined a histogram of the residuals with an overlay of a normal curve, and normal probability plots (i.e., standardized residuals compared with the normal distribution). The researcher looked for a normal curve shape of the histogram and a 
straight diagonal line on the normal probability plots. Next, the assumption of multicollinearity was checked through the variance inflation factor (VIF) and tolerance. The final assumption of outliers was checked by examining Cook's distance (Cook's D) (Stevens, 2009).

To address research question number two [i.e., Are the different levels of social media intensity of usage (i.e., low, moderate, and high) related to future intentions (i.e., future participation intention, future support of the organization, and participants' willingness to refer)?] the researcher used MANOVA, examining differences in social media intensity of usage on future intentions. Similar to analysis of variance (ANOVA), which examines group differences on one dependent variable, MANOVA assesses group differences across more than one dependent variable (Field, 2009). To examine differences in social media intensity of usage as they relate to future intentions, the researcher employed MANOVA using future participation intentions, future support of the organization, and participants' willingness to refer as the dependent variables, and social media intensity of usage as the independent variable. Dependent variables in MANOVA should be related conceptually and have low to moderate correlations with one another. Researchers warn, however, against using dependent variables that are highly correlated, as one runs the risk of multicollinearity problems. Prior to analysis, correlations between the dependent variables were examined along with the other assumptions discussed next.

Although social media intensity of usage was a continuous variable, for the purposes of this analysis, the researcher treated social media intensity of usage as a categorical variable, using a tripartite split of the data into high, moderate, and low 
intensity of usage groups. This method of artificially categorizing a continuous variable into categorical data may result in the loss of variation between individual scores (e.g., 2.10 and 2.20), yet allows for the researcher to identify greater diversity in the groups themselves (e.g., high and low intensity) (Field, 2009). The researcher used MANOVA to determine relative differences in future outcomes based on levels of social media intensity of usage.

Prior to analysis, Stevens (2009) identified three assumptions (i.e., independence, normality, and equality of covariance) that must be met prior to conducting MANOVA. The researcher ensured independence of responses by asking participants to complete only one survey, and to do so independently of any other respondents. The researcher examined a histogram of data of the dependent variables in relation to a normal curve in order to determine if the assumption of normality will be met. The equality of covariance assumption was tested by the Box's test of equality of covariance matrices, looking for a non-significant result indicating no differences in variability between groups (Stevens, 2009).

MANOVA was used to address research question two, as opposed to other methods of analysis, for multiple reasons. First, conducting three ANOVAs separately analyzing differences in groups on each of the outcome variables would increase the Type I error rate (Field, 2009; Stevens, 2009). Second, MANOVA is a powerful test, which examines group differences across multiple variables simultaneously. MANOVA is a more efficient way of evaluating group differences; however, Field (2009) suggested there should be empirical and theoretical research supporting the grouping of dependent variables into a single analysis. The dependent variables in the current study (i.e., future 
participation intention, future support of the organization, and participants' willingness to refer) are all interrelated concepts assessing participant's future support of the nonprofit, in one form or another.

To address research question number three (i.e., What is the factor structure of social media consumption motivation?) the researcher conducted an exploratory factor analysis to determine the underlying constructs amidst numerous previously identified social media consumption motivations (e.g., information sharing, making friends, entertainment). Exploratory factor analysis is usually performed in the early stages of research. It provides a method for consolidating variables and generating hypotheses about underlying processes (Tabachnick \& Fidell, 1989). In this context, exploratory factor analysis will provide the researcher with greater insight into the underlying constructs, which are specific to the given sample of charity sport participants.

Prior to conducting exploratory factor analysis, four assumptions must be met: (1) sample size, (2) multivariate normality, (3) linearity, and (4) outliers among variables (Stevens, 2009). First, a large sample size is necessary to conduct a factor analysis. Stevens (2009) recommends a minimum sample size of 200. Next, multivariate normality is the assumption that all variables, and linear combinations of variables, are normally distributed. Normality was checked by examining the curve of the normality probability plot, and will be assumed if the variables are normally distributed. The assumption of linearity was checked through an examination of scatterplots. Outliers among variables will exhibit a low squared multiple correlation with all other variables and low correlations with all important factors. These outliers among the variables were removed from the analysis (Stevens, 2009). In addition, since exploratory factor analysis seeks to 
determine underlying constructs among variables, the variables themselves should be correlated. To examine the correlation between variables, the Kaiser-Meyer-Olkin (KMO) measure of sampling adequacy statistic was analyzed, with the researcher looking for sufficient correlation between variables (i.e., greater than .60). Correlation between variables was also examined through Bartlett's test of sphericity. If Bartlett's test is significant, there is sufficient correlation between the variables to run the analysis (Stevens, 2009).

To address researcher question number four [i.e., Are the social media consumption motives significant predictors of future intentions (i.e., future participation intention, future support of the organization, and participants' willingness to refer)?] the underlying constructs developed through the exploratory factor analysis, were then used as the independent variables in a multiple regression analysis to determine how social media consumption motives predict future outcome variables. The researcher regressed the dependent future intention variables (i.e., future event participation, future support of the organization, participants' willingness to refer) on the independent variable set of underlying social media consumption constructs. Similar to the multiple regression analyses conducted in research question one, the researcher first examined the assumptions, and then ran three separate regressions using social media consumption constructs as the predictor variables and future intentions (i.e., future event participation, future support of the organization, and participants' willingness to refer) individually as the dependent variable.

Research question five (i.e., What typologies of social media users exist based on intensity and consumption motivations?) aimed to create typologies of social media users 
by segmenting respondents based on social media intensity of usage and consumption motivations. To achieve this task, the researcher used cluster analysis. Cluster analysis is primarily used to identify and classify individuals into groups based on the similarities of the characteristics they possess (Punj \& Stewart, 1983). Cluster analysis seeks to minimize within-group variance and maximize between-group variance, resulting in a number of heterogeneous groups with homogeneous contents (Ross, 2007). The primary use of cluster analysis is market segmentation; however, it has also been used to gain a better understanding of consumer's buying behaviors, determine consumers thoughts on potential new product innovations, and to consolidate data into a more manageable format (Punj \& Stewart, 2007; Ross, 2007), Previous sport marketing researchers also found cluster analysis useful in segmenting their customers based on emotional attachment (Koo, Andrew, Hardin, \& Greenwell, 2009), sport motivations (Luna-Arocas $\&$ Tang, 2007), brand associations (Ross, 2007), and charity sport motivations (Nettleton \& Hardey, 2006). The current study used cluster analysis to aggregate individual responses about social consumption motivations and intensity of usage. Forming social media typologies aided future researchers and practitioners in understanding individual's usage of social media and how they can segment the market and tailor marketing strategies accordingly.

The researcher used a similar two-staged cluster analysis similar to that set forth by Burns and Burns (2008). The two-stage analysis used Ward's method--a hierarchical clustering method--to determine the appropriate number of clusters within the given sample. To do so, the researcher analyzed the clustering coefficients, with small coefficients indicating homogeneous clusters are being merged and larger coefficients 
representing two very different clusters being merged. As noted by Ross (2007), "the optimal number of clusters is determined by finding the largest difference among clustering coefficients" (p. 17). The second stage of analysis once again uses Ward's method, however, an assigned number of clusters was determined in stage one and included in stage two to define cluster membership. The assumptions of cluster analysis included, (1) representative sample, (2) multicollinearity, and (3) outliers. First, the researcher took care to ensure that the respondents in the given study were representative of the population. Multicollinearity and the presence of outliers were examined in a similar way to which it was assessed in multiple regression.

The researcher addressed research question six [i.e., Are there differences in social media typologies related to charity sport motivations (i.e., cause, philanthropy, social, sport, health and fitness)?] by using MANOVA. The researcher conducted this statistical procedure in a similar way to the MANOVA analyses conducted in research question two. Prior to running MANOVA, the researcher checked all of the previously mentioned assumptions. The researcher used the newly formed clusters as levels of the independent variable and the charity sport motives as the dependent variables. This statistical analysis provided managers with information about differences in typologies of social media users based upon their motivation for participating in charity sport events.

Finally, research question seven [i.e., Are charity sport motives (i.e., cause, philanthropy, social, sport, health and fitness) significant predictors of future intentions (i.e., future participation intention, future support of the organization, and participants' willingness to refer) for each social media typology?] was analyzed through a set of multiple regression analyses. The researcher checked the assumptions for multiple 
regression previously mentioned in research question one. The analysis was similar to that of research question one, with different variables. To address the current research question, the researcher regressed each future intention (i.e., future participation intention, future support of the organization, and participants' willingness to refer) on the charity sport motives (i.e., cause, philanthropy, social, sport, and health and fitness) for each social media typology identified in research question four. The researcher also employed a Bonferroni adjustment due to the quantity of multiple regression equations run, to control for alpha inflation (i.e., Type I error) and ensure the significance is not by chance (Stevens, 2009).

\section{Summary of Method}

In summary, the researcher used survey design to examine the influence of social media on future intentions of charity sport participants, sampled from an international sample of TNT participants. Prior to collecting data, a series of pretests were administered to assess the reliability, validity, and readability of the instrument. Surveys were disseminated through email, Facebook, and other social media platforms using purposive and snowball sampling. The survey contained four major subsections: (a) charity sport participation, (b) social media, (c) future intentions, and (d) demographic information. The complete survey is located in Appendix A. The researcher used multiple regression, MANOVA, EFA, and cluster analysis to address the seven research questions.

Specifically, multiple regression was used to address research question one. Research question two used MANOVA. Research question three was analyzed by using EFA. Research question four used multiple regression. Cluster analysis was used to address research question five, while MANOVA will be used to address research 
question six. Finally, the researcher used multiple regression to address research question seven. 


\section{CHAPTER IV}

\section{RESULTS}

The purpose of this study was to determine how charity sport organizations can leverage social media to enhance recruitment, retention, and future support of their organization. More specifically, the researcher aimed to (1) examine which charity sport participation motives were likely to predict future intentions, (2) determine which levels of social media intensity of usage best predicted future intentions, (3) establish a set of social media consumption motivations within a charity sport context, (4) determine which social media consumption motivations best predicted future intentions, (5) develop social media user typologies based on consumption motives and intensity of usage, (6) provide profiles of social media typologies based on their motives of charity sport participation, and (7) understand which charity sport participation motives predict future intentions for each social media typology.

Data were collected from Team in Training participants. Respondents were assessed in terms of four major constructs: (1) charity sport motivations, (2) social media usage, (3) future intentions, and (4) demographic data. The researcher used multiple regression, Multivariate Analysis of Variance (MANOVA), exploratory factor analysis (EFA), and cluster analysis to address the seven research questions and gain a better understanding of the influence of social media on the future intentions of charity sport 
participants. Results of these analyses are presented below.

\section{Scale Validation}

Prior to collecting data, the researcher ensured the validity, reliability, and readability of the scale through a series of pretests. First, the researcher sent the survey to a panel of experts, including faculty members and researchers specializing in participation sport, and/or social media at universities across the country. The panel of experts was given a brief explanation of the study and asked to review the survey for validity and readability. Feedback from the panel of experts was assessed, and small adaptations to the survey format and items were made.

Next, the researcher examined the readability of the instrument through a field test by conducting think-aloud interviews, as recommended by Dillman (2007). Graduate and doctoral students at a large Midwestern university were instructed to answer the items of the survey while the researcher sat beside them. The researcher encouraged the participants to identify any issues (e.g., wording, formatting, question order) they experienced with the survey as they were taking it. Seven separate think-aloud interviews were conducted prior to the pilot study. The researcher made modifications to the survey after each interview, most notably randomizing some of the items on the online survey.

After slight modifications to the instrument, a pilot study was conducted to assess scale reliability one week prior to the actual data collection. Similar to the actual data collection techniques, the survey was distributed through email and Facebook, targeting TNT participants and alumni. For the pilot study, the researcher contacted two small charity sport organizations comprised primarily of TNT alumni. The survey was emailed 
and posted on the Facebook pages of both training groups (i.e., Team Believe and Road Warriors). Forty-eight usable surveys were collected for the pilot study.

DeVellis (2003) refers to reliability as the extent to which similar items measure the same construct. The researcher examined internal consistency measures for each of the charity sport motives and future intention variables. Nunnally and Bernstein (1994) recommend Cronbach's alpha levels at the .70 value or higher. Internal consistency reliabilities were calculated for each of the independent and dependent variables in the study. Cronbach's alpha for each of the variables exceeded the recommended acceptable value of .70 (Nunnally \& Bernstein, 1994). The Cronbach's alpha coefficients for the independent variables were $\alpha=.781$ for cause, $\alpha=.790$ for philanthropy, $\alpha=.918$ for social, $\alpha=.790$ for sport, and $\alpha=.884$ for health and fitness. The Cronbach's alpha coefficients for the dependent variables were $\alpha=.941$ for future participation intention, $\alpha=.848$ for future support of the organization, and $\alpha=.919$ for participants' willingness to refer, which all yielded acceptable results. Due to the high Cronbach's alpha coefficients, no items were removed, and the instrument was deemed a reliable measure of charity sport motivation.

The last pre-test included a "final check" by a panel of experts. The survey was distributed to a small group of doctoral students and faculty members at a Midwestern university, and they were asked to look over the survey for any errors or typographical errors. No additional modifications were made to the survey. The complete survey is located in Appendix B. 


\section{Descriptive Statistics}

Data were collected from participants and alumni of TNT. Three hundred forty six total surveys were collected, and 69 were incomplete, leaving a final sample of 277 participants. The sample size exceeded the threshold of 250 recommended by Stevens (2005) for conducting the various statistical analyses in this study (See Chapter III). Additionally, Dillman (2007) suggested a sample of 245 respondents to accurately generalize results to a diverse (i.e., $80 / 20$ split) population of 50,000 with 5\% sampling error. The sample in the current study also exceeded that recommendation.

The sample consisted of $190(72.5 \%)$ females and $72(27.5 \%)$ males. In regard to age, participants ranged from 21 to 66 years old with an average age of 39 years old (SD $=9.67)$. In addition, $74.7 \%$ of the sample was between the ages of 28 and 48 years old. In relation to ethnicity, the majority of the sample was White/Caucasian $(n=224,85.5 \%)$ with the next highest categories being Asian/Asian American $(n=10,3.8 \%)$, Black/African American $(n=6,2.3 \%)$, Latino/a or Spanish origin, $(n=6,2.3 \%)$, and Multiracial/Biracial $(n=5,1.9 \%)$. Participants reporting an annual household income of $\$ 94,00$ - $\$ 99,999$ comprised $41.5 \%(n=100)$ of the total sample. Those reporting $\$ 100,000$ or above comprised $10.0 \%(n=24)$ of the total sample, and $\$ 65,000-\$ 74,999$ comprised $8.7 \%(n=21)$ of the total sample. In addition, the majority of participants completed a Bachelor's degree or higher $(80.5 \%, n=211)$, and $37 \%(n=97)$ of the sample completed a Master's degree or higher (Table 1). 
Table 1

Frequency Distributions for Demographic Variables

\begin{tabular}{|c|c|c|}
\hline Variable & Percent & Total \\
\hline \multicolumn{3}{|l|}{ Gender } \\
\hline Female & 72.5 & 190 \\
\hline Male & 27.5 & 72 \\
\hline \multicolumn{3}{|l|}{ Age } \\
\hline Under 21 & 0 & 0 \\
\hline $21-24$ & 3.0 & 8 \\
\hline $25-29$ & 14.9 & 39 \\
\hline $30-34$ & 19.8 & 52 \\
\hline $35-39$ & 17.3 & 45 \\
\hline $40-44$ & 15.0 & 39 \\
\hline $45-49$ & 13.4 & 35 \\
\hline $50-54$ & 9.1 & 24 \\
\hline $55-59$ & 5.0 & 13 \\
\hline $60+$ & 2.4 & 6 \\
\hline \multicolumn{3}{|l|}{ Annual Household Income } \\
\hline Less than $\$ 24,999$ & 6.2 & 15 \\
\hline$\$ 25,000-\$ 34,999$ & 4.6 & 11 \\
\hline$\$ 35,000-\$ 44,999$ & 5.0 & 12 \\
\hline$\$ 45,000-\$ 54,999$ & 7.9 & 19 \\
\hline$\$ 55,000-\$ 64,999$ & 5.4 & 13 \\
\hline$\$ 65,000-\$ 74,999$ & 8.7 & 21 \\
\hline$\$ 75,000-\$ 84,999$ & 4.6 & 11 \\
\hline$\$ 85,000-\$ 94,999$ & 6.2 & 15 \\
\hline$\$ 95,000-\$ 99,000$ & 41.5 & 100 \\
\hline$\$ 100,000+$ & 10 & 24 \\
\hline \multicolumn{3}{|c|}{ Highest Level of Education Completed } \\
\hline Less than High School Degree & 9.2 & 24 \\
\hline Associates Degree & 10.3 & 27 \\
\hline Bachelor's Degree & 43.5 & 114 \\
\hline Master's Degree & 27.1 & 71 \\
\hline Higher than a Master's Degree & 9.9 & 26 \\
\hline \multicolumn{3}{|l|}{ Ethnicity } \\
\hline White/Caucasian & 85.5 & 224 \\
\hline Black/African American & 2.3 & 6 \\
\hline American Indian/Native American & 0.8 & 2 \\
\hline Pacific Islander & 1.5 & 4 \\
\hline Asian/Asian American & 3.8 & 10 \\
\hline Latino/a, Spanish Origin & 2.3 & 6 \\
\hline Multiracial/Biracial & 1.9 & 5 \\
\hline Other & 1.9 & 5 \\
\hline
\end{tabular}


Other demographic data specific to TNT included the event type and previous event experience (Table 2). As far as types of events, the majority of participants most recently participated in running events $(64.8 \%, n=171)$, with $34.1 \%(n=90)$ of the sample participating in a full marathon and 30.7\% $(n=81)$ participating in a halfmarathon. Triathlon events comprised $23.9 \%(n=63)$ of the sample, with $16.7 \%(n=44)$ participating in Olympic distance triathlons, $4.9 \%(n=13)$ participating in half-ironman distance triathlons, and 2.3\% $(n=6)$ participating in ironman distance triathlons. Only 8 participants competed in cycling events $(2.3 \%)$ and 1 in a hiking adventure $(.5 \%)$. In addition, $8.0 \%(n=21)$ of the participants listed Other as their participation category and listed events such as a cross-country skiing competition, an ultra-marathon, and a multiday bike event. In relation to previous event experience, $81.1 \%(n=215)$ of the sample participated in one or more TNT events previously, while $18.9 \%(n=50)$ were first-time participants. The highest percentage of respondents previously participated in one event $(23.0 \%, n=61)$, followed by two events $(15.1 \%, n=40)$, and three events $(10.6 \%, n=$ 28). Interestingly, another large percentage of respondents participated in ten or more TNT events $(9.4 \%, n=25)$.

Participants were also asked to identify how they heard about the survey. The majority of individuals heard about this survey from Facebook $(68.7 \%, n=182)$, followed by email $(15.5 \%, n=41)$, and online training forums (e.g., slowtwitch.com, runnersworld.com) $(10.7 \%, n=37)$. Five respondents $(1.4 \%)$ listed Other (e.g., friends, TNT newsletter) as the method of how they heard about the survey. 
Table 2

Frequency Distributions for TNT Demographic Variables

\begin{tabular}{lrr}
\hline Variable & Percent & Total \\
\hline Type of Event & 30.7 & \\
Half Marathon & 34.1 & 81 \\
Marathon & 3.0 & 90 \\
Century Ride & 16.7 & 84 \\
Olympic Triathlon & 4.9 & 13 \\
Half-Ironman Triathlon & 2.3 & 6 \\
Ironman Triathlon & 0.4 & 1 \\
Hiking Adventure & 8.0 & 21 \\
Other & & \\
Previous TNT Participation & 18.9 & 50 \\
First event (0) & 23.0 & 61 \\
1 & 15.1 & 40 \\
2 & 10.6 & 28 \\
3 & 5.7 & 15 \\
4 & 6.0 & 16 \\
5 & 4.9 & 13 \\
6 & 2.3 & 6 \\
7 & 3.0 & 8 \\
8 & 1.1 & 3 \\
9 & 9.4 & 25 \\
\hline $10+$ & & \\
\hline Survey & 15.5 & 41 \\
Email & 68.7 & 182 \\
Facebook & 14.0 & 37 \\
Forum & 1.9 & 5 \\
\hline Other & &
\end{tabular}

Descriptive statistics for all of the independent and dependent variables were also analyzed. The questionnaire items were measured on a 7-point Likert-type scale where 1 $=$ strongly disagree and $7=$ strongly agree. The researcher also examined internal consistency measures on the data to confirm the reliability of the instrument prior to further data analyses. 


\section{Charity Sport Motivations}

Descriptive statistics. Charity sport motives were used as independent variables (i.e., cause, philanthropy, social, sport, health and fitness) throughout this study. Cause represents motivation to support the specific charitable organization. Philanthropy represents motivation for the greater altruistic good. Social represents motivation for camaraderie. Sport represents motivation for the specific type of sport in which the individual participated in (e.g., running, cycling, hiking). And health and fitness represents motivation to get in shape or lose weight. For the entire sample, cause had a mean score of $5.83(S D=.97)$, philanthropy had a mean score of $6.15(S D=.90)$, social had a mean score of $6.25(S D=.89)$, sport had a mean score of $5.65(S D=.99)$, and health and fitness had a mean score of $5.98(S D=1.05)$.

Reliability analysis. The independent variables had Cronbach's alpha levels of .775 (cause), .879 (philanthropy), .902 (social), .666 (sport), and .911 (health and fitness). Four of the independent variables (i.e., cause, philanthropy, social, and health and fitness) had Cronbach's alpha values above the recommended cut-off of .70 (Nunnally \& Bernstein, 1994). Sport had a Cronbach's alpha slightly lower than the accepted value; however, previous charity sport literature found sport to be a significant motivation for participation (Bennett et al., 2007; Snelgrove \& Wood, 2010). Additionally, researchers (Hair, Black, Babin, Anderson, \& Tatham, 2006; Nunnally \& Bernstein, 1994) indicated Cronbach's alpha levels between .50 and .60 to be acceptable for exploratory research. For those reasons, the researcher retained the sport motive. 


\section{Social Media Intensity}

Social media intensity of usage was a variable modified from Ellison et al.'s (2007) Facebook intensity of usage scale. The current variable included five items. Four attitudinal items, "Social media usage is part of my everyday life", "Using social media platforms has become part of my daily routine", "I feel out of touch when I have not logged on to social media platforms in a while", and "Using social media makes me feel like I am part of a virtual community" measured on a 7-point Likert-type scale. The variable also included one item measuring frequency of usage, "How many times per day do you use social media platforms?" measured on a 1 (not at all) to 7 (all the time) scale.

Descriptive statistics. Social media intensity of usage was also used as an independent variable. Social media intensity of usage for the entire sample had a mean score of $5.23(S D=1.18)$.

Reliability analysis. Considering modifications were made from Ellison et al.'s (2007) Facebook intensity of usage scale, internal consistency measures were examined to ensure the reliability of the modified construct. The five items used to measure social media intensity of usage yielded a Cronbach's alpha of .878 . 
Table 3

Descriptive statistics of Independent and Dependent Variables

\begin{tabular}{lrrr}
\hline Variable & Mean & $S D$ & $\alpha$ \\
\hline Charity Sport Motivation & & & \\
$\quad$ Cause & 5.83 & .97 & .775 \\
Philanthropy & 6.15 & .90 & .879 \\
Social & 6.25 & .89 & .902 \\
$\quad$ Sport & 5.65 & .99 & .666 \\
$\quad$ Health and Fitness & 5.98 & 1.05 & .911 \\
\hline Social Media Intensity of Usage & 5.23 & 1.18 & .878 \\
\hline Future Intentions & & & \\
$\quad$ Future Participation Intent & 5.79 & 1.38 & .941 \\
$\quad$ Future Support of the Organization & 6.24 & 1.00 & .884 \\
$\quad$ Participants' Willingness to Refer & 6.33 & .93 & .876 \\
\hline
\end{tabular}

\section{Future Intentions}

Descriptive statistics. Dependent variables in this study included future intentions (i.e., future participation intention, future support of the organization, and participants' willingness to refer). For the entire sample, future participation intention had a mean score of $5.79(S D=1.38)$, future support of the organization had a mean score of $6.24(S D=1.00)$, and participant's willingness to refer had a mean score of $6.33(S D=$ $.93)$.

Reliability analysis. In regard to the dependent variables of future intentions, the Cronbach's alpha levels were all above the acceptable value of .700 . Future participation intention had a value of .941, future support of the organization had a value of .884, and participants' willingness to refer had a value of .876. Therefore, all items and variables were retained for the analysis.

\section{Representative Population}

To assess the characteristics of the sample in relation to the population, the researcher obtained demographic data from the national chapter of TNT. Chi-square 
analyses were used to analyze the similarities and differences in the demographic variables of (1) gender and (2) education level of the current sample to the population. Chi-square analyses showed no significant differences between the respondents and the population for each of the demographic variables: (1) gender $\left(\chi^{2}=.03, d f=1, p>.05\right)$, and (2) education level $\left(\chi^{2}=.48, d f=1, p>.05\right)$. Additionally, a one-sample $t$-test was conducted to examine the similarities and differences in age between the sample and the population. The average age of the population was 32 years old, and the average age of the sample was 39 years old. Results of the $t$-test yielded significant differences between the sample and the population on the basis of age $(t=11.88, p<.01)$, indicating the current sample is significantly older than the population. Population demographics also indicate the majority of participants were between the ages of 25 and 54 years old (TNT, 2012c). The current sample has $89.6 \%(n=234)$ of participants within that range; therefore, while the mean age may be slightly higher than the population mean, the age range of participants was similar. Overall, results indicate that the sample appears to be representative of the population based on the demographic variables of age, gender, and education level.

\section{Response Bias}

The researcher also conducted analyses between respondents and non-respondents to examine non-response bias and determine if the sample was representative of the population. Creswell (2002) indicated late respondents have similar characteristics of

non-respondents. Additionally, previous researchers suggested non-significant differences between early and late respondents indicated the sample was sufficiently representative of non-respondents (Groves, 2006; Siebert, 2008). One-way analyses of 
variance were conducted to determine if early and late respondents differed significantly. There were no significant differences $(p>.05)$ found between early and late respondents on charity sport motives, future intentions, social media intensity of usage, and social media consumption motivations. These results indicated no significant differences between early and late respondents, supporting the idea that respondents of the survey are representative of the population based on their charity sport motives, future intentions, social media intensity of usage, and social media consumption motivations.

\section{Data Analysis}

Seven major research questions were developed to address the study purpose. The researcher conducted a combination of quantitative statistical analyses to address the research questions. The following section will detail data analysis and results of each research question.

\section{Research Question 1}

RQ1: Are the charity sport motives of cause, philanthropy, social, health and fitness, and sport significant predictors of future intentions (i.e., future participation intention, future support of the organization, and participants' willingness to refer)?

The researcher used a series of multiple regression equations to gain a better understanding of the influence of the charity sport motives on future intentions of participants and address research question one. In the first multiple regression equation the researcher used the charity sport motives (i.e., cause, philanthropy, social, sport, and health and fitness) as the independent variables and future participation intention as the dependent variable. In the second multiple regression equation charity sport motives were 
the independent variables and future support of the organization was the dependent variable. The third multiple regression equation used charity sport motives as the independent variables and participants' willingness to refer as the dependent variable. As previously discussed in Chapter III, the researcher used simultaneous entry for all of the multiple regression equations to understand which charity sport motivations would best predict the future intention variable. Additionally, a Bonferroni adjustment was used to control for alpha inflation (i.e., Type I error) and ensure the significance was not by chance due to multiple analyses (Stevens, 2009). The adjusted alpha level was set at .017 (i.e., $p / 3$ or $.05 / 3=.017$ ).

Prior to conducting multiple regression analysis, six assumptions were examined: (1) independence, (2) linearity, (3) homoscedacity, (4) normality of residuals, (5) multicollinearity, and (6) outliers (Field, 2009; Stevens, 2009). First, respondents took the survey only once and did so independently of one another; therefore, the independence assumption was met. Next, the researcher examined residual plots to check the assumption of linearity and homoscedacity. The residual plots yielded evidence of a random scatter around zero, fulfilling the assumptions. To examine the assumption of normality of residuals, the researcher examined a histogram of the residuals with an overlay of a normal curve and normal probability plots (i.e., standardized residuals compared with the normal distribution). The researcher identified a normal curve shape of the histogram and a straight diagonal line on the normal probability plots, thus fulfilling the assumption of normality of residuals. Next, the researcher examined variance inflation factor (VIF) and tolerance statistics to ensure the assumption of multicollinearity was met. Results yielded VIF values ranging from 1.57 to 2.37, which 
are below the recommended value of 10 (Stevens, 2009). Additionally, results evidenced tolerance levels of .42 to .64 , which are above the .10 commonly accepted value indicated by Stevens (2009). Thus, the assumption of multicollinearity was met. Lastly, the researcher examined outliers through the Cook's distance (Cook's D) statistic. Data yielded a value of .01, which is smaller than the recommended 1.0, indicating the assumption was met (Stevens, 2009). After checking the assumptions, the researcher conducted a series of three multiple regression equations.

In the first multiple regression equation the researcher used future participation intention as the dependent variable and the charity sport motivations of cause, philanthropy, social, health and fitness, and sport as the five independent variables. The regression model was significant $[F(5,271)=24.50, p<.001]$. Results yielded an $R^{2}$ value of .311 , indicating $31.1 \%$ of the variance in future participation intention was explained by the five charity sport motives. Additionally, standardized regression coefficients indicated both cause $(\beta=.28, t=3.89, p<.001)$ and health and fitness $(\beta=$ $.25, t=3.72, p<.001)$ were significant predictors of future participation intention. The other variables, philanthropy $(\beta=.10, t=1.31, p=.191)$, social $(\beta=.14, t=1.91, p=$ $.057)$, and sport $(\beta=-.02, t=-.30, p=.764)$, were not statistically significant. Results indicated cause and health and fitness predicted future participation intention. Further indicating, for every one unit increase in cause, future participation intent increased .28 units. Similarly, for every one unit increase in health and fitness, future participation intention increased .25 units. 
Table 4

Summary of Regression Analyses for Variables Predicting Future Intentions of Charity Sport Events

\begin{tabular}{|c|c|c|c|c|c|c|}
\hline & $R^{2}$ & $B$ & $S E B$ & $\beta$ & $t$ & $p$ \\
\hline Future Participation Intention & $.311 * * *$ & & & & & \\
\hline Cause & & .41 & .11 & .28 & 3.89 & $.000 * * *$ \\
\hline Philanthropy & & .16 & .13 & .10 & 1.31 & .191 \\
\hline Health & & .33 & .09 & .25 & 3.72 & $.000 * * *$ \\
\hline Sport & & -.03 & .09 & -.02 & -.30 & .764 \\
\hline Social & & .21 & .11 & .14 & 1.91 & .057 \\
\hline Future Support of the Organization & $.438^{* * *}$ & & & & & \\
\hline Cause & & .30 & .07 & .29 & 4.37 & $.000 * * *$ \\
\hline Philanthropy & & .21 & .08 & .18 & 2.55 & $.011^{*}$ \\
\hline Health & & .16 & .06 & .17 & 2.83 & $.005^{* *}$ \\
\hline Sport & & -.12 & .06 & -.11 & -1.99 & .048 \\
\hline Social & & .32 & .07 & .28 & 4.34 & $.000 * * *$ \\
\hline Participants' Willingness to Refer & $.473 * * *$ & & & & & \\
\hline Cause & & .26 & .06 & .26 & 4.17 & $.000 * * *$ \\
\hline Philanthropy & & .14 & .07 & .13 & 1.92 & .056 \\
\hline Health & & .26 & .05 & .29 & 4.96 & $.000 * * *$ \\
\hline Sport & & -.07 & .05 & -.07 & -1.28 & .201 \\
\hline Social & & .29 & .07 & .27 & 4.44 & $.000^{* * *}$ \\
\hline
\end{tabular}

Adjusted $R^{2:}$ Future Participation Intention (.299), Future Support of the Organization (.428), Participants' Willingness to Refer (.463) ${ }^{*} p<.017$ (Bonferonni adjustment); ${ }^{* *} p<.01 ; * * * p<.001$

Future support of the organization was the dependent variable in the second multiple regression equation. Similar to the first multiple regression equation, the independent variables were the five charity sport motives (i.e., cause, philanthropy, social, health and fitness, and sport). The researcher found the regression model to be significant at the .001 alpha level $[F(5,271)=42.27, p<.001]$. Results yielded an $R^{2}$ value of .438 , indicating $43.8 \%$ of the variance in future participation intention was explained by the five charity sport motives. An examination of the standardized regression coefficients indicated cause $(\beta=.29, t=4.37, p<.001)$, philanthropy $(\beta=.18$, $t=2.55, p<.017)$, health and fitness $(\beta=.17, t=2.83, p<.01)$, and social $(\beta=.28, t=$ 
$4.34, p<.001)$ were significant predictors of future support of the organization. The charity sport motive of sport $(\beta=-.11, t=-1.99, p=.048)$ was not statistically significant. The results indicated for every one unit increase in cause, future support of the organization increased .29 units. In addition, for every one unit increase in philanthropy, future support of the organization increased .18 units. Also, for every one unit increase of health and fitness, future support of the organization increased .17 units, and for every one unit increase of social, future support of the organization increased .28 unites. Similar to future participation intention, results revealed the importance of cause and health and fitness as predictors of future support of the organization. Social and philanthropic motives, however, were also significant predictors of future support of the organization.

Next, the researcher employed multiple regression using participants' willingness to refer as the dependent variable and the five charity sport motives as the independent variables (i.e., cause, philanthropy, social, health and fitness, and sport). The researcher found the regression model to be significant at the .001 alpha level $[F(5,271)=48.67, p$ $<.001)$. Results yielded an $R^{2}$ value of .473 , indicating $47.3 \%$ of the variance in participants' willingness to refer was explained by the five charity sport motives. An examination of the standardized regression coefficients indicated cause $(\beta=.26, t=4.17$, $p<.001)$, health and fitness $(\beta=.29, t=4.96, p<.001)$, and social $(\beta=.27, t=4.44, p<$ .001) were significant predictors of participants' willingness to refer. The charity sport motives of philanthropy $(\beta=.13, t=1.92, p=.056)$ and sport $(\beta=-.07, t=-1.28, p=$ .201) were not statistically significant. This indicates for every one unit increase in cause, participants' willingness to refer increased .26 units. Likewise, for every one unit 
increase in health and fitness, participants' willingness to refer increased .29 units. And, for every one unit increase in social, participants' willingness to refer increased .27 units. Similar to future support of the organization, cause, health and fitness, and social motives were significant predictors of participants' willingness to refer.

\section{Research Question 2}

RQ2: Are the different levels of social media intensity of usage (i.e., low, moderate, and high) related to future intentions (i.e., future participation intention, future support of the organization, and participants' willingness to refer)?

To address research question 2, the researcher used MANOVA to examine whether future intentions differed based on levels of social media intensity. For this analysis the researcher used future participation intention, future support of the organization, and participants' willingness to refer as the dependent variables, and social media intensity of usage as the independent variable. Since MANOVA requires categorical data, the researcher used a tripartite split, creating high, moderate, and low groups based on intensity of usage scores. This categorization method may result in the loss of variation between individual scores, yet allows the researcher to identify greater diversity in groups (e.g., high and low intensity) (Field, 2009). Categorizing the data into three groups based on social media intensity levels assisted the researcher in determining how other variables (i.e., future intentions) differed based on those levels. In this case, the researcher is less concerned about small differences in scores (i.e., 3.1 and 3.2) and more interested in larger differences between groups. 
In turn, the high intensity group had a mean of $6.34(S D=.28, n=92)$, the moderate intensity group had a mean of $5.44(S D=.29, n=96)$, and the low intensity group had mean of $3.82(S D=.94, n=88)$. To ensure each group was significantly different from the others in relation to intensity of social media usage, the researcher conducted an ANOVA. Results confirmed significant group differences between each level of social media intensity $[F(2,273)=437.74, p<.001]$. These three groups (i.e., high, moderate, and low social media intensity of usage) were used as levels of the independent variable.

Prior to analysis, the researcher examined three assumptions: (1) independence, (2) normality, and (3) equality of covariances. The researcher ensured independence of responses through the methods identified in RQ1. Next, the researcher examined a histogram of data of the dependent variables and noted the dependent variables were positively skewed in relation to the normal curve. Stevens (2009) noted that due to the robustness of the $F$ statistic, there are minimal effects of non-normal data on the significance in MANOVA. The researcher examined the Box's test of equality of covariance matrices, and found significant results (Box's $M=54.92, F=4.50, p<.01$ ), indicating differences in variability between groups and failing to meet the requirements of the third assumption (Stevens, 2009). Field (2009) and Stevens (2009) both note the robust nature of the $F$ statistic in MANOVA. Further, Stevens (2009) recommends fairly equal group sizes, suggesting the largest group should be no larger than 1.5 the size of the smallest group. The group sizes were relatively equal with high $(n=92)$, moderate $(n=$ 96), and low $(n=88)$ intensity of usage. Additionally, Bartlett's Test of Sphericity was statistically significant (approximate $\chi^{2}=515.15, p<.001$ ), indicating sufficient 
correlation between the dependent variables to proceed with the analysis. Although the data failed the assumptions of normality and equality of covariances, the $F$ statistic is robust. The researcher proceeded with the analysis, yet interpreted results with caution.

The three-group MANOVA revealed the composite dependent variables differed based on levels of social media intensity of usage. Wilks's $\Lambda$ was $.932, F(6,542)=3.24$, $p<.01$, partial $\eta^{2}=.035$. The partial eta-squared value is the effect size, indicating approximately $3.5 \%$ of the variance in the dependent variables (i.e., future intentions) was accounted for by social media intensity of usage. The effect size helps to quantify practical significance, and in this case is relatively low (Stevens, 2002).

Since there were significant results in the multivariate analysis, a univariate analysis was conducted to determine where the significance existed. Prior to running a univariate test, the assumption of homogeneity of variances must be met. The Levene's Test of Equality of Error Variances, which tests for homogeneity of variance violations for each dependent measure, showed significant results for all of the dependent variables: future participation intention $(p<.01)$, future support of the organization $(p<.001)$, and participants' willingness to refer $(p<.01)$. The significant results did not uphold the assumption of homogeneity of variance, indicating there were significant differences in the dependent variables across levels of social media intensity of usage. As noted by Stevens (2009) and Field (2009) the $F$ statistic is robust, and the researcher proceeded with the univariate analysis.

The tests of Between-Subjects Effects evaluate each dependent variable separately (Table 5). For interpretation of the univariate analysis results, the researcher used the Bonferroni correction to adjust the alpha level for Type I error (i.e., $p / 3$ or $.05 / 3$, 
$p=.017)$. Results of the univariate tests reveal if there was a statistically significant influence of social media intensity of usage on the all three dependent variables of future participation intention, future support of the organization, and participants' willingness to refer. The univariate ANOVA, using levels of social media intensity as the independent variable and future participation as the dependent variable was statistically significant, $F(2,273)=5.66, p<.01$. The univariate ANOVA, using levels of social media intensity as the independent variable and future support of the organization as the dependent variable was statistically significant, $F(2,273)=7.72, p<.01$. The univariate ANOVA, using levels of social media intensity as the independent variable and participants' willingness to refer as the dependent variable had a statistically significant value of $F(2$, $273)=4.47, p<.017$. Results of the univariate analysis indicated participants future participation intention, future support of the organization, and participants' willingness to refer differed based on level of social media intensity of usage.

Table 5

MANOVA: Social Media Intensity of Usage on Future Intentions

\begin{tabular}{llcccccc}
\hline Sources & DV & $S S$ & $d f$ & $M S$ & $F$ & $p$ & $\eta^{2}$ \\
\hline SMI & Part Intent & 20.84 & 2 & 10.42 & 5.66 & .004 & .040 \\
& Support & 14.75 & 2 & 7.38 & 7.72 & .001 & .054 \\
& Refer & 7.48 & 2 & 3.74 & 4.47 & .012 & .032 \\
\hline Error & Part Intent & 502.53 & 273 & 1.84 & & & \\
& Support & 260.67 & 273 & 0.96 & & & \\
& Refer & 228.63 & 273 & 0.84 & & & \\
\hline \multirow{2}{*}{ Total } & Part Intent & 9775.56 & 276 & & & & \\
& Support & 11010.89 & 276 & & & & \\
& Refer & 11302.56 & 276 & & & & \\
\hline
\end{tabular}

The partial $\eta^{2}$ for future participation intention was .040, indicating about $4.0 \%$ of the variance in future participation intention was explained by social media intensity of 
usage. According to Stevens (2002) this is a small effect. The partial $\eta^{2}$ for future support of the organization was .054 , indicating $5.4 \%$ of the variance in future support of the organization was explained by social media intensity of usage. This was also a small effect (Stevens, 2002). In addition, the partial $\eta^{2}$ of participants' willingness to refer was .032 , indicating $3.2 \%$ of the variance in participants' willingness to refer was explained by social media intensity of usage. Similar to the previous variables, this was also considered a small effect according to Stevens (2002). The effect size helps to quantify practical significance, and in this case it was relatively low for all three variables.

Tukey HSD post hoc analysis was conducted to identify the between-group differences (Table 6). For future participation intention, results from the post hoc analysis revealed significant differences between high and low intensity users with high intensity users more likely to indicate future participation intention $(M=6.16, S D=1.08)$ than low intensity users $(M=5.49, S D=1.54)$ at the .01 alpha level. Post hoc analysis of future support of the organization revealed significant differences between low and moderate users $(p<.05)$ as well as between low and high users $(p<.001)$. An examination of the means indicated both high $(M=6.48, S D=.71)$ and moderate intensity users $(M=6.30$, $S D=.84$ ) were more likely to support the organization in the future than low intensity users $(M=5.92, S D=1.30)$. Similar to the result of future participation intention, there were also significant differences detected between low intensity users $(M=6.12, S D=$ $1.08)$ and users in the high intensity group $(M=6.53, S D=.83)$ at the .01 alpha level, indicating high intensity social media users are more likely to refer family, friends, and others to TNT programs and events. 
Table 6

Means and Standard Deviations for Social Media Intensity of Usage

\begin{tabular}{lcccccc}
\hline & \multicolumn{2}{c}{ Participation } & \multicolumn{2}{c}{ Support } & \multicolumn{2}{c}{ Refer } \\
\cline { 2 - 8 } Social Media Intensity & Mean & $S D$ & Mean & $S D$ & Mean & $S D$ \\
\hline Low & 5.49 & 1.54 & 5.92 & 1.30 & 6.12 & 1.08 \\
Moderate & 5.72 & 1.41 & 6.30 & .84 & 6.34 & .82 \\
High & 6.16 & 1.08 & 6.48 & .71 & 6.53 & .83 \\
\hline
\end{tabular}

\section{Research Question 3}

RQ3: What is the factor structure of social media consumption motivation?

To address research question number three, exploratory factor analysis was conducted to determine the underlying constructs of social media consumption motivations (i.e., 25 items discussed in Chapter III). Prior to conducting exploratory factor analysis, the researcher checked the four assumptions: (1) sample size, (2) multivariate normality, (3) linearity, and (4) outliers among variables (Stevens, 2009). First, Stevens (2009) recommends a minimum sample size of 200. The sample in the current study was 277 , fulfilling the first assumption. Next, the researcher examined the curve of the normality probability plot; the assumption was met since the variables were normally distributed. In addition, the researcher examined the scatterplots, which upheld the assumption of linearity after examination. Outliers among variables will exhibit a low squared multiple correlation with all other variables and low correlations with all important factors. These outliers among the variables should be removed from the analysis (Stevens, 2009).

Additionally, the nature of exploratory factor analysis is determining underlying constructs of variables; therefore, the variables should be correlated. The researcher examined the Kaiser-Meyer-Olkin (KMO) statistic and found .907, which is greater than the recommended value of .60, yielding sufficient correlation among the variables. 
Bartlett's Test of Sphericity was also statistically significant $\left(\chi^{2}=3867.70, d f=300, p<\right.$ $.001)$ and indicated sufficient correlation among the variables to run the analysis (Stevens, 2009). Communalities were extracted through a Principal Components Analysis (PCA). Initial communalities measured between .539 ("To participate in discussions") and .803 ("Because it gives me something to occupy my time"), which further confirms some shared common variance among survey items.

In order to determine the factors for extraction, two primary criteria were used-eigenvalues greater than 1.0 and visual examination of a scree plot. Eigenvalues were examined for each of the 25 components. According to Kaiser-Guttman (1960), any component with an eigenvalue greater than or equal to 1.0 should be retained for interpretation. Using the retention criterion of eigenvalues greater than 1.0 and examination of the scree plot, a five-factor solution was extracted. An examination of the scree plot yielded an "elbow" at the fifth component, also yielding evidence to the retention of a five-factor solution.

The initial five-factor solution accounted for $66.62 \%$ of the variance in participants' motivations for consumption of social media. Before data rotation, the percentage of variance explained by Factor 1 (Community) was 37.6\%; Factor 2 (Information) accounted for 10.2\%; Factor 3 (Pass Time) accounted for 7.5\%; Factor 4 (Social Interaction) accounted for 6.6\%; and Factor 5 (Entertainment) $4.7 \%$ of the variance in social media consumption motivations of participants. Following a Varimax rotation of the data, Factor 1 (Community) accounted for 21.0\%; Factor 2 (Information) accounted for 15.2\%; Factor 3 (Pass Time) accounted for 12.1\%; Factor 4 (Social 
Interaction) accounted for 11.7\%; and Factor 5 (Entertainment) $6.7 \%$ of the variance in social media consumption motivations, for a total of $66.6 \%$ of the variance.

Factor loadings are correlations between the item and the factor construct. As such, "any loading that is going to be used to interpret a factor should be statistically significant at a minimum" (Stevens, 2002, p. 331). When determining the loadings on each factor, the sample size should be taken into account. Stevens suggested that analyzing the number of participants per variable ( 5 participants) is a more appropriate way for ensuring adequate sample size for reliable factor analysis. The sample size $(N=$ 277) for this study exceeds Stevens' criterion for the number of variables (25) being analyzed for factor analysis.

To determine statistically significant factor loadings, it was important to examine sample size and standard error of estimate. Stevens (2002) suggested doubling the standard error (i.e., critical value) of factor loadings to determine significance levels for item correlation. The researcher used the tabled critical value for $n=200$, since the actual sample size was 277. According to Stevens (2002), $n=200$ has a critical value of .182 (p. 332), doubling the critical value to .364 suggests that any component with an absolute value of .364 or greater could be considered a factor construct. Stevens (2002), however, suggested using loadings of .40 or greater for interpretation purposes. Therefore, a factor structure coefficient criterion cutoff of .40 was selected to improve the interpretability of the factors. All factor loadings are presented in Table 6.

Nine items loaded onto Factor 1 (eigenvalue $=5.25)$ at or above .60 , well above the minimum of .40 suggested by Stevens (2002). According to Guadagnoli and Velicer (1988), loadings above .60 in absolute value are reliable no matter the sample size. The 
eight items loading on to Factor 1 included "To get peer support from others," "To meet interesting people," "To feel like I belong to the community," "To feel connected to other users on social media," "To make connections to other people on social media sites," "To belong to a group with same interests as mine," "To participate in discussions," "To share information about myself (e.g., personal interest, profile)," and "To express myself freely." These items all represented concepts involved with the community aspects of social media; therefore, Factor 1 was named Community (Table 7).

Factor $2($ eigenvalue $=3.79)$ had five loadings above .60 . They included items such as "Because it is easier to get information," "To learn about events," "To get useful information about product/services/events," "To search for information," "To keep up with current issues and events (e.g., news)." All of these items contained elements of social media consumption for informational purposes; therefore, Factor 2 was labeled Information (Table 7).

Factor 3 (eigenvalue 3.02) emerged with three items above the .60 factor loading level. Those three items included the items "To pass the time," "To escape from boredom," and "Because it gives me something to occupy my time." The previously mentioned items focused on consumption of social media to pass time, and Factor 3 was subsequently named Pass Time (Table 7).

Factor 4 (eigenvalue 2.91) contained three items above the .60 factor loading, including "To talk about something with others," "To stay in touch with people I know," "To communicate with friends and family." These items highlight the interactive elements of social media consumption, and the factor was labeled Social Interaction (Table 7). 
Table 7

Factor Structure Matrix for Exploratory Factor Analysis with Varimax Rotation of Social Media Consumption Motivations

\begin{tabular}{lccccc} 
Item & 1 & 2 & 3 & 4 & 5 \\
\hline To meet interesting people & $\mathbf{. 7 8 7}$ & .141 & -.020 & -.042 & .105 \\
To feel like I belong to a community & $\mathbf{. 7 7 4}$ & .146 & -.016 & .244 & .199 \\
To belong to a group with same interests as mine & $\mathbf{. 6 9 3}$ & .256 & -.036 & .176 & .148 \\
To make connections to other people & $\mathbf{. 6 7 5}$ & .279 & .089 & .063 & .082 \\
To get peer support from others & $\mathbf{. 6 6 1}$ & .173 & .043 & .331 & .140 \\
To participate in discussions & $\mathbf{. 6 4 9}$ & .250 & .101 & .177 & .118 \\
To express myself freely & $\mathbf{. 6 0 7}$ & .243 & .346 & .209 & -.154 \\
To feel connected to other users on social media & $\mathbf{. 5 9 2}$ & .191 & .076 & .247 & .309 \\
To share information about myself & $\mathbf{. 5 5 1}$ & .199 & .359 & .321 & -.281 \\
To search for information & .221 & $\mathbf{. 8 1 3}$ & .068 & -.041 & .016 \\
To get useful information about product/services & .233 &. $\mathbf{7 8 1}$ & .070 & .113 & .107 \\
To keep up with current issues and events & .210 & $\mathbf{. 7 5 3}$ & .184 & .210 & .031 \\
To learn about events & .177 & $\mathbf{. 7 3 0}$ & .137 & .243 & .187 \\
Because it is easier to get information & .286 & $\mathbf{. 6 3 5}$ & -.058 & .178 & .171 \\
To escape from boredom & .042 & .065 & $\mathbf{. 8 6 8}$ & .087 & .143 \\
It gives me something to occupy my time & .027 & .106 & $\mathbf{. 8 6 5}$ & .101 & .184 \\
To pass the time & .045 & .111 & $\mathbf{. 8 6 5}$ & .115 & .137 \\
To communicate with friends and family & .146 & .066 & .132 & $\mathbf{. 8 5 1}$ & .054 \\
To stay in touch with people I know & .193 & .200 & .072 & $\mathbf{. 8 3 5}$ & .094 \\
To talk about something with others & .341 & .282 & .049 & $\mathbf{. 6 9 1}$ & .088 \\
Because it is funny & .306 & .064 & .245 & .030 & $\mathbf{. 7 2 9}$ \\
Because it is entertaining & .149 & .303 & .300 & .149 & $\mathbf{. 6 9 5}$ \\
Eigenvalues & & & & & \\
Percentage Variance & 5.25 & 3.79 & 3.02 & 2.91 & 1.68 \\
Internal Consistency $(\alpha)$ & 21.01 & 15.17 & 12.06 & 12.24 & 6.73 \\
\hline Note: Factor & .897 & .863 & .903 & .854 & .718 \\
\hline
\end{tabular}

Note: Factor 1--Community; Factor2--Information; Factor 3--Pass Time;

Factor 4--Social Interaction; Factor 5--Entertainment

Factor 5 (eigenvalue 1.68) contained two factors above the .60 level including

"Because it is entertaining," and "Because it is funny." These items relate to the entertainment purposes for which some users consume social media. As such, the factor was labeled Entertainment (Table 7).

Three items did not load appropriately and were deleted. "Because it is entertaining" loaded on to Factor 1; however, that item was not similar to the other items 
loading on that factor and was deleted. The item "To share information with others (e.g., content--links, news, ideas)" cross-loaded on Factor 1 (.403), Factor 2 (.490), and Factor 4 (.488), and was deleted. The item "So I can get away from family, friends or others" also cross-loaded on Factor 1 (.461), Factor 3 (.473), and Factor 4 (-.331), and was deleted.

Overall, the factor analysis produced five primary underlying constructs of participants' social media consumption motivations, including Community, Information, Pass Time, Social Interaction, and Entertainment. To confirm the reliability of the newly formed factors, the researcher examined Cronbach's alpha internal consistency coefficients (Table 7). Community $(\alpha=.897)$, Information $(\alpha=.863)$, Pass Time $(\alpha=$ .903), Social Interaction ( $\alpha=.854)$, and Entertainment $(\alpha=.718)$ all had internal consistency reliability coefficients above the .70 alpha level recommended by Nunnally and Bernstein (1994).

\section{Research Question 4}

RQ4: Are the social media consumption motives significant predictors of future intentions (i.e., future participation intention, future support of the organization, and participants' willingness to refer)?

To address the next research question, the researcher conducted a series of three multiple regression equations. The newly formed social media consumption motivation constructs (i.e., community, information, pass time, social interaction, and entertainment) were used as the predictor variables and future intentions (i.e., future participation intention, future support of the organization, and participants' willingness to refer) individually were the dependent variables. The first multiple regression equation used 
future participation intention as the dependent variable. The second multiple regression equation used future support of the organization as the dependent variable. The third multiple regression equation used participants' willingness to refer as the dependent variable. Since there were multiple analyses, the researcher used a Bonferroni adjustment to adjust for alpha inflation (i.e., $p / 3$ or $.05 / 3, p=.017$ ).

Similar to RQ1, prior to analysis the researcher checked the assumptions of multiple regression (1) independence, (2) linearity, (3) homoscedacity, (4) normality of residuals, (5) multicollinearity, and (6) outliers (Field, 2009; Stevens, 2009). The assumption of independence was met (see RQ1). Next, the researcher examined residual plots, to check the assumption of linearity and homoscedacity. The residual plots yielded evidence of a random scatter around zero fulfilling the assumptions. To examine the assumption of normality of residuals, the researcher examined a histogram of the residuals with an overlay of a normal curve, and normal probability plots (i.e., standardized residuals compared with the normal distribution). The researcher identified a normal curve shape of the histogram and a straight diagonal line on the normal probability plots, thus fulfilling the assumption of normality of residuals. Next, the researcher examined variance inflation factor (VIF) and tolerance statistics to ensure the assumption of multicollinearity was met. Results yielded VIF values ranging from 1.21 to 1.85 , which is below the recommended value of 10 (Stevens, 2009). Additionally, results evidenced tolerance levels between .540 and .827 , which are above the .1 commonly accepted value indicated by Stevens (2009), thus the assumption of multicollinearity was met. Lastly, the researcher examined outliers through the Cook's distance (Cook's D) statistic. Data yielded a value of .005, which is smaller than the recommended 1.0, 
indicating the assumption was met (Stevens, 2009).

In the first multiple regression equation, the researcher used future participation intention as the dependent variable and the social media consumption motivation constructs (i.e., community, information, pass time, social interaction, and entertainment) as the five predictor variables. The researcher found the regression model to be significant at the .017 alpha level with an $F(5,260)$ value of $2.86(p<.017)$. The regression model had an $R^{2}$ value of .052 , indicating $5.2 \%$ of the variance in future participation intention was accounted for by the five social media consumption constructs. Although there was statistical significance, the low $R^{2}$ value represents low practical significance. Additionally, further examination of the standardized regression coefficients yielded non-significant values for all of the variables. Community $(\beta=.115, t$ $=1.40, p=.162)$, information $(\beta=.047, t=.62, p=.538)$, pass time $(\beta=-.065, t=-.98, p$ $=.327)$, social interaction $(\beta=.100, t=1.38, p=.170)$, and entertainment $(\beta=.042, t=$ $.59, p=.555)$ were not statistically significant, indicating none of the variables were significant predictors of future participation intention.

The second multiple regression equation used future support of the organization as the dependent variable and the social media consumption motivation constructs (i.e., community, information, pass time, social interaction, and entertainment) as the five predictor variables. The results yielded a significant regression model at the .001 alpha level $[F(5,260)=5.47, p<.001]$. The regression model had an $R^{2}$ value of .095 , indicating $9.5 \%$ of the variance in future support of the organization was accounted for by the five social media consumption constructs. Standardized coefficients indicated pass time $(\beta=-.188, t=-2.89, p<.01)$ as a significant predictor of future support of the 
organization. The negative beta value indicated those individuals motivated to consume social media to pass the time were less likely to support the organization in the future. Similarly, those not motivated to consume social media for the purposes of passing the time were more likely to support the organization in the future. The social media consumption motivations of community $(\beta=.019, t=.23, p=.816)$, information $(\beta=$ $.148, t=1.97, p=.050)$, social interaction $(\beta=.152, t=2.13, p=.034)$, and entertainment $(\beta=.099, t=1.42, p=.157)$ were not statistically significant.

The third multiple regression equation used participants' willingness to refer as the dependent variable and social media consumption motivation constructs (i.e., community, information, pass time, social interaction, and entertainment) as the five predictor variables. The results yielded a significant regression model at the .001 alpha level $[F(5,260)=5.54]$. The regression model had an $R^{2}$ value of .096 , indicating $9.6 \%$ of the variance in participants' willingness to refer was accounted for by the five social media consumption constructs. Standardized regression indicated social interaction $(\beta=$ $.240, t=3.38, p<.01)$ as a significant predictor of participants' willingness to refer. This significance indicates those participants that are motivated to consume social media for interaction purposes are more likely to use refer friends, family, and others to TNT programs and events. The social media consumption motivations of community $(\beta=-$ $.040, t=-.50, p=.618)$, information $(\beta=.157, t=2.09, p=.038)$, pass time $(\beta=-.116, t$ $=-1.80, p=.074)$, and entertainment $(\beta=.009, t=.13, p=.897)$ were not statistically significant. 
Table 8

Summary of Regression Analyses for Social Media Variables Predicting Future Intentions of Charity Sport Events

\begin{tabular}{ccccccc}
\hline & $R^{2}$ & $B$ & $S E B$ & $\beta$ & $t$ & $p$ \\
\hline Future Participation Intention & $.052^{*}$ & & & & & \\
Community & & .14 & .10 & .12 & 1.40 & .162 \\
Information & & .06 & .09 & .05 & .62 & .538 \\
Pass Time & & -.06 & .06 & -.07 & -.98 & .327 \\
Social Interaction & & .15 & .11 & .10 & 1.38 & .170 \\
Entertainment & .05 & .08 & .04 & .59 & .555 \\
Future Support of the Organization & $.095^{* * *}$ & & & & & \\
Community & & .02 & .07 & .02 & .23 & .816 \\
Information & & .13 & .06 & .15 & 1.97 & .050 \\
Pass Time & & -.12 & .04 & -.19 & -2.89 & $.004 * *$ \\
Social Interaction & & .16 & .07 & .15 & 2.13 & .034 \\
Entertainment & & .08 & .06 & .10 & 1.42 & .157 \\
Participants' Willingness to Refer & $.096^{* * *}$ & & & & & \\
Community & & -.03 & .06 & -.04 & -.50 & .618 \\
Information & & .12 & .06 & .16 & 2.09 & .038 \\
Pass Time & & -.07 & .04 & -.12 & -1.80 & .074 \\
Social Interaction & & .23 & .07 & .24 & 3.38 & $.001 * * *$ \\
Entertainment & & .01 & .05 & .01 & .13 & .897 \\
\hline
\end{tabular}

Adjusted $R^{2}$ : Future Participation Intention (.034),

Future Support of the Organization (.078), Participants' Willingness to Refer (.079)

$* p<.017$ (Bonferonni adjustment); ** $p<.01 ; * * * p<.001$

\section{Research Question 5}

RQ4: What typologies of social media users exist based on intensity of usage and consumption motivations?

In research question number five, the researcher created typologies of social media users by segmenting respondents based on social media intensity of usage and consumption motivations. Prior to conducting further analysis, the researcher examined the assumptions of cluster analysis: (1) representative sample, (2) multicollinearity, and (3) outliers. The researcher ensured that the sample was representative of the population by using appropriate data collection techniques. Additionally, the researcher analyzed the 
demographic variables to that of the population. The researcher also compared demographic variables and responses of early and late responders, as researchers found that late responders have similar responses to that of non-responders (Groves, 2006; Siebert, 2008). Results of these analyses (described in the descriptive statistics section) confirm the assumption of representative sample. Next, similar to the analyses in research question one, multicollinearity and the presence of outliers were examined and assumptions were met.

To classify individuals into groups based on the similarities of the characteristics they possess in regard to both social media consumption motivations and social media intensity of usage, the researcher employed a two-stage cluster analysis. First, Ward's method--a hierarchical clustering method--was used to determine the appropriate number of clusters within the given sample. To determine the number of clusters appropriate to retain in the analysis, the researcher followed methods suggested by Burns and Burns (2008). The researcher analyzed the clustering coefficients, with small coefficients indicating homogeneous clusters are being merged and larger coefficients representing two very different clusters being merged. As noted by Ross (2007), "the optimal number of clusters is determined by finding the largest difference among clustering coefficients" (p. 17). The agglomeration clustering coefficient for a two-cluster solution was 2111.28, three-cluster solution was 1614.10 , four-cluster solution was 1381.55 , and five-cluster solution was 1212.44 .

Examining the change in agglomeration clustering coefficients based on the number of clusters retained aided the researcher in determining the appropriate number for clusters to retain. To determine the clustering coefficient change, the researcher 
calculated the difference of the agglomeration clustering coefficients between the number of retained clusters (i.e., two and three clusters, three and four cluster, etc.,). The clustering coefficient change (i.e., difference between the agglomeration clustering coefficients of two and three clusters) of retaining two clusters was 497.18. The clustering coefficient change of retaining three clusters was 232.56 . The clustering coefficient change of retaining four clusters was 169.11 , and the clustering coefficient change of retaining five clusters was 111.96. The largest coefficient change and demarcation was at the four-cluster mark. The researcher also examined the dendrogram to confirm the four-cluster solution. The dendrogram supported the agglomeration schedule and showed two clear clusters and two smaller ones; therefore, the researcher retained a four-cluster solution.

The researcher then re-analyzed the data through Ward's hierarchical analysis with four distinct clusters to first segment the users based on social media intensity of usage and social media consumption motivations and then further define cluster membership. Based on Ward's method for the four-cluster solution, cluster 1 consisted of 101 participants, cluster 2 had 31 participants, cluster 3 had 95, cluster 4 had 39. The researcher also conducted a $k$-means analysis to examine cluster classification through a non-hierarchical method. After further examination of the difference in clustering coefficients and cluster membership between the two methods, Ward's method yielded more equal group sizes and a more harmonious solution; therefore, the four cluster solution obtained through Ward's method was retained and $k$-means was not.

A follow-up ANOVA was conducted to identify differences in clusters using cluster membership as the independent variable and social media intensity of usage and 
social media consumption motivations (i.e., community, information, pass time, social interaction, and entertainment) as the dependent variables. The clusters were significantly different at the .05 alpha level on all variables. Follow-up post hoc analysis using Tukey HSD and an examination of the means and standard deviations provided the researcher with greater insight to cluster membership and differences among clusters (Table 9).

Cluster 1: Avid users $(\boldsymbol{n}=\mathbf{1 0 1})$. Participants classified into cluster 1 had a social media intensity of usage mean of $5.98(S D=.57)$, which was significantly higher than all other clusters $(p<.05)$. Cluster 1 also had the highest mean scores for all social media consumption variables, aside from social interaction. Participants had statistically higher mean scores of information $(M=6.12, S D=.62)$ and pass time $(M=5.60, S D=.93)$ at the .05 alpha level compared to all other clusters. Participants had significantly higher community $(M=5.09, S D=.93)$ and social interaction $(M=6.43, S D=.59)$ scores than clusters 3 and 4, although there were non-statistically significant differences from cluster 2. The entertainment mean $(M=5.44, S D=1.09)$ for cluster 1 was significantly higher than cluster 4, but not 2 and 3. Overall, cluster one was characterized as having high social media intensity of usage scores and high consumption motivations across all variables; therefore, cluster one was renamed Avid Users.

Cluster 2: Purposive users $(\boldsymbol{n}=\mathbf{3 1})$. Cluster 2 participants had a mean social media intensity of usage of $5.47(S D=1.10)$. This was the second highest social media intensity of usage mean, and was statistically lower than that of clusters 1 and statistically higher than clusters 3 and 4 at the .001 alpha level. Participants in this cluster had a community mean of $4.70(S D=1.11)$, which was statistically higher than cluster $4(p<$ 
$.001)$. The mean information score was $5.70(S D=.73)$, which was statistically lower than cluster 1 but higher than clusters 3 and $4(p<.05)$. Cluster 2 had the lowest pass time mean of all the clusters $(M=2.28, S D=.73)$ and was statistically lower than all other clusters at the .001 alpha level. The social interaction mean $(M=6.54, S D=.50)$ for cluster 2 was significantly higher than clusters 3 and $4(p<.05)$, but not statistically lower than cluster 1 . The entertainment mean $(M=5.00, S D=1.11)$ for cluster 2 was the second lowest of the four clusters, although it was not statistically lower than clusters 1 or 3. It was, however, significantly higher than cluster $4(p<.001)$. Cluster two was compromised of high intensity social media users who were primarily motivated to consume social media for social interaction and informational purposes. Participants were disinterested in using social media to pass time and were moderately motivated to be a part of community or to seek entertainment. Since these users had high intensity of usage and driven to interact and seek information, they were labeled Purposive Users, using social media frequently and for a purpose.

Cluster 3: Leisurely users $(\boldsymbol{n}=\mathbf{9 5})$. Cluster 3 participants had a mean social media intensity of usage of $5.05(S D=.90)$. This was the second lowest social media intensity of usage mean, and was statistically lower than that of cluster 1 and higher than that of cluster 4 at the .001 alpha level. Participants in this cluster had a community mean of $4.36(S D=.84)$, which was statistically lower than cluster 1 and higher than cluster 4 $(p<.001)$. The mean information score of $4.92(S D=.71)$ was statistically lower than clusters 1 and 2 and higher than cluster $4(p<.001)$. Cluster 3 had the second highest pass time mean of all the clusters $(M=4.89, S D=.65)$. Pass time was statistically higher than clusters 2 and 4, and lower than cluster $1(p<.001)$. The social interaction mean $(M$ 
$=6.09, S D=.72$ ) for cluster 3 was significantly lower than clusters 1 and 2 and higher than cluster $4(p<.05)$. The entertainment mean $(M=5.47, S D=.62)$ for cluster 3 was the highest of the four clusters and statistically higher than clusters $4(p<.001)$. Cluster 3 was comprised of moderate intensity social media users who were primarily motivated to consume social media to interact with others, be entertained, and pass the time.

Considering the enjoyment and escapist motives for social media usage characterized in this group, cluster three was labeled Leisurely Users.

Table 9

Cluster Analysis Means and Standard Deviations

\begin{tabular}{lcccc}
\hline & $\begin{array}{c}\text { Avid } \\
n=101\end{array}$ & $\begin{array}{c}\text { Purposive } \\
n=31\end{array}$ & $\begin{array}{c}\text { Leisurely } \\
n=95\end{array}$ & $\begin{array}{c}\text { Minimalist } \\
n=39\end{array}$ \\
\hline Community & & & & \\
$\quad$ Mean & 5.09 & 4.70 & 4.36 & 3.14 \\
$\quad S D$ & .93 & 1.11 & .84 & 1.10 \\
Information & & & & \\
$\quad$ Mean & 6.12 & 5.70 & 4.92 & 3.73 \\
$\quad S D$ & .62 & .73 & .71 & 1.06 \\
Pass Time & & & & \\
$\quad$ Mean & 5.60 & 2.28 & 4.89 & 3.42 \\
$\quad S D$ & .93 & .73 & .65 & 1.24 \\
Social Interaction & & & & \\
$\quad$ Mean & 6.43 & 6.54 & 6.09 & 5.23 \\
$\quad S D$ & .59 & .49 & .72 & 1.47 \\
Entertainment & & & & \\
$\quad$ Mean & 5.44 & 5.00 & 5.47 & 3.74 \\
$\quad S D$ & 1.09 & 1.11 & .62 & 1.37 \\
SM Intensity & & & & \\
$\quad$ Mean & 5.98 & 5.47 & 5.05 & 3.87 \\
$S D$ & .57 & 1.10 & .90 & 1.14 \\
\hline
\end{tabular}

Cluster 4: Minimalist users $(\boldsymbol{n}=39)$. Participants classified into cluster 4 had the lowest social media intensity of usage mean of $3.87(S D=1.14)$, which was significantly lower than all other clusters $(p<.001)$. Cluster 4 also had low mean scores for all of the social media consumption variables. Participants had statistically lower 
mean scores of community $(M=3.13, S D=1.10)$, information $(M=3.73, S D=1.06)$, social interaction $(M=5.23, S D=1.47)$, and entertainment $(M=3.74, S D=1.37)$ than all other clusters $(p<.001)$. The pass time mean $(M=3.42, S D=1.24)$, for cluster 4 was significantly lower than clusters 1 and 3, and significantly higher than cluster 2. Cluster 4 was characterized by low social media intensity of usage and relatively low means across the consumption variables; therefore, cluster 4 was renamed Minimalist Users.

\section{Research Question 6}

RQ6: Are there differences in social media typologies related to charity sport motivations (i.e., cause, philanthropy, social, sport, health and fitness)?

To examine whether charity sport motives differed based on social media typologies (established in RQ5), the researcher conducted MANOVA. The newly formed clusters (i.e., avid, purposive, leisurely, and minimalist users) were used as levels of the independent variable, and the charity sport motives (i.e., cause, philanthropy, social, health and fitness, and sport) were the dependent variables. It should also be noted that there was a sharply disproportionate number of participants in each cluster, however, the results of the cluster analysis justified this difference in group size.

Prior to running MANOVA, the researcher checked the assumptions of (1) independence, (2) normality, and (3) equality of covariances. The researcher ensured independence of responses through the methods identified in RQ1. Next, similar to RQ3, the researcher examined a histogram of data of the dependent variables and noted the dependent variables were positively skewed in relation to the normal curve. Stevens (2009) noted that due to the robustness of the $F$ statistic, there are minimal effects of non-

normal data on the significance in MANOVA. The researcher examined the Box's test of 
equality of covariance matrices, and found significant results (Box's $M=141.84, F=$ $3.01, p<.001)$. This indicated failure to meet the requirements of the third assumption (Stevens, 2009), potentially due to the differences in group sizes of the clusters. As noted in RQ3, Field (2009) and Stevens (2009) both noted the $F$ statistic is robust in MANOVA. Additionally, Bartlett's Test of Sphericity was statistically significant (approximate $\chi^{2}=519.48, p<.001$ ), indicating sufficient correlation between the dependent variables to proceed with the analysis. Although the data failed the assumptions of normality and equality of covariances, the $F$ statistic was robust. The researcher proceeded with the analysis, yet interpreted the results with caution.

The MANOVA revealed statistical significance between the levels of social media typologies on the composite dependent variables. Wilks's $\Lambda=.868, F(15,712.63)$ $=2.51, p<.01$. The multivariate partial $\eta^{2}$ was .046 , indicating $4.6 \%$ of the variance in dependent variables was accounted for by the clusters. According to Stevens (2002), this is considered a small effect. Since there were significant results in the multivariate analysis, a univariate analysis was conducted to determine where the significance existed. Prior to running a univariate test, the assumption of homogeneity of variances must be met. The Levene's Test of Equality of Error Variances, which tests for homogeneity of variance violations for each dependent measure, did not show significant results for sport $(p=.947)$. There were significant results for the other dependent variables of cause ( $p<$ $.01)$, philanthropy $(p<.001)$, health $(p<.01)$, and social $(p<.001)$. The results of Levene's test partially upheld the assumption of homogeneity of variance. As stated in the assumption of MANOVA, Field (2009) and Stevens (2009) noted the robustness of the $F$ statistic; therefore, the researcher proceeded with the analysis. 
Table 10

MANOVA: Differences in Charity Sport Motives by Cluster

\begin{tabular}{|c|c|c|c|c|c|c|c|}
\hline Sources & DV & $S S$ & $d f$ & $M S$ & $F$ & $p$ & $\eta^{2}$ \\
\hline \multirow[t]{5}{*}{ Cluster } & Cause & 7.50 & 3 & 2.50 & 2.88 & .036 & .032 \\
\hline & Philanthropy & 15.04 & 3 & 5.02 & 7.65 & .000 & .081 \\
\hline & Health & 15.87 & 3 & 5.29 & 5.15 & .002 & .056 \\
\hline & Sport & 3.55 & 3 & 1.18 & 1.22 & .304 & .014 \\
\hline & Social & 13.72 & 3 & 4.57 & 6.87 & .000 & .073 \\
\hline \multirow[t]{5}{*}{ Error } & Cause & 227.27 & 262 & 0.87 & & & \\
\hline & Philanthropy & 171.80 & 262 & 0.66 & & & \\
\hline & Health & 269.29 & 262 & 1.03 & & & \\
\hline & Sport & 254.59 & 262 & 0.97 & & & \\
\hline & Social & 174.48 & 262 & 0.67 & & & \\
\hline \multirow[t]{5}{*}{ Total } & Cause & 9389.50 & 266 & & & & \\
\hline & Philanthropy & 10409.40 & 266 & & & & \\
\hline & Health & 9894.19 & 266 & & & & \\
\hline & Sport & 8770.44 & 266 & & & & \\
\hline & Social & 10691.63 & 266 & & & & \\
\hline
\end{tabular}

The tests of Between-Subjects Effects evaluated each dependent variable separately. The researcher also used Bonferroni correction to adjust the alpha level based on multiple statistical analyses to reduce the inflation of Type I error rate. The adjusted alpha level for the univariate analysis was .01 (i.e., $p / 5$ or $.05 / 5=.01$ ). Results of the univariate tests revealed statistically significant differences in charity sport motives based on social media typologies for three of the five dependent variables. Follow-up analyses revealed significant differences in charity sport motives of philanthropy $[F(3,262)=$ $7.65, p<.001]$, health and fitness $[F(3,262)=5.15, p<.01]$, and social $[F(3,262)=$ $15.73, p<.001]$ based on social media typology. There were no significant differences in the charity sport motives of cause $[F(3,262)=2.88, p=.036]$ and sport $[F(3,262)=$ $1.22, p=.304]$ based on social media typology (Table 10$)$.

The partial $\eta^{2}$ for philanthropy was .081, indicating about $8.1 \%$ of the variance in 
philanthropy was explained by social media typology. According to Stevens (2002) this was a medium effect. The partial $\eta^{2}$ for health and fitness was .056, indicating $5.6 \%$ of the variance in health and fitness was explained by cluster. This was also a medium effect according to Stevens (2002). The partial $\eta^{2}$ for social was .073, in other words, $7.9 \%$ of the variance in social was accounted for by social media typology. Similarly, Stevens (2002) classified that effect size as medium.

There were significant differences in charity sport motives of philanthropy, health and fitness, and social, based on social media typology (Table 11). The charity sport motives of cause and sport did not differ between typologies. Considering there were four typologies of social media users, a Tukey HSD post hoc analysis was conducted to identify between-group differences. For avid users, results from the post hoc analysis revealed significantly higher levels of philanthropy $(M=6.39, S D=.62)$, health and fitness $(M=6.26, S D=.75)$, and social $(M=6.44, S D=.68)$ motives than minimalist users at the .01 alpha level. Additionally, avid users had higher levels of health and fitness motivation than leisurely users $(M=5.84, S D=1.14)$ at the .05 alpha level.

Table 11 Means and Standard Deviations for Clusters

\begin{tabular}{lcccccccccc}
\hline & \multicolumn{2}{c}{ Cause } & \multicolumn{2}{c}{ Philanthropy } & \multicolumn{2}{c}{ Health } & \multicolumn{2}{c}{ Sport } & \multicolumn{2}{c}{ Social } \\
\cline { 5 - 14 } Clusters & Mean & $S D$ & Mean & $S D$ & Mean & $S D$ & Mean & $S D$ & Mean & $S D$ \\
\hline Avid & 6.00 & .86 & 6.39 & .62 & 6.26 & .75 & 5.75 & 1.03 & 6.44 & .68 \\
Purposive & 6.11 & .93 & 6.44 & .78 & 6.21 & 1.14 & 5.78 & .98 & 6.57 & .54 \\
Leisurely & 5.74 & .81 & 6.12 & .71 & 5.84 & 1.14 & 5.62 & .95 & 6.21 & .75 \\
Minimalist & 5.63 & 1.31 & 5.72 & 1.34 & 5.63 & 1.18 & 5.42 & .96 & 5.83 & 1.33 \\
\hline
\end{tabular}

Purposive users had very similar charity sport motivations as avid users. There were no significant differences in motivations, although there were some slight differences in mean scores. Purposive users, however, were significantly more likely to 
participate for philanthropic reasons $(M=6.44, S D=.78)$ than minimalist users $(M=$ $5.72, S D=1.34$ ) at the .01 alpha level. Purposive users also had significantly higher mean scores of social motives $(M=6.57, S D=.54)$ than minimalist users $(p<.01)$.

Leisurely users had significantly higher mean scores of philanthropy $(M=6.12$, $S D=.71)$ than minimalist users $(M=5.72, S D=1.34)$ at the .05 alpha level. Leisurely users also had significantly lower scores of health and fitness $(M=5.84, S D=1.14)$ than avid users $(M=6.26, S D=.75)$ at the .05 alpha level.

Minimalist users had the lowest mean scores across all of the variables, and their means were significantly lower than the avid, purposive, and leisurely users in relation to philanthropic motives $(M=5.72, S D=1.34)$. Minimalist users had lower mean scores of health and fitness $(M=5.63, S D=1.18)$ and social $(M=5.83, S D=1.33)$ than avid users at the .01 alpha level. In addition, minimalist users had significantly lower scores for the social motive than purposive users $(M=6.57, S D=.54)$ at the .01 alpha level.

\section{Research Question 7}

RQ7: Are charity sport motives (i.e., cause, philanthropy, social, sport, health and fitness) significant predictors of future intentions (i.e., future participation intention, future support of the organization, and participants' willingness to refer) for each social media typology?

To address the seventh research question, the researcher used a series of multiple regression equations and regressed each relevant outcome (i.e., future participation intention, future support of the organization, and participants' willingness to refer) on the charity sport motives (i.e., philanthropy, cause, sport, health and fitness, and social) for each social media typology (i.e., avid, purposive, leisurely, and minimalist users). Similar 
to the previous research questions, a Bonferroni adjustment was employed to control for alpha inflation (i.e., Type I error). The adjusted alpha level was set at .004 (i.e., $p / 12$ or $.05 / 12=.004)$.

Avid users. In regard to the avid user typology, the first multiple regression equation used future participation intention as the dependent variable and charity sport motives (i.e., cause, philanthropy, social, health and fitness, and sport) as the five predictor variables. The results yielded a significant regression model at the .004 alpha level $[F(5,95)=4.73]$. The regression model had an $R^{2}$ value of .199 , indicating $19.9 \%$ of the variance in future participation intention was accounted for by the five charity sport motives. The regression model was significant; however, there were no statistically significant predictor variables. Health and fitness $(\beta=.35, t=2.82, p<.01)$, although not statistically significant, did influence future participation intentions for avid users. This indicates, for every one unit change in health and fitness, future participation intention changed .35 units.

The second multiple regression equation used future support of the organization as the dependent variable and charity sport motives (i.e., cause, philanthropy, social, health and fitness, and sport) as the five predictor variables. The results yielded a significant regression model at the .004 alpha level $[F(5,95)=4.40]$. The regression model had an $R^{2}$ value of .188 , indicating $18.8 \%$ of the variance in future support of the organization was accounted for by the five charity sport motives. Although there was no statistical significance, cause was an influential predictor of future support of the organization $(\beta=.30, t=2.40, p<.05)$. The results indicate those avid users motivated to participate for cause were more likely to support the organization in the future. This 
indicates for every one unit change in cause, future support of the organization changed .30 units.

Table 12

Avid Users: Summary of Regression Analyses for Charity Sport Motivations Predicting Future Intentions

\begin{tabular}{ccccccc}
\hline & $R^{2}$ & $B$ & $S E B$ & $\beta$ & $t$ & $p$ \\
\hline Future Participation Intention & $.199^{*}$ & & & & & \\
Cause & & .29 & .18 & .20 & 1.61 & .111 \\
Philanthropy & & -.06 & .25 & -.03 & -.24 & .809 \\
Health & & .59 & .21 & .35 & 2.82 & .006 \\
Sport & & -.23 & .15 & -.19 & -1.56 & .123 \\
Social & .40 & .22 & .22 & 1.83 & .070 \\
Future Support of the Organization & $.188^{*}$ & & & & & \\
Cause & & .27 & .11 & .30 & 2.40 & .018 \\
Philanthropy & & -.04 & .16 & -.04 & -.28 & .777 \\
Health & & .25 & .13 & .24 & 1.92 & .058 \\
Sport & & -.16 & .09 & -.22 & -1.75 & .083 \\
Social & .26 & .14 & .23 & 1.88 & .063 \\
Participants' Willingness to Refer & $.268^{* * *}$ & & & & & \\
Cause & & .03 & .09 & .04 & .31 & .755 \\
Philanthropy & & .24 & .12 & .23 & 1.93 & .057 \\
Health & & .21 & .10 & .25 & 2.08 & .040 \\
Sport & & -.12 & .07 & -.19 & -1.59 & .115 \\
Social & .30 & .11 & .31 & 2.77 & .007 \\
\hline
\end{tabular}

Adjusted $R^{2}$ : Future Participation Intention (.157),

Future Support of the Organization (.145), Participants' Willingness to Refer (.230)

$* p<.004$ (Bonferonni adjustment); *** $p<.001$

The third multiple regression equation used participants' willingness to refer as the dependent variable and charity sport motives (i.e., cause, philanthropy, social, health and fitness, and sport) as the five predictor variables. The results yielded a significant regression model at the .001 alpha level $[F(5,95)=6.97]$. The regression model had an $R^{2}$ value of .268 , indicating $26.8 \%$ of the variance in participants' willingness to refer was accounted for by the five charity sport motives. Similar to future participation intention and future support of the organization, there were no statistically significant 
predictors. The social motive $(\beta=.31, t=2.77, p<.01)$ was an influential predictor of participants' willingness to refer. This indicates for every one unit change in cause, participants' willingness to refer changed .31 units. This significance indicated that those avid users that were motivated to participate in charity sport events for social reasons were more likely to refer friends, family, and others to TNT programs and events in the future.

Purposive users. The first multiple regression equation for the purposive user typology used future participation intention as the dependent variable and charity sport motives (i.e., cause, philanthropy, social, health and fitness, and sport) as the five predictor variables. The researcher found a significant regression model with an $F(5,25)$ value of $9.12(p<.001)$. The regression model had an $R^{2}$ value of .646 , indicating $64.6 \%$ of the variance in future participation intention was accounted for by the five charity sport motives for the purposive user typology. A further examination of the standardized coefficients yielded significance of cause $(\beta=.83, t=3.84, p<.001)$ and health and fitness $(\beta=.57, t=3.41, p<.004)$ motives as significant predictors of future participation intention. This indicates for every one unit change in cause, future participation intention changed .83 units. Similarly, for every one unit change in health and fitness, future participation intention changed .57 units. The results indicated those purposive users motivated to participate for cause and health and fitness related reasons were more likely to participate in future events. The other three motives of philanthropy, social, and sport were not significant predictors of future participation intention. 
Table 13

Purposive Users: Summary of Regression Analyses for Charity Sport Motivations Predicting Future Intentions

\begin{tabular}{ccccccc}
\hline & $R^{2}$ & $B$ & $S E B$ & $\beta$ & $t$ & $p$ \\
\hline Future Participation Intention & $.646^{* * *}$ & & & & & \\
Cause & & 1.38 & .36 & .83 & 3.84 & $.001^{*}$ \\
Philanthropy & & -.70 & .46 & -.35 & -1.51 & .145 \\
Health & & .76 & .22 & .57 & 3.41 & $.002^{*}$ \\
Sport & & .22 & .25 & .14 & .89 & .380 \\
Social & -.52 & .47 & -.18 & -1.11 & .279 \\
Future Support of the Organization & $.665^{* * *}$ & & & & & \\
Cause & & .81 & .19 & .89 & 4.20 & $.000 * * *$ \\
Philanthropy & & -.51 & .25 & -.46 & -2.05 & .051 \\
Health & & .32 & .12 & .42 & 2.63 & .014 \\
Sport & & -.03 & .14 & -.03 & -.19 & .855 \\
Social & .30 & .25 & .19 & 1.20 & .240 \\
Participants' Willingness to Refer & $.499 *$ & & & & & \\
Cause & & .73 & .30 & .63 & 2.42 & .023 \\
Philanthropy & & -.34 & .39 & -.24 & -.87 & .393 \\
Health & & .53 & .19 & .56 & 2.84 & .009 \\
Sport & & .01 & .21 & .01 & .03 & .978 \\
Social & & -.20 & .39 & -.10 & -.52 & .608 \\
\hline
\end{tabular}

Adjusted $R^{2}$ : Future Participation Intention (.575), Future Support of the Organization (.598), Participants' Willingness to Refer (.399) $* p<.004$ (Bonferonni adjustment); *** $p<.00$

The second multiple regression equation used future support of the organization as the dependent variable and charity sport motives (i.e., cause, philanthropy, social, health and fitness, and sport) as the five predictor variables. The results yielded a significant regression model at the .001 alpha level $[F(5,25)=9.93]$. The regression model had an $R^{2}$ value of .665 , indicating $66.5 \%$ of the variance in future support of the organization was accounted for by the five charity sport motives. A further examination of the standardized coefficients yielded the significance of cause $(\beta=.89, t=4.20, p<$ .001). This indicates for every one unit change in cause, future support of the organization changed .89 units. The results indicated those purposive users motivated to 
participate for cause related reasons were more likely to support the organization in the future. While the motive of health and fitness was not a significant predictor of future support, it did have a strong predictive value $(\beta=.42, t=2.63, p<.05)$. Likewise, for every one unit change in health and fitness, future support of the organization changed .42 units.

The third multiple regression equation used participants' willingness to refer as the dependent variable and charity sport motives (i.e., cause, philanthropy, social, health and fitness, and sport) as the five predictor variables. The results yielded a significant regression model at the adjusted .004 alpha level $[F(5,25)=4.98]$. The regression model had an $R^{2}$ value of .499, indicating $49.9 \%$ of the variance in participants' willingness to refer was accounted for by the five charity sport motives. Although there were no significant predictors, health and fitness was an influential predictor $(\beta=.56, t=2.84, p<$ $.01)$. This indicates for every one unit change in health and fitness, participants' willingness to refer changed .56 units. The results indicated those purposive users motivated to participate in charity sport events for health and fitness motives were more likely to refer friends, family, and others to TNT programs and events in the future.

Leisurely users. For the leisurely user typology, the first multiple regression equation used future participation intention as the dependent variable and charity sport motives (i.e., cause, philanthropy, social, health and fitness, and sport) as the five predictor variables. The researcher found the regression model to be significant with an $F(5,89)$ value of $5.63(p<.001)$. The regression model had an $R^{2}$ value of .240 , indicating $24.0 \%$ of the variance in future support of the organization was accounted for by the five charity sport motives. Although none of the predictor variables were 
statistically significant, philanthropy $(\beta=.27, t=2.25, p<.05)$ was a strong predictor of future participation intention. This indicates for every one unit change in philanthropy, future participation intention changed .27 units.

Table 14

Leisurely Users: Summary of Regression Analyses for Charity Sport Motivations Predicting Future Intentions

\begin{tabular}{ccccccc}
\hline & $R^{2}$ & $B$ & $S E B$ & $\beta$ & $t$ & $p$ \\
\hline Future Participation Intention & $.240^{* * *}$ & & & & & \\
Cause & & .26 & .17 & .18 & 1.56 & .122 \\
Philanthropy & & .46 & .20 & .27 & 2.25 & .027 \\
Health & & .18 & .13 & .17 & 1.39 & .167 \\
Sport & & -.07 & .14 & -.06 & -.52 & .605 \\
Social & .16 & .20 & .10 & .80 & .424 \\
Future Support of the Organization & $.353 * * *$ & & & & & \\
Cause & & .24 & .10 & .24 & 2.31 & .023 \\
Philanthropy & & .34 & .13 & .30 & 2.69 & .009 \\
Health & & .15 & .08 & .21 & 1.89 & .062 \\
Sport & & -.19 & .08 & -.23 & -2.27 & .026 \\
Social & .16 & .12 & .15 & 1.30 & .196 \\
Participants' Willingness to Refer & $.430 * * *$ & & & & & \\
Cause & & .34 & .11 & .32 & 3.28 & $.001 *$ \\
Philanthropy & & .07 & .13 & .05 & .53 & .599 \\
Health & & .25 & .08 & .33 & 3.11 & $.003 *$ \\
Sport & & -.06 & .09 & -.07 & -.73 & .468 \\
Social & & .32 & .12 & .28 & 2.62 & .010 \\
\hline
\end{tabular}

Adjusted $R^{2}$ : Future Participation Intention (.198), Future Support of the Organization (.316), Participants' Willingness to Refer (.398)

$* p<.004$ (Bonferonni adjustment); *** $p<.001$

The second multiple regression equation used future support of the organization as the dependent variable and charity sport motives (i.e., cause, philanthropy, social, health and fitness, and sport) as the five predictor variables. The results yielded a significant regression model at the .001 alpha level $[F(5,89)=9.70]$. The regression model had an $R^{2}$ value of .353 , indicating $35.3 \%$ of the variance in future support of the organization was accounted for by the five charity sport motives. Similar to future 
participation intention, although none of the predictor variables were statistically significant, philanthropy $(\beta=.30, t=2.69, p<.01)$ was a strong predictor of future support of the organization. For every one unit change in philanthropy, future participation intention changed .30 units. The results indicated those leisurely users motivated to participate for philanthropic reasons were more likely to support the organization in the future.

The third multiple regression equation used participants' willingness to refer as the dependent variable and charity sport motives (i.e., cause, philanthropy, social, health and fitness, and sport) as the five predictor variables. The results yielded a significant regression model at the .001 alpha level $[F(5,89)=13.43)$. The regression model had an $R^{2}$ value of 430 , indicating $43.0 \%$ of the variance in participants' willingness to refer was accounted for by the five charity sport motives. Upon further examination of the standardized coefficients, cause $(\beta=.32, t=3.23, p<.004)$ and health and fitness $(\beta=$ $.33, t=3.11, p<.004)$ motives were statistically significant predictors of participants' willingness to refer. For every one unit change in cause, participants' willingness to refer increased .32 units. Likewise, for every one unit change in health and fitness, participants' willingness to refer changed .33 units. These results indicated those leisurely users motivated to participate in charity sport events for cause, health and fitness reasons were more likely to refer friends, family, and others to TNT programs and events in the future.

Minimalist users. For the minimalist user typology, the first multiple regression equation used future participation intention as the dependent variable and charity sport motives (i.e., cause, philanthropy, social, health and fitness, and sport) as the five 
predictor variables. The regression model was significant with an $F(5,33)$ value of 4.87 ( $p<.004$ ). The regression model had an $R^{2}$ value of .424 , indicating $42.4 \%$ of the variance in future participation intention was accounted for by the five charity sport motives. Although none of the predictor variables were statistically significant, cause ( $\beta=$ $.58, t=2.51, p<.05)$ was a strong predictor of future participation intention, indicating those minimalist users motivated to participate for cause reasons were more likely to participate in future events. This indicates for every one unit change in cause, future participation intention changed .58 units.

Table 15

Minimalist Users: Summary of Regression Analyses for Charity Sport Motivations Predicting Future Intentions

\begin{tabular}{ccccccc}
\hline & $R^{2}$ & $B$ & $S E B$ & $\beta$ & $t$ & $p$ \\
\hline Future Participation Intention & $.424^{*}$ & & & & & \\
Cause & & .73 & .29 & .58 & 2.51 & .017 \\
Philanthropy & & -.07 & .30 & -.06 & -.23 & .819 \\
Health & & .13 & .25 & .09 & .49 & .626 \\
Sport & & .33 & .30 & .19 & 1.08 & .287 \\
Social & & .13 & .25 & .10 & .51 & .613 \\
Future Support of the Organization & $.559^{* * *}$ & & & & & \\
Cause & & .41 & .23 & .36 & 1.79 & .082 \\
Philanthropy & & .23 & .24 & .21 & .96 & .344 \\
Health & & -.02 & .20 & -.02 & -.11 & .914 \\
Sport & & .28 & .24 & .18 & 1.19 & .243 \\
Social & & .27 & .19 & .24 & 1.39 & .173 \\
Participants' Willingness to Refer & $.640^{* * *}$ & & & & & \\
Cause & & .31 & .16 & .36 & 1.94 & .061 \\
Philanthropy & & .16 & .16 & .20 & 1.00 & .323 \\
Health & & .11 & .14 & .12 & .81 & .425 \\
Sport & & .08 & .17 & .07 & .48 & .633 \\
Social & & .25 & .13 & .30 & 1.88 & .069 \\
\hline
\end{tabular}

Adjusted $R^{2}$ : Future Participation Intention (.337), Future Support of the Organization (.493), Participants' Willingness to Refer (.586)

$* p<.004$ (Bonferonni adjustment); *** $p<.001$ 
The second multiple regression equation used future support of the organization as the dependent variable and charity sport motives (i.e., cause, philanthropy, social, health and fitness, and sport) as the five predictor variables. The results yielded a significant regression model at the .001 alpha level $[F(5,33)=8.38]$. The regression model had an $R^{2}$ value of .559 , indicating $55.9 \%$ of the variance in future support of the organization was accounted for by the five charity sport motives. Although the overall regression model was significant, there were no strong predictors of future support of the organization.

The third multiple regression equation used participants' willingness to refer as the dependent variable and charity sport motives (i.e., cause, philanthropy, social, health and fitness, and sport) as the five predictor variables. The results yielded a significant regression model at the .001 alpha level $[F(5,33)=11.75]$. The regression model had an $R^{2}$ value of .640 , indicating $64.0 \%$ of the variance in participants' willingness to refer was accounted for by the five charity sport motives. Similar to future support of the organization, while the regression model was significant, there were no significant predictors of participants' willingness to refer.

\section{Summary of Results}

This study used multiple regression, MANOVA, EFA, and cluster analysis to address the seven research questions. First, the researcher found the set of charity sport motivations (i.e., cause, philanthropy, social, health and fitness, and sport) to effectively predict future intention variables. Cause and health and fitness motivations significantly predicted future participation intention. Similarly, cause, health and fitness, and social 
motivations were the strongest predictors of both future support of the organization and participants' willingness to refer.

Additionally, MANOVA results yielded statistical differences participants' future intentions between levels of social media intensity of usage, with high intensity users being more likely to participate and support the organization in the future, as well as refer their family and friends, than low intensity users.

Through exploratory factor analysis, five underlying constructs of social media consumption motivation were developed, including community, information, pass time, social interaction, and entertainment. Although there were small levels of variance accounted for, the set of social media consumption variables (i.e., community, information, pass time, social interaction, and entertainment) were significantly predictive of participants' future intentions. Pass time was a negative predictor of future support of the organization, indicating those individuals motivated to consume social media to pass the time were not likely to support the organization in the future. Social interaction was a significant predictor of participants' willingness to refer, indicating individuals motivated to consume social media for interaction purposes were more likely to refer friends, family, and others to TNT programs and events.

In addition, the researcher identified four distinct clusters based on social media intensity of usage and consumption motivations--avid users, purposive users, leisurely users, and minimalist users. Avid users had high intensity of usage and high consumption motivations, whereas minimalist users had low intensity of usage and lower levels of consumption motivations. Purposive users were high intensity users who consumed social media for a purpose, driven by social interaction and information. Leisurely users 
had a moderate intensity of usage and were motivated to consume for social interaction, entertainment, and to pass the time. MANOVA revealed significant differences in charity sport motives of cause, philanthropy, health and fitness, and social motives across social media typologies. No significant differences existed in the sport motive among the clusters. Overall, avid users had higher levels of charity sport motivation across all variables than minimalist users.

Multiple regression equations were also used to examine differences in charity sport motives as predictors of future intentions for each cluster. For avid users, health and fitness was a strong predictor of future participation intention, while cause best predicted future support of the organization, and social motives were the strongest predictors of participants' willingness to refer. For purposive users, cause and health and fitness significantly predicted future participation intention. Cause was also a significant predictor of future support of the organization for purposive users. For leisurely users, cause and health and fitness were the significant predictors of participants' willingness to refer, and while not significant, philanthropy was a strong predictor of both future participation intention and future support of the organization. Sport was also a strong predictor of future support of the organization for leisurely users. For minimalist users, although none of the motives were significant, cause was a strong predictor of future participation intention. 


\section{CHAPTER V}

\section{DISCUSSION}

The primary purpose of this study was to determine how charity sport organizations could leverage social media to enhance recruitment, retention, and future support of their organization. To guide the research and analysis, the researcher developed seven research questions.

RQ1: Are the charity sport motivations of cause, philanthropy, social, health and fitness, and sport significant predictors of future intentions (i.e., future participation intention, future support of the organization, and participants' willingness to refer)?

RQ2: Are the different levels of social media intensity of usage (i.e., low, moderate, and high) related to future intentions (i.e., future participation intention, future support of the organization, and participants' willingness to refer)? RQ3: What is the factor structure of social media consumption motivation?

RQ4: Are the social media consumption motivations significant predictors of future intentions (i.e., future participation intention, future support of the organization, and participants' willingness to refer)?

RQ5: What typologies of social media users exist based on intensity of usage and 
consumption motivations?

RQ6: Are there differences in social media typologies related to charity sport motivations (i.e., cause, philanthropy, social, sport, health and fitness)?

RQ7: Are charity sport motivations (i.e., cause, philanthropy, social, sport, health and fitness) significant predictors of future intentions (i.e., future participation intention, future support of the organization, and participants' willingness to refer) for each social media typology?

The next section will discuss the results in relation to each research question (mentioned in Chapter IV) and the theoretical and practical implications. In addition, directions for future research and a summary of the entire study will be provided.

\section{Summary of Results}

Analysis of the data revealed seven main findings regarding future intentions of charity sport participants. First, the findings from the regression of future participation intention on the set of charity sport motivations (i.e., cause, philanthropy, social, sport, and health and fitness) indicated that charity motivations as a whole explained approximately $31 \%$ of the variance in future participation intention. Of the five charity sport motivations, cause and health and fitness were the two significant predictors with cause being the more important of the two. With regard to future support o the organization, the same five predictors explained approximately $44 \%$ of the variance in future support. Cause, philanthropy, health and fitness, and social were the four significant predictors. Of the four significant predictors, cause was the most important predictor of future support of the organization, followed by social, philanthropy, and health and fitness. In respect to participants' willingness to refer, the five charity sport 
motivations explained approximately $47 \%$ of the variance in participants' willingness to refer. Health and fitness was the strongest predictor, followed by social, and cause.

Additionally, the charity sport motivations of cause and health and fitness were significant predictors for all three future intention variables (i.e., future participation intention, future support of the organization, and participants' willingness to refer). The results indicate that individuals motivated to participate in charity sport events for cause and health and fitness related reasons were more likely to participate in future charity sport events, support the organization in the future, and encourage others to participate in events. The social motive was also a significant predictor of future support of the organization and participants' willingness to refer. Therefore, individuals motivated to participate in charity sport events for social reasons were more likely to support the organization, either monetarily or with their time, in the future and tell others about their positive participation experience. In addition, the charity sport motive of philanthropy was also a significant predictor of future support of the organization, indicating individuals motivated to participate for altruistic reasons were more likely to support the organization in the future.

Second, MANOVA indicated future intentions differed depending on an individual's level of social media intensity of usage. High intensity users were significantly more likely to express a desire to participate again in the future, further support the organization, and refer others to the charitable organization than low intensity users. Moderate intensity users were also more likely to support the organization than low intensity users. 
Third, five underlying constructs of social media consumption were formed. Exploratory factor analysis revealed five distinct social media consumption motivations of (1) community, (2) information, (3), pass time, (4) social interaction, and (5) entertainment. Community refers to individuals using social media platforms to connect with others through an online group, participate in discussions with others that have similar interests, and feel a connection with a community. Information refers to using social media platforms to search for information, stay up to date with currents news and events, and learn new things. Those motivated to consume social media to pass time refers to social media consumption as an escape from boredom, and social media as a source that occupies time. Social interaction refers to individuals using social media to communicate with friends and family as well as stay in touch and interact with others. Individuals motivated to consume social media for entertainment purposes refers to the enjoyment and amusement that social media provide.

Fourth, multiple regression analyses indicated the set of social media consumption motivations of community, information, pass time, social interaction, and entertainment were significant predictors of future participation intention, future support of the organization, and participants' willingness to refer. Within the set of social media consumption motivations, there were several significant predictors of future intentions, including pass time and social interaction. Pass time was a negative predictor of future support of the organization, indicating that those motivated to consume social media for escapist and diversion reasons were less likely to support the organization in the future. Not surprisingly, social interaction was a significant predictor of participants' willingness to refer, indicating individuals motivated to consume social media to connect and interact 
with others were also more likely to encourage others to participate in charity programs and events.

Fifth, the results of the cluster analysis indicated that there were four distinctive typologies: avid, purposive, leisurely, and minimalist users. The typologies of social media users (i.e., avid, purposive, leisurely, and minimalist users) were formed based on social media intensity of usage and social media consumption motivations. Avid users were characterized as having high social media intensity of usage and high levels of all social media consumption motivations. Purposive users were characterized as having high social media intensity of usage, and were primarily motivated to use social media for social interaction and information seeking purposes. Leisurely users had a moderate social media intensity of usage, and were primarily motivated to consume social media for social interaction and entertainment purposes as well as to pass the time. Minimalist users had low social media intensity of usage and relatively were less motivated to consume social media across all of the motivations.

Sixth, the MANOVA results showed that the four typologies of social media users differed significantly in their charity sport motives, and the univariate follow-up showed that the multivariate significance was due to cause, philanthropy, health and fitness, and social motives. No significant differences existed in sport participation motive between typologies. Avid users had significantly higher levels of philanthropic, health and fitness, and social motivation than minimalist users. Purposive users had very similar charity sport motivations as avid users--and although there were some slight differences in means, there were no significant differences in motivations. Purposive users were also more likely to participate by philanthropic reasons than minimalist users. Leisurely users 
were more motivated by philanthropic reasons than minimalist users, and also less motivated by health and fitness than avid users. Minimalist users were the least motivated by charity sport motives.

Finally, multiple regression analyses was used to identify differences in charity sport motives as predictors of future intentions for each typology. Within the avid user typology, health and fitness was a strong predictor of future participation intention. Cause was a strong predictor of future support of the organization, and social was a strong predictor of participants' willingness to refer. This indicates those avid users motivated to participate in charity sport events by health and fitness reasons were more likely to participate again the future, while those motivated by cause-related reasons were more likely to continue to support the organization. Those motivated by social reasons were more likely to refer their family and friends in the future. Within the purposive user typology, cause, and health and fitness were significant predictors of future participation intention; cause was a predictor of future support of the organization; and health and fitness was a predictor of participants' willingness to refer. For leisurely users, philanthropy predicted both future participation intention and future support of the organization, while cause, and health and fitness predicted participants' willingness to refer. For minimalist users, cause was a strong predictor of future participation intention, however there were no significant or strong predictors of future support of the organization or participants' willingness to refer.

Results indicate similarities and differences among the typologies based on charity sport motives and future intentions. Avid and purposive users both indicated health and fitness was a strong predictor of future participation intention, whereas 
philanthropy was a strong predictor of future participation intention for leisurely users. In addition, cause was a strong predictor of future participation intention for both purposive and minimalist users. Similarly, cause was a significant predictor of future support of the organization for avid and purposive users, whereas philanthropy was a strong predictor for leisurely users. Health and fitness was also a strong predictor of future support of the organization for purposive users. In regard to participants' willingness to refer, social was a strong predictor for avid users, while health and fitness were strong predictors of participants' willingness to refer for purposive and leisurely users. Cause was also a strong predictor of participants' willingness to refer for leisurely users.

\section{Theoretical Implications}

The following section will discuss the results of this study as they relate to previous research. The section will discuss theoretical implications in the context of charity sport and social media.

\section{Charity Sport}

In relation to charity sport, there were two major contributions of this study, (1) the validation of existing charity sport motivations and (2) the expansion of the literature to include the influence of those motivations on future intentions of participants.

Motivation. The current study examined five charity sport motivations: cause, philanthropy, social, sport, and health and fitness. The set of five charity sport motivations significantly predicted all of the future intention variables and accounted for a significant portion of the variance in future participation intention $(31.1 \%)$, future support of the organization (43.8\%), and participants' willingness to refer $(47.3 \%)$. The large percentage of variance accounted for by the charity sport motivations provides 
evidence to the predictive nature of the variables. Also, the large variance explained shows that the variables assessed a significant portion of the motivations of charity sport participants. Therefore, the results confirm the importance of inclusion of each of the charity sport motives.

Charity sport participation is operationalized as individuals simultaneously raising money for a cause and participating in an athletic event (Filo et al., 2009). Due to the seemingly broad nature of the activity, researchers explored varying bodies of research with the aim of understanding motivations for charity sport participation. Previous charity sport researchers explored motives related to individuals' charitable giving (e.g., Dawson, 1988; Guy \& Patton, 1989; Sargeant et al., 2004), athletic giving (e.g., Gladden et al., 2004), and sport participation behaviors (Funk et al., 2011; Havenar \& Lochbaum, 2003; Kilpatrick et al., 2005; Recours et al., 2004) to develop items that accurately represented individuals' motivation for participation in charity sporting events (e.g., Bennett et al., 2007; Filo et al., 2008; Filo et al., 2009; Won \& Park, 2010).

Many of the previous charity sport studies were exploratory, seeking to understand motivations of individuals. The current study looked to build upon the work of others and move the body of literature beyond exploratory research. The findings effectively confirm the variables of cause (Filo et al., 2008; 2009; 2010), philanthropy (Filo et al., 2010; Won \& Park, 2010), social (Bennett et al., 2007; Filo et al., 2009; Won \& Park, 2010), sport (Bennett et al., 2007; Snelgrove \& Wood, 2010), and health and fitness (Bennett et al., 2007; Snelgrove \& Wood, 2010), and as primary charity sport motives. Previous literature identified a diverse set of constructs, however, the current study created a clear and concise set of charity sport motivations. Prior research 
examined differing numbers of participant motives ranging from three (i.e., camaraderie, cause, and competency; Filo et al., 2009) to ten (i.e., involvement with the charity, desire to pursue a healthy lifestyle, involvement with the sport, exhibitionism, desire to mix socially, feels a duty to participate, desire to experience fun and enjoyment, attracted to the status of the event, desire to experience physical and mental stimulation, and desire to experience helpers high; Bennett et al., 2007). This is the first study, however, to establish a parsimonious set of five charity sport motives. In addition, the five charity sport motives yielded excellent validity and acceptable Cronbach's alphas coefficients of internal consistency for the selected items.

The current study not only confirms the primary motives of charity sport motivations established by previous researchers (e.g., Bennett et al., 2007; Filo et al., 2008; Snelgrove \& Wood, 2010), but also can be used as the basis for confirmatory factor analysis and scale development. As the popularity of charity sporting events continues to grow, it is important to expand the literature base and establish a valid and reliable scale for measurement. Results of the current study help in advancing the body of literature away from other disciplines (e.g., individual giving motivation, athletic giving, sport participation) and more toward the creation and expansion of a charity sport literature base. Previous researchers set the foundation for charity motivational research, yet results of the current study confirm the motivations.

Additionally, a valid and reliable charity sport motivation scale could aid future researchers in more accurately and consistently measuring participant motives. In order to move the literature base beyond that of research examining motivations of participation, a confirmed charity sport motivation scale is necessary. The establishment of a charity 
sport motivation scale could then provide the opportunity for future research to explore other elements associated within the charity sport environment.

Future intentions. Results of the current study provide evidence to the predictive value of the set of five charity sport motives on multiple future intentions. The set of motives (i.e., cause, philanthropy, social, health and fitness, and sport) significantly predicted future participation intention, future support of the organization, and participants' willingness to refer. Within the set of charity sport motives, cause, philanthropy, social, and health and fitness, were significant predictors of one or more future intentions. The importance of this finding is two-fold: first, it expands the literature base beyond participant motivations, and second, it provides additional confirmation of the charity sport motives as predictors of future intentions.

First, the current study is one of the few to examine outcome-based concepts (Filo et al., 2011) such as retention, future support, and positive word of mouth behaviors. The vast majority of research in the field of charity sport pertains to participant motivations (e.g., Bennett et al., 2007; Filo et al., 2008; Filo et al., 2009; Snelgrove \& Wood, 2010; Won \& Park, 2010). Fewer studies have examined retention among participants (Bennett et al., 2007; Filo et al., 2011) and none have examined other future intentions such as future support of the organization and participants' willingness to refer. In order to remain successful in a competitive charity sport environment, it is important for organizations to gain a better understanding of retention and other behavioral outcomes. Charity researchers note the lifetime value of donors and the cost effectiveness of building relationships with donors over time as opposed to spending resources recruiting 
new ones (Waters, 2011). Similarly, Hightower et al. (2002) found it costs an organization less money to retain a customer than it does to recruit a new one.

The current study expanded the charity sport literature base to include multiple outcomes. It is also important for charity sport managers to recognize the variation in the future intentions measured within the current study. While enhancing each of the future intentions may provide benefits to the charitable organization, managers should understand that individuals may have differing attitudes and opinions regarding the feasibility of each of the future intentions of retention, support, and recruitment. For some individuals it may be easier to register and train to participate in future events, however they would not feel comfortable reaching out to others to recruit them to participate. Other individuals may be intimidated by the time and fundraising commitments of future participation, while volunteering to support the organization or reaching out to their family and friends may be more reasonable. In an increasingly competitive charity sport environment with a growing number of alternatives for participation (RWRF, 2012), a greater knowledge of retention, future support of the organization, and word of mouth behaviors could aid in the success of organizations.

Second, in addition to the set of charity sport motives effectively predicting future intentions, the current study also identified the predictive nature of each charity sport motive. The charity sport motives of cause and health and fitness were predictive of all three future intention variables of future participation intention, future support of the organization, and participants' willingness to refer. Cause and health and fitness were the only two motives to predict all three future intention variables; however, the social charity sport motive was a significant predictor of future support of the organization and 
participants' willingness to refer. Philanthropy was also identified as a significant predictor of future support of the organization. The following section will further discuss the theoretical implications of these findings.

Charity sport motivations as predictors of future intentions. As previously mentioned, cause and health and fitness were significant predictors of all three future intention variables. This finding indicates those respondents motivated to participate in charity sport events for cause and health and fitness related reasons were more likely to participate again in the future, continue to support the organization, and recruit their family and friends to participate.

Cause. Specifically examining cause, previous researchers identified the variable as a motive for participation (e.g., Filo et al., 2008; 2009) and the purpose for planning charity sport events (Wharf Higgons \& Lauzon, 2003). Wharf Higgons and Lauzon (2003) identified cause as one of the primary purposes for hosting charity sporting events from an organizational perspective. The current findings support this purpose, and also show the importance participants place on supporting the cause. As defined in this study, cause represents an individual motivated to participate in an event to support the mission of a specific charitable organization. The finding that cause is a significant predictor of all three future intentions provides evidence of the dedication and future support in which those participants could provide to the charitable organizations. Additionally, there has been limited exploration of the charity sport motive of cause as a predictor of future intentions (Filo et al. 2009). Filo et al. (2009) identified cause as the symbolic meaning that an event assumes, and proposed cause as a point of attachment for participants. They theorized event attachment to influence positive behavioral intentions such as retention. 
The current study quantitatively confirms their theoretical hypothesis, in that those individuals motivated to participate in charity sporting events for cause-related reasons are also more likely to participate again in the future.

Health and fitness. In respect to the health and fitness motive, the same study by Filo et al. (2009) found those motivated to participate in charity sports for competency aspects (e.g., physical fitness, health and well being) were linked to event attachment (Filo et al., 2009). Similarly, the quantitative findings from the current study confirm this hypothesized attachment, and indicate those individuals motivated to participate in charity sporting events for health and fitness reasons were more likely to participate in future events, continue supporting the organization, and recruit others to support the organization as well. Additionally, in a non-charity setting, Funk et al. (2011) found strength and endurance, positive health, weight management, ill health avoidance, and health pressures--all which could loosely be interpreted as health and fitness motives--to positively influence running commitment and future exercise intention. On the contrary, Havenar and Lochbaum (2003) found those motivated by weight concerns were more likely to drop out of training programs. The current study confirms the findings of Funk et al. (2011) in that health and fitness motivations predict future intentions, and are contradictory of Havenar and Lochbaum's (2003) findings.

Similar to cause, additional attention should be paid to those individuals motivated to participate in charity sporting events for health and fitness reasons, since they are more likely to participate in the future, provide further support to the organization, and speak highly about their participation and recruit others to join. Many individuals looking to get in shape or lose weight may be attracted to charity sporting 
events for the less competitive atmosphere that they provide (Bennett et al., 2007). Charity sport organizations are known for assisting people in running their first marathon or completing their first triathlon. In addition, many charity sport organizations provide training assistance to help individuals achieve their goals (Bennett et al., 2007). This training could come in the form of training schedules and nutrition plans to organized group training sessions. The results of the current study not only place an emphasis on those motivated to participate for health and fitness reasons, but also show that these same participants are loyal in terms of their behavioral outcomes. Organizations should leverage this information and actively help participants set and achieve their health and fitness goals. By providing the necessary support, organizations may satisfy the needs of individuals and aid in facilitating long-term relationships with them.

Social. In regard to the social motive, results indicated those motivated to participate in charity sport events for social reasons were more likely to support the organization in the future and speak highly of their experience to others, potentially recruiting them to participate in future events. Results of the current study partially confirm previous research by Chalip (2006) which indicated that providing the opportunity for participants to socialize, become part of the community, and celebrate their accomplishments had the potential to increase identification levels and brand loyalty. Chalip (2006) also indicated that creating social opportunities for participants is an effective avenue to increase retention. The social charity sport motive was a significant predictor of future support of the organization, and participants' willingness to refer; however, it did not significantly influence retention. 
The finding that the social motive was a significant predictor of future support of the organization and participants' willingness to refer, and not future participation intention, is not particularly surprising. Charity sporting events tend to attract an overall "less athletic" group of individuals than non-charity related events (Bennett et al., 2007). In addition, many charity sport participants are motivated for social reasons (e.g., Filo et al., 2009; 2010; Won et al., 2011). The results of this study further indicate that while participants may be motivated to run, walk, or ride in one particular charity sporting event, their overall motivations may be more closely aligned with the social aspects than the sport itself. In this case, they would be more than willing to positively speak about their experience to others and could still fulfill their social needs by volunteering with the organization in the future, but do not find it necessary to participate in future athletic events. From an organizational perspective, this finding provides valuable information about future intentions of participants. Therefore, organizations looking to expand their donor and volunteer network, as well as recruit more participants to future events, may target those motivated by social reasons. Conversely, charitable organizations with the goal of retaining participants may find more success targeting individuals motivated by cause and health and fitness reasons.

Philanthropy. In addition, the results indicated philanthropy as a significant predictor of future support of the organizations. Therefore, individuals may not want to participate in any other events, or even feel comfortable encouraging others to participate, yet they still feel the intrinsic need to support the organization in the future. In an individual giving context, researchers urged non-profit organizations to leverage the donor's intrinsic need to help others in order to build long lasting relationships with 
donors (Guy \& Patton, 1989; King, 2001). The results of this study confirm that finding, reiterating the fact that those individuals motivated for philanthropic reasons were more likely to support the organization in the future. In this study, philanthropy was characterized as the general altruistic nature of individuals. Those motivated for philanthropic reasons want to make the world a better place, or improve the community they live in. The finding that those motivated for philanthropic reasons were more likely to support the organization again in the future is somewhat surprising since those individuals do not have a direct affiliation with the cause. Therefore, in order to satisfy their philanthropic needs they could participate or volunteer with any number of charitable organizations. Results of this study, however, indicate they are more likely to continue supporting the same organization in the future.

Sport. The charity sport motive of sport was not a significant predictor of future intentions--an important finding for organizations. In the context of this study, sport represented individuals' motivation by the physical activity itself. Sport was identified as a primary motive of participation by various researchers (e.g., Bennett et al., 2007; Snelgrove \& Wood, 2010) This study does not disconfirm that finding; however, it indicates that although some participants may be drawn to participate in the charity sport event for the sport itself, there is no relationship between those individuals motivated by sport-related reasons and future intentions. Therefore some participants may show behavioral loyalty, however sport was not a predictor of individuals decisions to participate again in the future, support the organization going forward, or refer others to the charity sport event. This finding indicates that charity sporting events have an enhanced meaning beyond that of the sport itself, and charity sport managers should be 
cognizant of this if they want to enhance future intentions among participants. The goal of most charity sport events is to raise awareness and funds for a cause (Wharf Higgons \& Lauzon, 2003), thus organizers may want to focus their marketing and communication efforts toward participants motivated by cause, philanthropy, social, and health and fitness-related reasons.

Overall, the current study provided a set of charity sport motives that were significantly predictive of future intentions. Marketers and managers should target those individuals motivated by cause, health and fitness, philanthropy, and social-related reasons as having the greatest retention, future support, and positive word of mouth behaviors. In a competitive charity sport environment, it is crucial for managers to leverage these motives to enhance future outcomes and remain successful (Filo et al., 2010).

\section{Social Media}

Major implications from this study include identification of motivational constructs for social media consumption, the establishment of social media typologies, and the creation of a working definition of social media.

Consumption motivations. The current study identified five major social media consumption motivations within a charity sport context: community, information, pass time, social interaction, and entertainment. These findings had three theoretical implications: they (1) confirm the validity and reliability of the social media consumption motivations, (2) identify motivations based on an integrated concept of social media, and (3) provide charity sport organizations with specific social media consumption motivations. 
First, each of these motives were similar to those identified by previous researchers and confirm the social media consumption motivations of community (Anderson, 2011; Chen, 2011; Lampe et al., 2010; Sanderson, 2010; Shao, 2009), information (Bonds-Raacke \& Raacke, 2010; Hanson \& Haridakis, 2008; Johnson \& Yang, 2010; Lampe et al., 2010; Park et al., 2009; Shao, 2009), pass time (Dunne, et al., 2010; Haridakis \& Hanson, 2009), social interaction (Bonds-Raacke \& Raacke, 2010; Clavio \& Kian, 2010; Dunne et al., 2010; Shao, 2009), and entertainment (Haridakis \& Hanson, 2009; Lampe et al., 2010; Park et al., 2009; Shao, 2009) previously set forth in the literature. The results of the current study confirm the motivations to use social media similar to prior research. This confirmation yields evidence of common motivations and the potential for defined constructs that could be used in other contexts in the future.

Previous literature identified a diverse set of constructs; however, the current study created a clear and concise set of social media consumption motivations. Prior research on social media consumption motivation identified additional motives such as information sharing (e.g., Johnson \& Yang, 2010; Lampe et al., 2010; Shao, 2009), information seeking (e.g., Hanson \& Haridakis, 2008; Johnson \& Yang, 2010; Lampe, et al., 2010; Shao, 2009), friendship (e.g., Bonds-Raacke \& Raacke, 2010; Raacke \& Bonds-Raacke, 2008), and social support (Anderson, 2011; Lampe et al., 2010; Sanderson, 2010). While these motivations did not emerge as primary social media consumption motives in the current study, aspects of the motivations may be represented within the underlying constructs identified in this study. For instance, both information seeking and information sharing identified by previous researchers (e.g., Johnson \& Yang, 2010; Hanson \& Haridakis, 2008; Shao, 2009) were identified as overarching 
social media consumption motivation of information. Although information seeking and information sharing behaviors were previously identified as distinct concepts and differing motives of consumption, results of the current study did not identify differences. Additionally, individuals may perceive elements of friendship within the more comprehensive motivations of community or social interaction identified in the current study. So while there is not a distinct motivation of individuals to use social media for friendship purposes, the community or social interaction motivations may fulfill some of the friendship needs identified by individuals in previous research (e.g., Bonds-Raacke \& Raacke, 2010; Raacke \& Bonds-Raacke, 2008). The same could be said for social support. Previous researchers identified it as a motivation of consumption (Anderson, 2011; Lampe et al., 2010; Sanderson, 2010); however, the community and social interaction motives identified in the current study may fulfill those needs of individuals. These results aid in extending the literature by creating a more comprehensive set of social media consumption motivations. They extend prior research and could be used as the first analysis in the scale validation process. Stevens (2009) recommends researchers to fully explore constructs prior to validating items and a scale using confirmatory factor analysis. As social media prominence continues, it is important for researchers to move beyond exploratory research and establish a valid and reliable scale so that researchers could attain consistent and accurate results.

Second, this is one of the first studies to examine social media as an integrated concept. Previous researchers identified motivation for usage of specific social media platforms such as Twitter (e.g., Chen, 2011; Johnson \& Yang, 2009), Facebook (e.g., Bonds-Raacke \& Raacke, 2010; Raacke \& Bonds-Raacke, 2008), and YouTube 
(Haridakis \& Hanson, 2009); however, few examined social media as an integrated concept (Hanna, Rohm, \& Crittenden, 2011). Researchers and practitioners have embraced social media as a hybrid element to the promotional mix (Mangold \& Faulds, 2009) and a crucial aspect of integrated marketing communication strategies (Lucenko, 2012). As social media platforms become more prevalent and are more often included in marketing and communications plans, it is important for organizations to understand why individuals are motivated to consume social media across various platforms, as opposed to analyzing motivations for one platform. Hanna et al. (2011) conceptualized this concept as the social media ecosystem, and confirmed the necessity of organizations to understand the interconnectedness of social media platforms.

In addition, social media platforms emerge and evolve over time. For example, Facebook was originally developed as a social platform, encouraging users to connect and "friend" each other. Since its inception in 2006, however, the features Facebook offered continued to evolve, adding the "wall"--a space where users can interact with each other on their profile page, the "newsfeed"--a list of status updates and current happenings among users, groups, events, chat, and now photo and video uploading features (Fach, 2011). Additionally, as social media platforms begin to integrate more comprehensive features into their sites (King, 2013), and organizations continue to use integrated marketing communication strategies to leverage their message across multiple platforms (Porterfield, 2012), it is essential to understand the motivations for social media consumption as opposed to platform-specific motivations. This study is one of the first to identify social media consumption motivations as opposed to platform-specific motivations. 
Third, the current study is the first to examine the social media behaviors specific to charity sport participants. The current study provides evidence to the primary social media usage motivations of charity sport participants. While there has been research identifying motivations of sport fans (Clavio \& Kian, 2010), there is limited audiencebased research examining sport participants. To date, this study is the first of its kind to establish social media consumption motivations of charity sport participants. The results provide charity sport organizations with further details about the social media consumption motivations of their participants and alumni. Findings indicate that charity sport participants are primarily motivated to use social media to be a part of a virtual community, gather and share information, pass the time and escape from their daily lives, interact with others, and be entertained. It is also important for individual organizations to understand the consumption motivations of their users to effectively create integrated marketing communication strategies to meet the social media needs of users and potentially enhance loyalty to the organization. A greater knowledge of social media behaviors could assist sport managers to engage their audience, facilitate interaction, and build lasting relationships with their donors.

Also, the set of social media consumption motivations were significant predictors of future intentions. The previously identified set of social media constructs (i.e., community, information, pass time, social interaction, and entertainment) were not only indicative of participant motivations, they also predicted future participation intention, future support of the organization, and participants' willingness to refer. More specifically, pass time was a negative predictor of future support of the organization and social interaction was a significant predictor of participants' willingness to refer. 
Typologies. Another major contribution from the results of this study is the development of social media typologies. The results yielded four distinct typologies of users based on social media consumption motivations and social media intensity of usage--avid, purposive, leisurely, and minimalist users.

\begin{tabular}{|c|c|}
\hline $\begin{array}{l}\text { Avid } \\
\text { Users }\end{array}$ & $\begin{array}{l}\text { High intensity users highly motivated by all social media } \\
\text { consumption variables }\end{array}$ \\
\hline $\begin{array}{l}\text { Purposive } \\
\text { Users }\end{array}$ & $\begin{array}{l}\text { High intensity users primarily motivated by social interaction and } \\
\text { information }\end{array}$ \\
\hline $\begin{array}{l}\text { Leisurely } \\
\text { Users }\end{array}$ & $\begin{array}{c}\text { Moderate intensity users primarily motivated by social interaction, } \\
\text { to pass the time, and entertainment }\end{array}$ \\
\hline $\begin{array}{l}\text { Minimalist } \\
\text { Users }\end{array}$ & $\begin{array}{l}\text { Low intensity users and the least motivated by all social media } \\
\text { consumption variables }\end{array}$ \\
\hline
\end{tabular}

Figure 1. Social Media Typologies. This figure illustrates the differences in social media intensity of usage a consumption motivations for each typology.

Figure 1 shows a representation of the distinct typologies of social media users based on the social media intensity of usage and social media consumption motivations. Avid users are characterized as high intensity social media users with high levels of motivation across each of the consumption variable. Purposive users were also high intensity users; however, members of this typology were primarily motivated to use social media for social interaction and informational purposes. Leisurely users exhibited a moderate level of social media intensity of usage with primary motivations of social interaction, entertainment, and to pass the time. Minimalist users had low social media intensity of usage and relatively low social media consumption motivation scores. Another important point to note is the relatively high level of social interaction cited by all participants, regardless of typology. While motivations varied across typologies, 
social interaction was the primary motive for each of the typologies. It is important for organizations to understand the motivations of users and embrace an interactive online culture to satisfy the needs of users.

The current study expanded the literature base by creating social media typologies in a charity sport context. Many researchers have identified motivations for social media consumption (e.g., Anderson, 2011; Bonds-Raacke \& Raacke, 2010; Chen, 2011; Johnson \& Yang, 2009; Raacke \& Bonds-Raacke, 2008), which answer the question of why individuals use social media. Other researchers explored the duration and frequency (Zuniga et al., 2012) to which individuals use social media platforms. In addition, some researchers even expanded the literature base to include attitudinal measure to duration and frequency, and explore social media intensity of usage (e.g., Ellison et al., 2007; Valenzuela et al., 2009). This study combined all of the previous elements to form typologies and gain a better understanding of individual's social media habits.

Developing typologies of consumers is commonly used in marketing research (Punj \& Stewart, 2007; Ross, 2007); yet there is a limited research addressing social media typologies (Brandtzaeg, 2010) and a complete lack of research in a sport or charity sport context. The creation of social media typologies provides charity sport organizations with a more holistic view of their users and can be used to distinctly segment their consumer base in regard to social media behaviors. This information will help organizations to understand who uses social media, why they use it, and how often. By creating social media typologies, organizations are provided greater insights about their users and can more effectively craft messages to meet the needs of their target audience. In addition, much of the social media user typology research is conceptually 
based (Brandtzaeg, 2010). The current study looked to expand the current literature base and develop typologies based on quantitative data.

The current study also examined charity sport motives and future intentions for each of the typologies. The results indicated significant differences in charity sport motivations of cause, philanthropy, health and fitness, and social motives across social media typologies. There were no significant differences, however, in relation to sport. Figure 2 provides a graphic representation of differences in mean scores across typologies. While there were statistically significant differences between clusters based on charity sport motives, the actual mean score differences were slight.

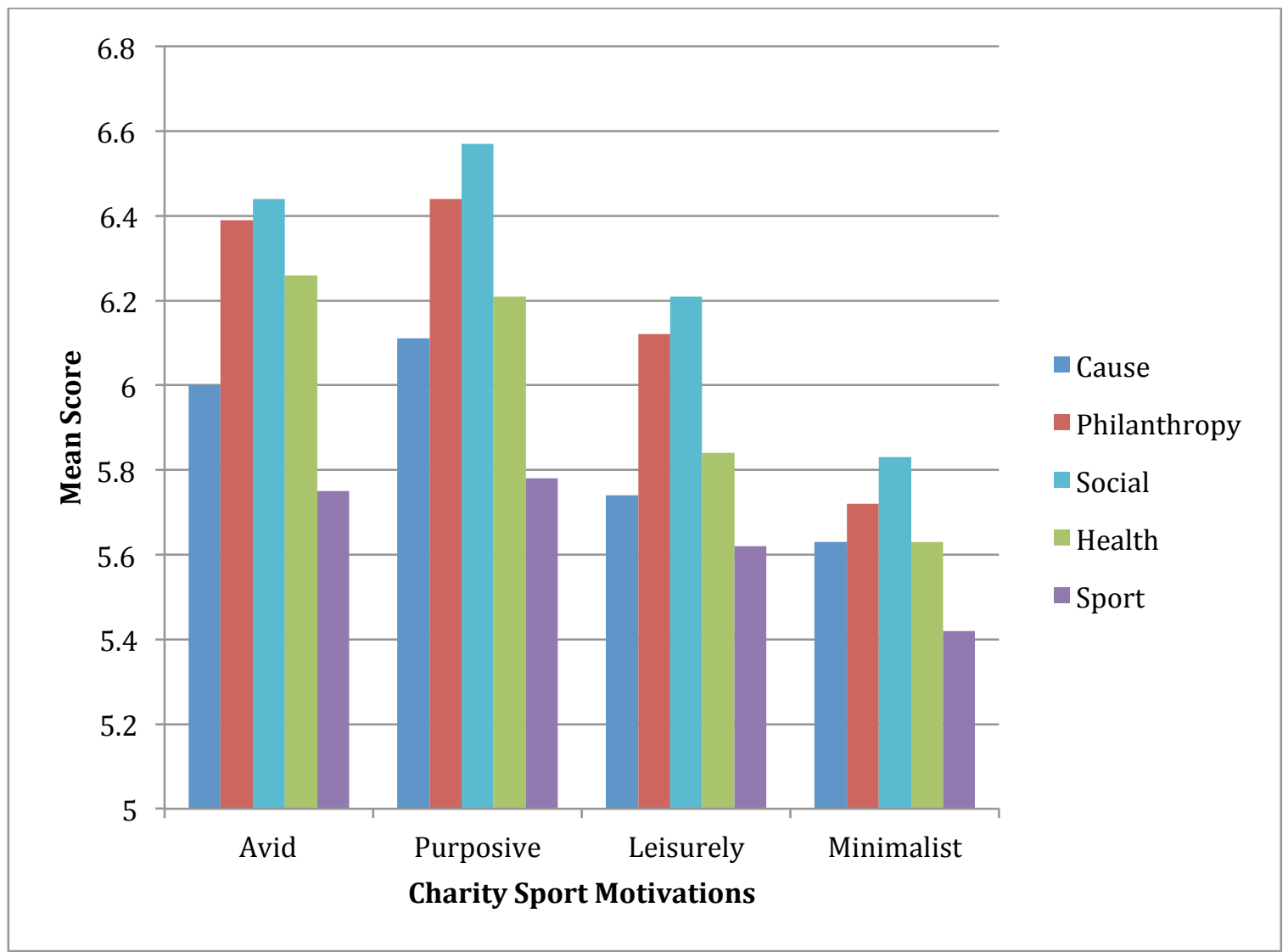

Figure 2. Charity sport motivations of social media typologies. This figure illustrates the mean scores of charity sport motivations for each social media typology. 
More importantly, there were significant differences in charity sport motives as predictors of future intentions for each typology. Figure 3 graphically shows the charity sport motivations that strongly predicted the future intentions for each of the social media typologies. For avid users, health and fitness predicted future participation, cause predicted future support of the organization, and social predicted participants' willingness to refer. Within the purposive user typology, cause and health and fitness predicted both future participation intention and future support of the organization. Health and fitness was also a strong predictor of participants' willingness to refer. In the leisurely user typology, philanthropy future participation intention and future support of the organization, whereas cause and health and fitness predicted participants' willingness to refer. In the minimalist user typology, cause predicted future support of the organization.

Table 16 Charity Sport Motive Predictors of Future Intentions for each Typology

\begin{tabular}{llll}
\hline Typologies & Charity Sport Motives & & Future Intentions \\
\hline Avid Users & & & \\
& Health and Fitness & $\rightarrow$ & Future Participation Intention \\
& Cause & $\rightarrow$ & Future Support of the Organization \\
& Social & $\rightarrow$ & Participants' Willingness to Refer \\
\hline Purposive Users & & & \\
& Cause & $\rightarrow$ & Future Participation Intention \\
& Health and Fitness & $\rightarrow$ & Future Participation Intention \\
& Cause & $\rightarrow$ & Future Support of the Organization \\
& Health and Fitness & $\rightarrow$ & Future Support of the Organization \\
& Health and Fitness & $\rightarrow$ & Participants' Willingness to Refer \\
\hline Leisurely Users & & & \\
& $\begin{array}{l}\text { Philanthropy } \\
\text { Philanthropy }\end{array}$ & $\rightarrow$ & Future Participation Intention \\
& Cause & $\rightarrow$ & Future Support of the Organization \\
& Health and Fitness & $\rightarrow$ & Participants' Willingness to Refer \\
& & & \\
\hline Minimalist Users & & $\rightarrow$ & Future Participation Intention \\
\hline
\end{tabular}


As previously discussed, the development of social media typologies provides organizations with greater knowledge about the intensity and consumption habits of users. Further examination of charity sport motives and their influence on future intentions creates an even more complete view of the user. Results of this study provide charitable organizations with information about online and offline behaviors. The findings yield a comprehensive examination of charity sport participants. This information could provide vital information to sport managers in creating effective marketing and communication strategies to meet the needs of consumers. Sport managers could segment the market based on social media typologies and target specific motives of charity sport participants within a particular typology in order to enhance future intentions and achieve organizational goals.

Definition. Another major contribution of this study was the creation of a working definition of social media for charitable organizations. The definition created for the current study was online communities built through communication platforms, whereby individuals collectively create, share, and improve information and user generated content while interacting with others (Blackshaw \& Nazzaro, 2004; Mangold \& Faulds, 2009; Williams \& Chin, 2010). The definition aimed to highlight the sense of community as well as the interactions that are enabled by social media platforms. In an ever-changing social media environment, the previous definition provides a starting point for charity sport organizations. It is important for organizations to first understand what social media is, prior to successfully implementing a social media strategy. Considering the definition of social media is theorized differently across various contexts (e.g., Blackshaw \& Nazzaro, 2004; Williams \& Chin, 2010), the working definition provides 
charity sport organizations with a purpose and conceptualization of social media in their industry. This definition emphasizing community and interaction should be implemented in a charity sport context and some of the elements could also translate to the larger nonprofit context as well.

The findings from the current study provide further evidence for the inclusion of these elements in the definition. Both community and social interaction were primary motivations of individuals to use social media platforms. Social media platforms not only provide the tools for individuals to connect online, but to be a part of a community and to feel a sense of belonging as one person connected to many. From a charity sport context, the online communities facilitating interaction could also assist individuals in meeting their charity sport needs and potentially increasing future intentions. Results of the current study yielded evidence that those motivated to participate in charity sport events for cause, philanthropic, social, and health and fitness reasons were more likely to participate in future events, support the organization in the future, and refer their family and friends. Charitable organizations should leverage social media to enhance those motives and influence future intentions.

Through social media, charity sport organizations have the opportunity to raise awareness about the cause, and the need of individuals to participate and donate to support the organization. Creating online communities for present and past participants to interact and socialize enables individuals to share stories, experiences, triumphs, tribulations, and potentially increase their attachment to the organization by bonding with other participants and feeling like they are a part of the community. Organizations could use social media as an interactive way to provide information about the health and fitness 
benefits of participation. In sum, social media platforms are a great way for charitable organizations to build a sense of community, facilitate relationships, and positively influence social change.

\section{Practical Implications}

In an increasingly competitive charity sport environment, the use of social media could be an effective avenue to enhance future intentions of participants (Filo et al., 2010). The following section will discuss practical implications of social media in a charity sport context from a managerial, marketing, and communications perspective.

\section{Managerial}

The consensus among researchers and practitioners is for organizations to (1) embrace social media (e.g., Bernoff \& Li, 2008; Blackshaw \& Nazzaro, 2004, Kaplan \& Haenlein, 2010), (2) engage users (e.g., Kaplan \& Haenlein, 2010; King, 2013; Williams \& Chin, 2010), and (3) facilitate action through offline behaviors (Valenzuela et al., 2009). Each of these aspects will be discussed in relation to the results of this study and the incorporation of social media by charity sport organizations.

Embrace social media. First, the current study of charity sport participants confirmed the enormity of social media use with $99 \%(n=274)$ of respondents indicating they use at least one social media platform. This finding shows the importance of charitable organizations to embrace social media in order to communicate and connect with their participants and donors. Charitable organizations use sporting events to raise awareness about their cause (Wharf Higgons \& Lauzon, 2003). Creating a social media presence could assist charitable organizations in raising awareness about the cause as well as promote the charity sporting event, recruit new participants, and foster 
relationships with participants and alumni. Many organizations recognize the scope of social media, yet have been hesitant to embrace the platforms due to the lack of control over information dissemination (Bernoff \& Li, 2008; Kaplan \& Haenlein, 2010; Mangold $\&$ Faulds, 2009). The results of the current study reemphasize the adoption of social media regardless of the control organizations may have over the information provided through the two-way communication platforms.

Engage users. Second, the current study conducted audience-based research to understand the demographics and psychographics of charity sport participants' social media usage and its effect on future intentions. Findings of the current study revealed similarities in charity sport participation motives and social media consumption motivations, where social, interactive, and community elements existed in both realms. Due to the overlap in motivations, organizations could leverage a virtual community where participants could interact and socialize online. This would not only assist organizations in meeting the needs of participants, but could also enhance future intentions of participants.

In order for organizations to engage users, they must first understand who their users are and why they are motivated to use social media. In a sport context, the majority of previous research conducted on social media has been content-based (e.g., Hambrick et al., 2010; Kassing \& Sanderson, 2010) with fewer studies examining the motivations of users (e.g., Clavio \& Kian, 2010). This is the first study to examine motivations of users in a participant context, whereas previous researchers primarily focused on the motivations of social media usage in relation to fandom and spectator behaviors (Clavio \& Kian, 2010). 
Based on the findings, the social media consumption motivation of social interaction was a significant predictor of participants' willingness to refer, while the social charity sport motive was a significant predictor of future support of the organization and participants' willingness to refer. To enhance the future intentions of charity sport participants, organizations could highlight the social aspects and support systems available through the online community. Charitable organizations could create an interactive space (e.g., forum, Facebook group) where the organization, participants and alumni could interact and provide insights about proper exercise and nutrition throughout their training programs, creative ways to raise money, or reemphasize the importance of their participation to the cause.

Facilitate action through offline behaviors. Extending the practical applications of this study, the third major implication of the results is the ability of charity sport organizations to interpret the findings to facilitate action. While the study provides evidence to the differences between typologies of social media users, the primary purpose was to understand how organizations could use that information in order to facilitate offline behaviors. The results provide charitable organizations with a road map to connect with their participants and donors online with the goal of encouraging them to take action offline. These offline actions could include participating in other charity sport programs, volunteering at other charity events, or helping to raise awareness and recruit new participants in their own community.

Embracing social media usage at the organizational level and further encouraging individual participants to interact with the organization and each other online could provide additional opportunities for offline socialization (Valenzuela et al., 2009). In 
essence, the online space provides a discussion forum for offline behaviors. Previous researchers identified the ability of social media to encourage offline behaviors and foster social change (Briones et al., 2011; Lovejoy et al., 2012; Valenzuela et al., 2009). Charity sport organizations have the ability to create an online presence, meet their own goals and objectives, and encourage social change through social media.

In the current study cause and health and fitness were significant predictors of retention, future support of the organization, and participants' willingness to refer. In addition, community and social interaction were also two of the primary motives for social media consumption by charity sport participants. By strategically leveraging these aspects on social media platforms, organizations could meet the needs of their audience and further enhance future intentions. Through organization facilitation, the participants could interact and build a community with the common goals of raising money for a cause and achieving their health and fitness goals. For instance, many charity sport organizations host one training event each week; however, through social media interaction participants may coordinate with each other and conduct smaller group training sessions independently. This would aid in satisfying the health and fitness as well as the social needs of participants through the online community, all with the intentions of further supporting the cause.

\section{Marketing and Communication}

From a marketing perspective, the current study is one of very few studies (Filo et al., 2010) to examine future intentions of charity sport participants. Outcome based research helps sport managers develop specific marketing strategies based on retention factors. In the current study, cause and health and fitness were significantly predictive of 
future event participation, future support of the organization, and participants'

willingness to refer. The social motive was significantly predictive of future support of the organization, and participants' willingness to refer, and the philanthropic motive was predictive of future support of the organization. Research provides evidence that it costs more to recruit a new customer (or, in this case, participant) than it does to retain an existing one (Hightower et al., 2002).

By utilizing the results of this study, organizations can focus on targeting participants with specific motives that were predictive of retention, future support, and word of mouth behaviors. For example, if the organization wanted to focus on retention of participants, they should create marketing strategies to recruit participants that are motivated for cause and health and fitness reasons, considering those participants are more likely to participate again in the future. If the main goal of the organization is to increase volunteer and monetary support of the organization in the future, they could craft marketing campaigns to attract individuals motivated for cause, health and fitness, social, and philanthropic reasons. In addition, for those organizations looking to increase their participation numbers by recruiting new participants, marketers would be wise to focus on developing marketing campaigns around the motivational aspects of cause, health and fitness, and social. Those individuals tend to be more motivated to refer others to the charity sport programs in the future and could be leveraged as valuable assets in their word-of-mouth behaviors.

Marketers could also create strategies to foster each of these behaviors. This study's results yielded those motivated for cause and health and fitness reasons were most predictive of all future intentions. Celebration of the cause in a social setting following 
the completion of a health and fitness goal (i.e., the charity sport event) could satisfy the various motivational needs of participants while also enhancing future outcomes. Chalip (2006) discussed the influence of community and social aspects at sporting events on behavioral loyalty. Peloza and Hassay (2007) further recognized the importance of celebration and social events to engage the uninvolved supporter (e.g., spectator, community member) in charity events. Typically, the goal of charity sporting events is to raise awareness about a cause and raise funds (Wharf Higgons \& Lauzon, 2003). Event planners and sport marketers could highlight these aspects to satisfy the needs of existing participants yet also recruit new participants. By increasing the social elements in the charity sport environment, those motivated for social reasons would be more likely to support the organization and refer others in the future. An atmosphere of collective action and socialization could also aid in involving spectators with the celebration of the cause and potentially recruit new participants.

Additionally, the researcher identified four social media typologies (i.e., avid, purposive, leisurely, and minimalist users) with varying intensities of social media usage and consumption motivations. These social media typologies provide an extensive amount of information to marketing and communication managers and could be used as the basis for marketing tactics. Marketers could use social media typologies to segment the market and create target markets. From a communication perspective, that same information could be used to create the content and distribution methods of content. Charitable organizations could specifically craft messages to effectively target markets based on their social media typology as well as their motivations to participate in charity sport events. 
Avid users were characterized as high intensity users with high levels of all social media consumption motivations. In addition, within this typology, health and fitness was the strongest predictor of future participation, while cause was most predictive of future support of the organization, and social in predicting participants' willingness to refer. Considering avid users had the highest intensity of usage, marketers could use a grassroots marketing technique and specifically target these participants to help them spread the message about the cause. Since the social charity sport motive was a significant predictor of participants' willingness to refer, charity sport organizers could create a campaign encouraging participants and alumni to reach out to their social networks in order to recruit new participants. Online communications should emphasize the need to support the cause, and that individual's participation in the campaign would help the organization remain successful and facilitate social good. To highlight these elements, organizations could create a promotional contest encouraging participants and alumni to recruit their family and friends to participate in the charitable sporting event. The organization could leverage the social and interactive aspects of the contest by tracking the number of participants each individual successfully recruits and rewarding their efforts with prizes, while also highlighting the impact that their efforts will have in assisting the charitable organization with their mission.

Purposive users were high intensity users motivated for social interaction and information purposes. Within that typology cause was a significant predictor of participant retention and future support of the organization. Marketers could target purposive users by creating an online marketing campaign around the need for charitable giving and information about the importance of their individual giving and participation 
to the cause. Specific messages could be tailored to provide information about the amount of funds raised and the impact that they had on society. Additional messages could facilitate interaction among participants, for example, hosting an interactive discussion about unique fundraising techniques. This strategy would highlight the cause and also provide interaction between participants as well as valuable information about fundraising. Health and fitness was also a significant predictor for all future intentions within the purposive user typology. To enhance this motive, the charitable organization could create a training forum for participants and alumni to share training information and interact with one another. The organization could also create a platform for potential participants to interact with the charity sport community and ask questions before they decide to commit to participating in the event. The training forum would aid charitable organizations in leveraging the health and fitness aspects of participation through social interaction in a virtual community.

On the other hand, leisurely users were moderate intensity users primarily motivated for social interaction, to pass the time, and entertainment purposes. Additionally, philanthropy was a predictor of both future participation intention, and future support of the organization, while cause and health and fitness motives were significant predictors of participants' willingness to refer. Marketing campaigns targeted toward leisurely users should incorporate a lighter-hearted sentiment. Leisurely users are looking to interact with other users but they are also using social media to escape from their daily lives and be entertained. Also, considering philanthropy was a predictor of future participation intention and future support of the organization, communications should be geared toward the altruistic aspects of individuals' participation. Marketing 
campaigns could highlight the emotional aspects of giving back to society, and how the actions of each person can truly make the world a better place. Content for communications to leisurely users could include inspirational videos about the cause, a slideshow of pictures of previous events and training sessions highlighting the health and fitness benefits of participation, or contests and games to engage participants. For example, organizations could create a contest for participants to upload videos about their stories and inspiration for participation in the event. To encourage interaction among the charity sport community, the organization could have other participants and alumni vote for their favorites and award the winners with discounted race entries or merchandise.

Minimalist users had the lowest social media intensity of usage scores and were characterized as having relatively low social media consumption motivations. In addition, minimalist users had the lowest mean scores of all charity sport motives. There were no significant predictors, however cause was a strong predictor of future participation intention. Considering the low intensity of usage, marketers should avoid targeting this group through social media platforms. Participants of this group could be better reached through more traditional communication platforms. Additionally, since minimalist users had the lowest charity sport motivations and only one predictor of future intentions, marketers should not spend as much time or money targeting this group.

By incorporating social media as a part of the integrated marketing communications strategy, organizations can effectively increase their reach in a costeffective manner. Charity sport managers should, however, consider the method of communication when distributing information to various typologies. For instance, avid, purposive, and leisurely users had moderate to high social media intensity of usage; 
therefore, marketing through social media platforms would be an effective method. Minimalist users, on the other hand, were classified as low intensity users. In this case, marketers should primarily use traditional communication methods (e.g., newsletters, meetings, direct mailings) to reach those participants.

Social media can increase two-way communication (Kassing \& Sanderson, 2010), or the interaction between the organization and participants as well as participants with each other. As evidenced by the findings of community and social interaction as social media consumption motivations in this study, individuals desire to have the opportunity for two-way communication. Charitable organizations should take advantage of this opportunity to listen to the wants and needs of participants. Social media provides an excellent way for organizations to get feedback and advice from participants in improving programs in the future.

\section{Future Research}

In addition, the current study analyzed the influence of social media on future intentions of charity sport participants through quantitative analysis. Qualitative analysis may provide additional insights into not only participants' motivations to use social media platforms, but what they look for in content from an organization. Social media platforms are an excellent way for organizations to build relationships with their stakeholders; however, it is important to know what content, features, applications satisfy the needs of consumers and would potentially influence future intentions. While the quantitative analysis scraped the surface of those insights, qualitative analysis may be beneficial to explore the concept further. 
Future research could also examine the concept of a virtual community. Community and social interaction were two of the major motivations for social media consumption. Additionally, the charity sport motive of social was also a significant predictor of future intentions. Leveraging these motives by building a virtual community may enhance participants' satisfaction and increase future intentions. Previous research examined how online behaviors can be translated into offline behaviors and building social capital in a political context (Valenzuela et al., 2009). A similar notion could be applied to the charity sport setting with participants building social capital within a community and working together for social change. Using the current study as the basis, future research could examine the influence and potentially moderating effect of a virtual community on participants' future intentions.

Furthering the findings of the current study, the researchers could expand the development of the social media typologies. For instance, adding additional demographic variables such as age, gender, and ethnicity to the current analysis may provide marketers with a more holistic view of their consumer. Additional information about social media consumption habits such as the primary usage for specific social media platforms could also aid in providing sport managers with insights to their users. In addition, with the prevalence of smartphones, researchers have noted an increase in picture and video uploads to social media platforms. Greater knowledge of video and picture content viewing and uploading could assist researchers in better understanding their audience.

The results of the current study laid the foundation for future scale development research in both charity sport and social media. First, in charity sport, the five social media motives (i.e., cause, philanthropy, health and fitness, and sport) were not only 
predictive of future intention but also accounted for a significant portion of the variance in the variables. Additionally, the scale items yielded acceptable Cronbach's alpha levels indicating consistency of the items. Future research could use confirmatory factor analysis to confirm the psychometric properties of the scale. Similarly, in terms of social media consumption motivations, the current study identified five major social media consumption motivations--community, information, pass time, social interaction, and entertainment. Future research could use confirmatory factor analysis to confirm the scales reliability, construct validity, and predictive validity. Previous research, including this study, used exploratory factor analysis to better understand social media consumption motivations. However, confirmatory factor analysis and establishment of a social media scale is essential to expand the literature base and move the field further. Both fields of research could benefit greatly from the consistency in results a valid and reliable instrument would provide.

\section{Summary of Study}

The current study examined the influence of social media on the future intentions of charity sport participants. Survey data were collected from an international sample of Team in Training participants and alumni. Various quantitative analyses (e.g., multiple regression, multivariate analysis of variance, cluster analysis) were used to gain a better understanding of the social media usage of charity sport participants and the relation to charity sport motivations and future intentions.

Results yielded a significant influence of five charity sport motives (i.e., cause, philanthropy, social, health and fitness, and sport) on future intentions (i.e., future participation intention, future support of the organization, and participants' willingness to 
refer). Specifically, four charity sport motives (i.e., cause, philanthropy, social, and health and fitness) were predictive of future intentions. Five primary motivations for social media consumption in a charity sport context were identified (i.e., community, information, social interaction, pass time, and entertainment), and four distinct typologies (i.e., avid, purposive, leisurely, and minimalist users) were created based on social media consumption motives and social media intensity of usage. Further analysis revealed differences in social media typologies based on charity sport motivations and their impact on future intentions.

Overall, the results of this study confirm the primary motivations of charity sport participation as well as provide an established set of social media consumption motivations. Additionally, the creation of social media typologies provides organizations with a more holistic view of the social media consumption habits of their users as well as differences in charity sport motives and future intentions for each typology. Results demonstrate the need for sport managers to embrace social media within a charity sport context in order to better communicate with participants and build lasting relationships. In addition, results yield the need for marketing and communication managers to understand the differences in social media users when creating strategies to more effectively meet their needs. 


\section{REFERENCES}

Adler, J. (2012) Companies leverage giving with social media. Chicago Business. Retrieved from http:/www.chicagobusiness.com/giving-guide/leverage-givingsocial-media.html

Allender, S., Cowburn, G., Foster, C. (2006). Understanding participation in sport and physical activity among children and adults: A review of qualitative studies. Health Education Research, 21, 827-835.

Anderson, I. K. (2011). The uses and gratifications of online care pages: A study of CaringBridge. Health Communication, 26, 546-599.

Ary, D., Jacobs, L. C., Sorensen, \& C. Razavieh, A. (2010). Introduction to research in education ( $8^{\text {th }}$ ed.). Belmont, CA: Wadsworth Cengage Learning.

Bennett, R. (2006). Predicting the lifetime durations of donors to charities. Journal of Nonprofit \& Public Sector Marketing, 15, 45-67.

Bennett, R., Mousley, W., Kitchin, P., \& Ali-Choudhury, R. (2007). Motivations for participating in charity-affiliated sporting events. Journal of Customer Behavior, $6,155-178$. 
Berger, J. \& Milkman, K. L. (2011). Social transmission, emotion, and the virality of content. Unpublished manuscript, Wharton School, University of Pennsylvania, Philadelphia, PA.

Bernoff, J., \& Li, C. (2008). Harnessing the power of the oh-so-social web. MIT Sloan Management Review, 49 (3) 35-42.

Blackshaw, P., \& Nazzaro, M. (2004). Consumer-generated media (CGM) 101: Word-ofmouth in the age of the web- fortified consumer. [White paper]. Retrieved from http://www.nielsen-online.com/downloads/us/buzz/nbzm_wp_CGM101.pdf

Bissram, V. (2012, August 24). Ptch captures your life in video the way Instagram captures it in photos. Mashable. Retrieved from http://mashable.com/2012/08/24/ptch/

Bonds-Raacke, J., \& Raacke, J. (2010). MySpace and Facebook: Identifying dimensions of uses and gratifications for friend networking sites. Individual Differences Research, 8, 27-33.

Bosomworth, D. (2012, May 9). Statistics on mobile usage and adoption to inform your mobile marketing strategy. Retrieved from http://www.smartinsights.com/mobilemarketing/mobile-marketing-analytics/mobile-marketing-statistics/

boyd, d. m., \& Ellison, N. B. (2008). Social network sites: Definition, history, and scholarship. Journal of Computer Mediated Communication, 13, 210-230.

Brandtzaeg, P. B. (2010). Toward a unified Media-User Typology: A meta-analysis and review of the research literature on media-user typologies. Computers in Human Behavior, 26, 940-956. 
Briones, R. L., Kuch, B., Liu, B. F., \& Jin, Y. (2011). Keeping up with the digital age: How the American Red Cross uses social media to build relationships. Public Relations Review, 37, 37-43.

Burns, R. B., \& Burns, R. A. (2008). Business Research Methods and Statistics Using SPSS. Thousand Oaks, CA: Sage Publications.

Chalip, L. (2006). Towards social leverage of sport events. Journal of Sport \& Tourism, $11,109-127$.

Charity Commission. (2012). Our research. Retrieved from http://www.charitycommission.gov.uk/About_us/About_charities/Our_research_index.aspx

Chen, G. M. (2011). Tweet this: A uses and gratifications perspective on how active Twitter use gratifies a need to connect with others. Computers in Human Behavior, 27, 755-762.

Clavio, G. (2008). Demographics and usage profiles of users of college sport message boards. International Journal of Sport Communication, 1, 434-444.

Clavio, G. (2011). Social media and the college football audience. Journal of Issues in Intercollegiate Athletics, 4, 309-325.

Clavio, G., \& Kian, T. M. (2010). Uses and gratifications of a retired female athlete's Twitter followers. International Journal of Sport Communication, 3, 485-500.

Creswell, J. W. (2008). Educational research: Planning, conducting, and evaluating quantitative and qualitative research ( $3^{\text {rd }}$ ed.). Upper Saddle River, NJ: Pearson Education, Inc. 
Curtis, L., Edwards, C., Fraser, K. L., Gudelsky, S., Holmquist, J., Thornton, K., \& Sweester, K. D. (2010). Adoption of social media for public relations by nonprofit organizations. Public Relations Review, 36, 90-92.

Dawson, S. (1988). Four motivations for charitable giving: Implications for marketing strategy to attract monetary donations for medical research. Journal of Health Care Marketing, 8, 31-37.

Dillman, D. A. (2007). Mail and internet surveys: The tailored design method (2nd ed.). Hoboken, NJ: John Wiley \& Sons, Inc.

Dittmore, S. W., Stoldt, G. C., \& Greenwell, T. C. (2008). Use of an organizational weblog in relationship building: The case of a major league baseball team. International Journal of Sport Communication, 1, 384-397.

Divol, R., Edelman, D., \& Sarrazin, H. (2012, April). Demystifying social media. McKinsley Quarterly. Retrieved from http://www.mckinseyquarterly.com/Demystifying_social_media_2958

Dube, J. (2012, May 8). Why smartphones are the future of social networking. Forbes. Retrieved from http://www.forbes.com/sites/jondube/2012/05/08/whysmartphones-are-the-future-of-social-networking/

Dunne, A., Lawlor, M. A., \& Rowley, J. (2010). Young people's use of online social networking sites: A uses and gratifications perspective. Journal of Research in Interactive Marketing, 4, 46-58.

Ellison, N. B., Steinfield, C., \& Lampe, C. (2007). The benefits of Facebook “friends:” Social capital and college students' use of online social network sites. Journal of Computer-Mediated Communication, 12, 1143-1168. 
Facebook. (2012). Team in Training. Retrieved from http://www.facebook.com/myteamintraining

Fach, M. (2011, December 31). The evolution of Facebook features. Retrieved from http://www.searchenginejournal.com/the-evolution-of-facebook-features/37995/

Field, A. (2009). Discovering statistics using SPSS. ( $3^{\text {rd }}$ ed). Thousand Oaks, CA: Sage Publications.

Filo, K. R., Funk, D. C., \& O’Brien, D. (2008). It's really not about the bike: Exploring attraction and attachment to the events of the Lance Armstrong Foundation. Journal of Sport Management, 22, 501-525.

Filo, K., Funk, D. C., \& O'Brien, D. (2009). The meaning behind attachment: Exploring camaraderie, cause, and competency at a charity sport event. Journal of Sport Management, 23, 361-387.

Filo, K., Funk, D. C., \& O'Brien, D. (2010). The antecedents and outcomes of attachment and sponsor image within charity sport events. Journal of Sport Management, 24, 623-648.

Filo, K., Funk, D. C., \& O'Brien, D. (2011). Examining motivation for charity sport event participation: A comparison of recreation-based and charity-based motives. Journal of Leisure Research, 43, 491-518.

FirstGiving (2010). Marathon fundraising success guide for nonprofit organizations: Data analysis of 2010 Boston Marathon online fundraising. [White paper]. Retrieved from blog.firstgiving.com/wp.../Marathon-Fundraising-Success-Guide.pdf 
Funk, D. C., Jordan, J., Ridinger, L. \& Kaplanidou, K. (2011). Capacity of mass participant sport events for the development of activity commitment and future exercise intentions. Leisure Sciences, 33, 250-268.

Gladden, J. M., Mahony, D. F., \& Apostolopoulou, A. (2004). Toward a better understanding of college athletic donors: What are the primary motives? Sport Marketing Quarterly, 13, 194-208.

Gleason, C. (2012, July 24). 5 brands taking digital storytelling to the next level. Ignite Social Media. Retrieved from http://www.ignitesocialmedia.com/videomarketing/digital-storytelling-examples/

Green, B. C. (2001). Leveraging subculture and identity to promote sport events. Sport Management Review, 4, 1-19.

Grönroos, C. (2004). The relationship marketing process: communication, interaction, dialogue, value. Journal of Business \& Industrial Marketing, 19, 99-113.

Groves, R. M. (2006). Nonresponse rates and nonresponse bias in household surveys. Public Opinion Quarterly, 70, 646-675.

Guadagnoli, E. \& Velicer, W. F. (1988). Relation to sample size to the stability of component patterns. Psychological Bulletin, 103, 265-275.

Guy, B., \& Patton, W. E. (1989). The marketing of altruistic causes: Understanding why people help. The Journal of Consumer Marketing, 6, 19-30.

Hair, J., Black, W., Babin, B., Anderson, R., and Tatham, R. (2006). Multivariate Data Analysis. ( $6^{\text {th }}$ ed.). Upper Saddle River, NJ: Pearson Prentice Hall. 
Hambrick, M. E. (2012). Six degrees of information: Using social network analysis to explore the spread of information within sport social networks. International Journal of Sport Communication, 5, 16-34.

Hambrick, M. E., \& Mahoney, T. Q. (2011). 'It's incredible - trust me': Exploring the role of celebrity athletes as marketers in online social networks. International Journal of Sports Management and Marketing, 10, 161-179.

Hambrick, M. E., Simmons, J. M., Greenhalgh, G. P., \& Greenwell, T. C. (2010). Understanding professional athletes' use of Twitter: A content analysis of athlete tweets. International Journal of Sport Communication, 3, 454-471.

Hanna, R., Rohm, A., Crittenden, V. L. (2011). We're all connected: The power of the social media ecosystem. Business Horizons, 54, 265-273.

Hanson, G., \& Haridakis, P. (2008). YouTube users watching and sharing the news: A uses and gratifications approach. Journal of Electronic Publishing, 11, 3.

Hardin, R., Andrew, D. P. S., Koo, G., \& Bemiller, J. (2009). Motivational factors for participating in basic instruction programs. Physical Educator, 66, 71-84.

Haridakis, P., \& Hanson, G. (2009). Social interaction and co-viewing with YouTube: Blending mass communication reception and social connection. Journal of Broadcasting and Electronic Media, 53, 317-335.

Havenar, J., \& Lochbaum, M. (2003). Differences in participation motives of first-time marathon finishers and pre-race dropouts. Journal of Sport Behavior, 30, 270-279.

Hightower, R., Brady, M. K., \& Baker, T. L. (2002). Investigating the roles of the physical environment in hedonic service consumption: An exploratory study of sporting events. Journal of Business Research, 55, 697-707. 
Isaac, M. (2012, September 27). Instagram beats Twitter in daily mobile users for the first time, data says. All Things D. Retrieved from http://allthingsd.com/20120927/instagram-beats-twitter-in-daily-mobile-users-forthe-first-time-data-says/

Internet World Stats. (2012). Usage and population statistics. Retrieved from http://www.internetworldstats.com/facebook.htm

Johnson, P. R., \& Yang, S. U. (2010). Uses and gratifications of Twitter: An examination of user motives and satisfaction of Twitter use. Unpublished manuscript, S. I. Newhouse School of Public Communications, Syracuse University, Syracuse, NY.

Kaplan, A. M., \& Haenlein, M. (2010). Users of the world, untie! The challenges and opportunities of social media. Business Horizons, 53, 59-68.

Kassing, J. W., \& Sanderson, J. (2010). Fan-athlete interaction and twitter tweeting through the Giro: A case study. International Journal of Sport Communication, 3, 113-128.

Katz, E., Blumler, J. G., Gurevitch, M. (1974). Uses and gratifications research. The Public Opinion Quarterly, 37, 509-523.

Kietzmann, J. H., Hermkens, K., McCarthy, I. P., \& Silvestre, B. S. (2011). Social media? Get serious! Understanding the functional building blocks of social media. Business Horizons, 54(3), 241-251.

Kilpatrick, M., Hebert, E., \& Bartholomew, J. (2005). College students' motivation for physical activity: Differentiating men's and women's motives for sport participation and exercise. Journal of American College Health, 54, 87-94. 
King, S. (2001). An all-consuming cause: Breast cancer, corporate philanthropy, and the market for generosity. Social Text, 19, 115-143.

King, C. (2013, January 1). 21 social media predictions for 2013 from the pros. Retrieved from http:/www.socialmediaexaminer.com/social-media-predictions-2013/

Ko, Y. Y., Park, H., \& Claussen, C. L. (2008). Action sports participation: Consumer motivation. International Journal of Sports Marketing and Sponsorship, 9, 111-124.

Koo, G. Y., Andrew, D. P. S., Hardin, R., \& Greenwell, T. C. (2009). Classification of sport consumers on the basis of emotional attachment: A study of minor ice hockey fans and spectators. International Journal of Sport Management, 10, 307329.

Kottasz, R. (2004). How should charitable organisations motivate young professionals to give philanthropically? International Journal of Nonprofit and Voluntary Sector Marketing, 9, 9-27.

Lampe, C., Wash, R., Velasquez, A., \& Ozkaya, E. (2010). Motivations to participate in online communities. Proceedings of the ACM Conference on Human Factors in Computing Systems (CHI). Retrieved from http://rickwash.org/papers/pap1604_lampe.pdf

Leukemia and Lymphoma Society. (2011). Annual report. Retrieved from http://www.lls.org/content/nationalcontent/pdf/2011annualreport.pdf

Leukemia and Lymphoma Society. (2012). Fast Facts. Retrieved from http://www.lls.org/content/nationalcontent/pdf/about/factsheets/ TNTFactSheet.pdf 
Lindqvist, J., Cranshaw, J., Wiese, J., Hong, J., Zimmerman, J. (2011). I'm the mayor of my house: Examining why people use foursquare- a social-driven location sharing application. Conference proceedings for Computer Human Interactions, May 711, 2011, Vancouver, BC, Canada.

LIVESTRONG. (2012a). Fundraising Information. Retrieved from http://www.livestrong.org/Take-Action/Team-LIVESTRONGEvents/Fundraising-Information

LIVESTRONG. (2012b). Retrieved from http://www.livestrong.org/

Lovejoy, K., Waters, R. D., Saxton, G. D. (2012). Engaging stakeholders through Twitter: How nonprofit organizations are getting more out of 140 characters or less. Public Relations Review, 38, 313-318.

Lovejoy, K. and Saxton, G. D. (2012). Information, community, and action: How nonprofit organizations use social media. Journal of Computer-Mediated Communication, 17, 337-353.

Lucenko, K. (2012). Integrated marketing communications and social media: Systematic approach to social media incorporation to IMC strategies (Bachelor Thesis). Aarhus School of Business and Sciences, Denmark.

Luna-Arocas, R. \& Tang, T. L. P. (2007). The use of cluster analysis to segment clients of a sport center in Spain. European Sport Management Quarterly, 5, 381-413.

Mangold, W. G., \& Faulds, D. J. (2009). Social media: The new hybrid element of the promotion mix. Business Horizons, 52, 357-365.

McDonald, M. A., Milne, G. R., \& Hong, J. (2002). Motivational factors for evaluating sport spectator and participant markets. Sport Marketing Quarterly, 11, 100-113. 
Mooi, E., \& Sarstedt, M. (2011). A Concise Guide to Market Research. Springer: Berlin.

Morris, M. R., Counts, S., Hoff, A., Roseway, A., \& Schwarz, J. (2012). Tweeting is believing? Understanding microblog credibility perceptions. Proceedings of CSCW 2012. Retrieved from

http://research.microsoft.com/apps/pubs/default.aspx?id=155374

Muralidhara, S., Rasmussen, L., Patterson, D., Shin, J. (2011). Hope for Haiti: An analysis of Facebook and Twitter usage during the earthquake relief efforts. Public Relations Review, 37, 175-177.

National Sporting Goods Association. (2012). 2012 Participation - Ranked by total participation. Retrieved from http://www.nsga.org/i4a/pages/index.cfm?pageid=3483

Nettleton, S., \& Hardey, M. (2006). Running away with health: The urban marathon and construction of "charitable bodies." Health: An Interdisciplinary Journal for the Social Study of Health, Illness and Medicine, 10, 441-460.

Newmark, C. (2011, November 24). How the top 50 nonprofits use social media. Retrieved from http://connect-communicate-change.com/how-the-top-50nonprofits-use-social-media/

Nonprofit Research Collaborative. (2012, April). Nonprofit fundraising strategy: Covering charitable receipts at U.S. nonprofit organizations in 2011. [White paper]. Retrieved from http://www.nonprofitresearchcollaborative.org/nrc-report2011/

Nunnally, J. C., \& Bernstein, I. H. (1994). Psychometric theory (3rd ed.). New York: McGraw-Hill. 
Ortutay, B. (2012, October 4). Facebook tops 1 billion users. USA Today. Retrieved from http://www.usatoday.com/story/tech/2012/10/04/facebook-tops-1-billionusers/1612613/

Pachal, P. (2011, April 28). Why Friendster died: Social media isn't a game. PCMag. Retrieved from http://www.pcmag.com/article2/0,2817,2384588,00.asp

Park, N., Kee, K. F., \& Valenzuela, S. (2009). Being immersed in social networking environment: Facebook groups, uses and gratifications, and social outcomes. CyberPsychology \& Behavior, 12(6), 729-733.

Pegoraro, A. (2010). Look who's talking - athletes on Twitter: A case study. International Journal of Sport Communication, 3, 501-514.

Peloza, J., \& Hassay, D. N. (2007). A typology of charity support behaviors: Towards a holistic view of helping. Journal of Nonprofit \& Public Sector Marketing, 17, 135-151.

Porterfield, A. (2012, March 1). Three steps to an effective social media strategy. Retrieved from http://www.socialmediaexaminer.com/3-steps-to-an-effectivesocial-media-strategy/

Punj, G., \& Stewart, D. W. (1983). Cluster analysis in marketing research: Review and suggestions for application. Journal of Marketing Research, 134-48.

Raacke, J., \& Bonds-Raacke, J. (2008). MySpace and Facebook: Applying the uses and gratifications theory to exploring friend-networking sites. CyberPsychology \& Behavior, 11, 169-174. 
Rainie, L., Brenner, J., Purcell, K. (2012, September 13). Pew research center: Photos and videos as social currency online. [White paper]. Retrieved from http://pewinternet.org/ /media//Files/Reports /2012/PIP_OnlineLifeinPictures.pdf

Recours, R. A., Souville, M., \& Griffet, J. (2004). Expressed motives for informal and club/association-based sports participation. Journal of Leisure Research, 36, 1-22.

Reisinger, D. (2012, February 7). Is Facebook accurately counting its daily active users? Retrieved from http://news.cnet.com/8301-13506_3-57372392-17/is-facebookaccurately-counting-its-daily-active-users/

Rohm, A., Milne, G., \& McDonald, M. (2006). A mixed-method approach for developing market segmentation typologies in the sports industry. Sport Marketing Quarterly, 15, 29-39.

Ross, S. D. (2007). Segmenting sport fans using brand associations: A cluster analysis. Sport Marketing Quarterly, 16, 15-24.

Ruggiero, T. E. (2000). Uses and gratifications theory in the 21 st century. Mass Communication \& Society, 3, 3-37.

Run Walk Ride Foundation [RWRF]. (2012). Research. Retrieved from http://www.runwalkride.com/research.asp

Run Walk Ride Foundation [RWRF]. (2011). 2011 Run Walk Ride Fundraising Survey. Retrieved from http://www.runwalkride.com/uploads/2011\%20RWR\%20Top\%2030 \%20Summary\%20-\%20updated\%203-28-12.pdf

Sanderson, J. (2010). "The nation stands behind you”: Mobilizing social support on 38pitches.com. Communication Quarterly, 58, 188-206. 
Sanderson, J. (2011). Framing Tiger's troubles: Comparing traditional and social media. International Journal of Sport Communication, 3(4), 438-453.

Sargeant, A., Ford, J. B., \& Hudson, J. (2008). Charity brand personality: The relationship with giving behavior. Nonprofit and Voluntary Sector Quarterly, 37, 468-491.

Sargeant, A., West, D. C., \& Ford, J. B. (2004). Does perception matter?: An empirical analysis of donor behaviour. The Service Industries Journal, 24, 19-36.

Schoenstedt, L. J., \& Reau, J. (2010). Running a social-media newsroom: A case study of the Cincinnati flying pig marathon. International Journal of Sport Communication, 3, 377-386.

Schultz, B., \& Sheffer, M. L. (2010). An exploratory study of how Twitter is affecting sports journalism. International Journal of Sport Communication, 3, 226-239.

Seo, W. J., \& Green, B. C. (2008). Development of the motivation scale of sport consumption. Journal of Sport Management, 22, 82-109.

Shao, G. (2009). Understanding the appeal of user-generated media: A uses and gratification perspective. Internet Research, 19, 7-25.

Sheffer, M. L., \& Schultz, B. (2010). Paradigm shift or passing fad? Twitter and sports journalism. International Journal of Sport Communication, 3, 472-484.

Simpson, J. C. (1986, September 11). Baby boomers have 60's heritage, but charities say they're cheap. Wall Street Journal, 33.

Smith, A. (2011, November 15). Pew research center: Why Americans use social media. [White paper]. Retrieved from http://pewinternet.org/Reports/2011/WhyAmericans-Use-Social-Media.aspx 
Smith, A. C. T., \& Westerbeek, H. M. (2007). Sport as a vehicle for deploying corporate social responsibility. Journal of Corporate Citizenship, 25,43-54.

Snelgrove, R. \& Wood, L. (2010). Attracting and leveraging visitors at a charity cycling event. Journal of Sport \& Tourism, 15, 269-285.

Steinfield, C., Ellison, N. B., Lampe, C. (2008). Social capital, self-esteem, and use of online social network sites: A longitudinal analysis. Journal of Applied Developmental Psychology, 29, 434-445.

Stevens, J. (2009). Applied multivariate statistics for the social sciences. $\left(4^{\text {th }} \mathrm{ed}\right.$.). Mahawah, NJ: Lawrence Earlbaum Associates.

Swanson, S., Colwell, T., \& Zhao, Y. (2008). Motives for participation and importance of social support for athletes with physical disabilities. Journal of Clinical Sport Psychology, 2, 317-336.

Tabachnick, B. G., \& Fidell, L. S. (1989). Using multivariate statistics (2 ed.). New York, NY: Harper Collins Inc.

Team in Training [TNT]. (2012a). Retrieved from http://www.teamintraining.org Team in Training [TNT]. (2012b). Social Networking. Retrieved from http://www.teamintraining.org/firsttimehere/socialnetworking/

Team in Training [TNT]. (2012c). The mission and history. Retrieved from http://www.teamintraining.org/firsttimehere/themissionandhistory/

Team in Training [TNT]. (2012d). The corporate sponsor packet. Retrieved from Www.teamintraining.org/chapter/in/1368928/corpsponsor 
Tsorbatzoudis, H., Alexandris, K., Zahariadis, P., \& Grouios, G. (2006). Examining the relationship between recreational sport participation and intrinsic and extrinsic motivation and amotivation. Perceptual and Motor Skills, 103, 363-374.

Valenzuela, S., Park, N., \& Kee, K. F. (2009). Is there social capital in a social network site?: Facebook use and college students' life satisfaction, trust and participation. Journal of Computer-Mediated Communication, 14, 875-901.

Venkatesh, V., Morris, M. G., Davis, G. B., \& Davis, F. D. (2003). User acceptance of information technology: Toward a unified view. MIS Quarterly, 27, 425-478.

Walker, M., \& Kent, A. (2009). Do fans care? Assessing the influence of corporate social responsibility on consumer attitudes in the sport industry. Journal of Sport Management, 23, 743-769.

Wallace, N. (2012, June 15). Facebook fans increase by 70 percent at some nonprofits. The Chronicle of Philanthropy. Retrieved from http://philanthropy.com/blogs/social-philanthropy/facebook-fans-increase-by-70percent-at-some-nonprofits/31025

Wallace, L., Wilson, J., \& Miloch, K. (2011). Sporting Facebook: A content analysis of NCAA organizational sport pages and Big 12 conference athletic department pages. International Journal of Sport Communication, 4, 422-444.

Wasserman, T. (2012, April 6). Pinterest is now the no. 3 social network in the U. S. Mashable. Retrieved from http://mashable.com/2012/04/06/pinterest-number-3social-network/ 
Waters, R. D. (2011). Increasing fundraising efficiency through evaluation: Applying communication theory to the nonprofit organization--Donor relationship. Nonprofit and Voluntary Sector Quarterly, 40, 458-475.

Waters, R. D., Burke, K. A., Jackson, Z. J., Buning, J. D. (2010) Using stewardship to cultivate fandom online: Comparing how National Football League teams use their web sites and Facebook to engage their fans. International Journal of Sport Communication, 3, 163-177.

Waters, R. D., Burnett, E., Lamm, A., \& Lucas, J. (2009). Engaging stakeholders through social networking: How nonprofit organizations are using Facebook. Public Relations Review, 35, 102-106.

Waters, R. D., \& Jamal, J. J. (2011). Tweet, tweet, tweet: A content analysis of nonprofit organizations' Twitter updates. Public Relations Review, 37, 321-324.

Wharf Higgins, J., \& Lauzon, L. (2003). Finding the funds in fun runs: Exploring physical activity events as fundraising tools in the nonprofit sector. International Journal of Nonprofits and Voluntary Sector Marketing, 8, 363-377.

Williams, J., \& Chinn, S. J. (2010). Meeting relationship-marketing goals through social media: A conceptual framework for sport marketers. International Journal of Sport Communication, 3, 422-437.

Won, D., \& Park, M. (2010). Motivating factors influencing college students’ participation in charity sport events. International Journal of Sport Management and Marketing, 8, 296-321.

Won, D., Park, M., \& Turner, B. A. (2010). Motivations for participating in health related charity sport events. Journal of Venue and Event Management, 1, 17-44. 
Wood, L., Snelgrove, R., \& Danylchuk, K. (2010). Segmenting volunteer fundraisers at a charity sporting event. Journal of Nonprofit \& Public Sector Marketing, 22, 38-

54.

Zuniga, H. G., Jung, N., \& Valenzuela, S. (2012). Social media use for news and individuals' social capital, civic engagement and political participation. Journal of Computer-Mediated Communication, 17, 319-336. 


\section{APPENDIX A}

\section{Team in Training Dissertation Survey}

The following items are concerned with your behaviors and feelings related to Team in Training programs and events. Please select the response that best describes how you feel about each statement using a 7-point Likert-type scale

(Strongly Disagree $=1$, to Strongly Agree $=7$ ).

\section{Charity Sport Motives}

Cause

- A major reason I participate with TNT is to help enhance the status of the Leukemia and Lymphoma Society.

- My decision to participate with TNT was mainly determined by my desire to help support the Leukemia and Lymphoma Society.

- I participate in TNT to raise money for research and programs of the Leukemia and Lymphoma Society.

- I am proud to contribute to the Leukemia and Lymphoma Society through my participation with TNT.

\section{Philanthropy}

- I participate with TNT because I believe philanthropy is everyone's responsibility.

- I participate with TNT so that I can help out others in some small way.

- Supporting a charity gives me a sense of satisfaction.

- I participate with TNT because I think that it is important to give back.

- I participate with TNT because I feel a need to help others.

\section{Health and Fitness}

- I participate with TNT to stay active.

- I participate with TNT to stay in shape physically.

- Participating with TNT helps me maintain a healthy lifestyle.

- Participating with TNT aids in developing my physical fitness.

Sport

- Participating in this particular sport event (i.e., running/biking/triathlon) with TNT is an important part of my life.

- I am an enthusiast of running/biking/triathlon (i.e., the sport which you participate with TNT).

- My deep interest in running/biking/triathlon (i.e., the sport which you participate) sparked my interest in TNT.

- One of my reasons for engaging in TNT is to challenge my Social running/biking/triathlon abilities.

- Participating in TNT programs gave me a chance to meet new people with similar interests.

- I enjoy sharing the experience of participating with other TNT participants.

- Participating with TNT makes me feel like I belong to a group or community.

- I like the social interaction I have through my participation with TNT. 


\section{Social Media Consumption Motivations}

Social media consumption refers to the motivation of usage of various platforms (i.e., Facebook, Twitter, LinkedIn, YouTube, etc.). You will be asked about your motivations for usage of specific social media platforms next. However, the following questions are concerned with your generalized motivation for social media usage (i.e., across multiple platforms).

Please read the following statements and describe select the response that best describes how you feel about your motivation for social media usage, based on each of the following statements using a 7-point Likert-type scale (Strongly Disagree $=1$, Strongly Agree $=7$ ).

The primary reason I use social media is:

- To get peer support from others

- To meet interesting people

- To talk about something with others

- To stay in touch with people I know

- To communicate with friends and family

- To communicate with others

- To feel like I belong to a community

- To feel connected to other users on social media

- To make connections to other people on social media sites

- To belong to a group with same interests as mine

- To participate in discussions

- Because it is entertaining

- Because it is funny

- Because it is exciting

- Because it is easy to get information

- To learn about events

- To get useful information about product/services/events

- To search for information

- To keep up with current issues and events (e.g., news)

- To share information about myself (e.g., personal interests, profile)

- To share information with others (e.g., content-- links, news, ideas)

- To express myself freely

- To pass the time

- To escape from boredom

- So I can get away from family, friends or others

- Because it gives me something to occupy my time 
- My primary motivation for using Facebook is:

(open response)

- My primary motivation for using Twitter is: (open response)

- My primary motivation for using video social media platforms (e.g., YouTube, Vmeo, Viddy, etc.) is: (open response)

- My primary motivation for using photo social media platforms (e.g., Instagram, Pinterest, Flickr, etc.) is: (open response)

\section{Social Media Intensity Usage}

- Please check all social networks that you use:

○ Facebook, Twitter, YouTube, Pinterest, LinkedIn, FourSquare, Google+, Tumblr, Instagram, Ptch, Other (please specify)

- How are you accessing social media platforms?

○ Please check all that apply - mobile phone; mobile device/tablet (e.g., iPod, iPad, Kindle); laptop computer; desktop computer; public/shared computer; other

- Have you ever posted an original picture on a social media platform?

- Have you ever posted an original video on a social media platform?

- If yes, what method do you typically use to upload pictures or videos to social media platforms?

○ Mobile phone; mobile device/tablet (e.g., iPod, iPad, Kindle); laptop computer; desktop computer; public/shared computer; other

- Have you ever reposted or shared an existing picture on a social media platform?

- Have you ever reposted or shared an existing video on a social media platform?

- On a typical day, about how much time do you spend on social media platforms, such as Facebook, Twitter, YouTube, etc.?

○ No time at all, less than 30 minutes, 30 minutes to 1 hour, 1 to 2 hours, 2 to 3 hours, 3 to 4 hours, more than four hours each day

- On an average week, how many days per week do you use social media platforms?

o None, one day per week, two days per week, three days per week, four days per week, five days per week, six days per week, everyday

- How many times per day do you use social media platforms?

○ Not at all, very infrequently, somewhat infrequently, somewhat frequently, frequently, very frequently, all the time

Please select the response that best describes how you feel about each statement using a 7-point Likert-type scale (Strongly Disagree = 1, Strongly Agree =7).

- Social media usage is part of my everyday life

- Using social media platforms has become part of my daily routine

- I feel out of touch when I have not logged on to social media platforms in a while

- Using social media makes me feel like I am part of a virtual community 


\section{Behavioral Intentions}

Please select the response that best describes how you feel about each statement using a

7-point Likert-type scale ( Strongly Disagree $=1$, Strongly Agree $=7$ ).

\section{Future Event Participation Intent}

- It is likely that I will participate with TNT programs in the future

- The probability is high that I will participate in future TNT programs

- The likelihood of me participating with TNT next year is very high

Future Support of the Organization

- It is likely that I will donate to the Leukemia and Lymphoma Society in the future

- The probability is high that I will volunteer with TNT or the Leukemia and Lymphoma Society in the future

- I plan to support the Leukemia and Lymphoma Society in their programs and events in the future

Willingness to refer

- I will say positive things about participating with TNT to other people.

- I would recommend participating with TNT to someone who seeks my advice.

- I plan to encourage my friends and family to participate with TNT

\section{Demographic Information}

- Please select the event you most recently participated in with TNT.

- Half-Marathon, Marathon, Century Ride, Olympic Triathlon, HalfIronman, Ironman, Obstacle Race, Hiking Adventure, Other (please specify)

- When did you start participating in TNT? (List year)

- How many previous TNT seasons/events have you participated in? (List years)

- What chapter (or city) of TNT have you most recently participated with? (Open response)

- How did you hear about this survey?

- Email, Facebook, Twitter, Other (please specify)

- What is your gender?

- Male or Female

- What year were you born? (List years)

- What is your approximate household income?

○ Under $\$ 24,999 ; \$ 25,000$ - $\$ 34,999 ; \$ 35,000$ - $\$ 44,999 ; \$ 45,000$ - $\$ 54,999$; $\$ 55,000$ - $\$ 64,999 ; \$ 65,000$ - $\$ 74,999 ; \$ 75,000$ - $\$ 84,999 ; \$ 85,000$ $\$ 94,999 ; \$ 95,000$ - and above

- What is your highest level of education completed?

○ Less than high school degree; High school degree; Associates (2-yr) degree; Bachelor's (4-yr) degree; Master's degree; Higher than a Master's degree (i.e., $\mathrm{PhD}, \mathrm{MD}$, JD, etc.)

- What is your occupation? (Open response) 
- What is your ethnicity?

- White/Caucasian; Black/African American; American Indian/Native American; Pacific Islander; Asian/Asian American; Latino/a or Spanish Origin; Multiracial/Biracial; Other

- What else would you like to see through TNT online communications? 


\section{APPENDIX B}

\section{Email message sent from the TNT Director:}

Dear Team in Training participants,

Congratulations on successfully completing a season with TNT! In an effort to improve our programs and the communication channels we use to interact with you, we would love to have your input in this survey. Additionally, we have two $\$ 50$ Visa gift cards to give away to randomly selected survey respondents as an added incentive.

Please take ten minutes to complete the survey at https://www.surveymonkey.com/s/TNTDiss2 or contact the researchers: Dr. Chris Greenwell, Associate Professor at the University of Louisville (502-852-0555) or Tara Mahoney, at the University of Louisville (502-852-0312) for more information.

Thank you again for taking the time to fill out our TNT program survey and helping us to make these programs better for participants in the future. We could not do this without you-- You truly are saving lives, one mile at a time!

Click here to take the survey: https://www.surveymonkey.com/s/TNTDiss2

\section{Facebook and other social media platforms (blogs, forums):}

We are researchers with the University of Louisville, studying the use of social media by the charity sport organizations Team in Training. Are you someone who is (1) 18 years or older and (2) has participated in one or more TNT events? If so, we would like to hear from you. Additionally, we have two $\$ 50$ Visa gift cards to give away to randomly selected survey respondents as an added incentive.

Please take ten minutes to complete the survey at https://www.surveymonkey.com/s/TNTDiss2 or contact the researchers: Dr. Chris Greenwell, Associate Professor at the University of Louisville (502-852-0555) or Tara Mahoney, at the University of Louisville (502-852-0312) for more information.

\section{Twitter:}

Have you participated in 1+ Team in Training events and are 18+ yrs old? If so, please take this survey https://www.surveymonkey.com/s/TNTDiss2. Two $\$ 50$ giveaways as incentive! Contact Dr. Greenwell, at UofL (502-852-0555) for info. 
APPENDIX C

Other social media platforms used to disseminate TNT Survey:

- Bike Forum

○ Charity events

- Beginertriathlete.com

○ Triathlon Talk

- My Cup of Joe

- Competitor Forum

- DIS Boards

- IM Tri

- Road Bike Review

○ General Cycling Discussion

$\circ$ The lounge

- Runnersworld.com

- Beginners

- General Running

- Marathoners

- Not Related to Running

- Triathlon

- Slowtwitch.com

- Triathlon

o Women's

- Lavender room

- Spark People Forum

o Road Runners 2013

- Teamestrogen.com

- Charity Rides

- Trifuel.com

○ General Discussions 


\section{CURRICULUM VITA}

\section{Tara Quinn Mahoney}

tara.mahoney@louisville.edu

Work

110 B Studio Arts/HPES

Home

University of Louisville

Louisville, KY 40292

(502) 852-0312

1752 Deer Lane

Louisville, KY 40205

(315) 380-7981

\section{EDUCATION}

Ph.D. University of Louisville

(Anticipated May 2013)

Major Area: Educational Leadership \& Organizational Development Specialization: Sport Administration

Dissertation: Exploring the influence of social media on future intentions of charity sport participants

M.B.A. West Virginia Wesleyan College

2007

Major Area: Business Administration

B.S. Nazareth College of Rochester

2005

Major Area: Business Administration

Concentration: Sports Management 


\section{PROFESSIONAL EXPERIENCE}

University of Louisville, Louisville, KY

August 2010 - Present

Graduate Assistant, Department of Health and Sport Sciences

- Instructor:

- Organize and prepare all course materials including lectures, visual aids, assignments, exams, learning initiatives, as well as Blackboard course design and maintenance for the following:

- SPAD 489 Legal Aspects of Sport

- SPAD 404 Financial Principles in Sport

- SPAD 402/692 Internship in Sport Administration

- SPAD 401 Career Development in Sport

- SPAD 382 Organizational Behavior in Sport (Co-Instructor)

- Additional Graduate Assistant responsibilities include:

- Assist with COSMA accreditation process and self-study

- Assist with various grants and research projects for SPAD faculty

- Assist in coordination and implementation of various SPAD special events

- Served as Assistant to the Editor, Sport Management Education Journal

- Worked as teaching assistant to multiple SPAD courses

University of Louisville, Louisville, KY

Research Assistant, Department of Health and Sport Sciences

January 2012 - Present

- Assist with research and evaluation projects on a three-year, \$1.5 million federally funded grant from the Social Innovation Fund

- Assist with database creation for participation tracking.

- Assist with the development, testing, and administration of evaluation instruments.

- Conduct interviews and focus groups with community partners.

- Analyze quantitative and qualitative data from specified evaluation instruments, interviews, and websites.

- Assist with the development of the process, impact and outcome results to Meade Activity Center and Social Innovation Fund.

Town of Sullivan, Chittenango, NY

Recreation Supervisor, Department of Parks and Recreation

May 2007 - July 2010

- Plan, schedule, and coordinate recreational programs, leagues, and special events for over 5,000 participants yearly.

- Effectively train, supervise, and manage a staff of over 100 employees throughout the year.

- Coordinate special events such as Sullivan Community Council annual fishing derby, Easter egg hunt, summer concert series, and annual golf tournament. 
West Virginia Wesleyan College, Buckhannon, WV

August 2005 - May 2007

Outdoor Recreation Coordinator - Graduate Assistant, Department of Campus Activities

- Develop and market a yearly schedule of recreation events for over 3,000 students, faculty, staff, and alumni.

- Organize and lead trips; coordinate group reservations, transportation, liability, and insurance waivers.

- Manage budget: prepare proposals, record expenditures, and revenues plus implement cost saving techniques.

\section{SCHOLARLY \& ACADEMIC ACTIVITIES}

\section{Refereed Publications}

Ha, J. P., King, K. M., \& Mahoney, T. Q. (in review) Development and psychometric evaluation of the Point of Attachment in Physical Activity scale. Journal of Physical Activity and Health.

Mahoney, T. Q., Hambrick, M. E., Svensson, P. G., Zimmerman, M. (in review) Examining emergent niche sports YouTube exposure through the lens of the Psychological Continuum Model. International Journal of Sport Management and Marketing.

Hambrick, M. E., Simmons, J. M., \& Mahoney, T. Q. (in review) A mixed methods inquiry of female Ironman participants and their attitudes towards leisure-workfamily conflict. International Journal of Sport Management and Marketing.

Dodds, M., Han, P., \& Mahoney, T. Q. (in review) Illegal procedure: Regulating student athlete's social media usage. Case Studies in Sport Management.

Hambrick, M. E., Mahoney, T. Q., \& Calabrese, R. (2012). Clicking for a cause: Using social media campaigns to drive awareness for charitable organizations and professional golf tournaments. Case Studies in Sport Management, 1.

Hambrick, M. E., \& Mahoney, T. Q. (2011). 'It's incredible - trust me': Exploring the role of celebrity athletes as marketers in online social networks. International Journal of Sport Management and Marketing, 10, 161-179.

\section{Scholarly Presentations}

Svensson, P. G., Mahoney, T. Q., Hambrick, M. E. (2013, May). Exploring the usage of social media to enhance community action in a sport for development context. To be presented at the annual conference of the North American Society of Sport Management, Austin, Texas. 
Mahoney, T. Q., Svensson, P. G., \& Hambrick, M. E. (2013, March). Mobile applications--encouraging the competitive spirit or reckless behavior?: An examination of negligence and negligent marketing. Presented at the annual conference of the Sport Recreation and Law Association, Denver, Colorado.

Mahoney, T. Q., Hambrick, M. E., Svensson, P. G., Zimmerman, M. (2013, February). Examining emergent niche sports YouTube exposure through the lens of the Psychological Continuum Model. Presented at the Sixth Summit of Communication and Sport, Austin, Texas.

King, K. M., Ketterman, K., Gillespie, J. S., Mitchell, E. C., Kuhns, J. N., Turner, H. E., \& Mahoney, T. Q. (2012, November). Coalition effectiveness in promoting physical activity in rural Kentucky. Presented at the annual Kentucky Association for Health, Physical Education, Recreation and Dance conference, Louisville, Kentucky.

King, K. M., Mahoney, T. Q., Ketterman, K., Gillespie, J. S., Greenwell, A., Turner, H. E., Mitchell, E. C., \& Kuhns, J. N. (2012, October). The Meade Activity Center (MAC) Project: Process evaluation results from a rural community coalition's physical activity intervention. Presented at the annual Society for Public Health Education (SOPHE) conference, San Francisco, California.

Hambrick, M. E., Simmons, J. M., \& Mahoney, T. Q. (2012, May). A mixed-method inquiry into the perceptions of leisure-work-family conflict among female

Ironman participants. Presented at the annual conference of the North American Society of Sport Management, Seattle, Washington.

Hambrick, M. E., Mahoney, T. Q., \& Calabrese, R. (2012, March). Clicking for a cause: Using social media campaigns to drive awareness for charitable organizations and professional golf tournaments. Presented at the Fifth Summit on Communication and Sport, Peoria, Illinois.

Mahoney, T. Q., \& Moorman, A. M. (faculty advisor). (2012, March). Expansion of the transformative use test and the impact on sport video games and athlete privacy rights. Presented at the annual conference of the Sport Law and Recreation Association, Greensboro, North Carolina.

Mahoney, T. Q., Svensson, P. G., \& Moorman, A. M. (2012, March). Online social media usage in sports: Damages in 140 characters or less. Presented at the annual conference of the Sport Law and Recreation Association, Greensboro, North Carolina.

Mahoney, T. Q. (2012, March). Preliminary qualitative findings of female Ironman participants and their attitudes towards leisure-work-family conflict. Presented at the annual Spring Research Conference, Louisville, Kentucky.

Mahoney, T. Q. (2011, April). Using social media to facilitate partnerships in a sport for development context. Poster presented at the Louisville I.D.E.A.L.S. Festival, Louisville, Kentucky. 
Mahoney, T. Q., Hancock, M. G., Hambrick, M. E., \& Moorman, A. M. (2011, March). Title IX retaliation claims on the rise in college athletics: An analysis of athletic departments' mishandling of sex discrimination claims. Presented at the annual conference of the Sport Law and Recreation Association, Savannah, Georgia.

Hancock, M. G., Mahoney, T. Q., Hambrick, M. E., \& Moorman, A. M. (2011, March). 'After I complained... ': An analysis of non-discrimination and retaliation policies of university athletic departments involved in Title IX litigation. Presented at the annual conference of the Sport Law and Recreation Association, Savannah, Georgia.

\section{Scholarly Works in Progress}

Mahoney, T. Q., \& Moorman, A. M. Expansion of the Transformative Use Test and the Impact on Sport Video Games and Athlete Privacy Rights. To be submitted to Journal of Legal Aspects of Sport. (Final manuscript revisions)

Mahoney, T. Q., Hambrick, M. E., Calabrese, R. Friends with benefits: An examination of social media usage to increase event awareness raise funds for a cause. To be submitted to Sport Marketing Quarterly. (Final manuscript revisions)

Svensson, P. G., Mahoney, T. Q., Hambrick, M. E. Exploring the usage of social media to enhance community action in a sport for development context. To be submitted to Sport Management Review. (Manuscript revisions)

King, K. M., Mahoney, T. Q., Mitchell, E., Coleman, R. C. Coalition effectiveness in promoting physical activity in rural Kentucky. To be submitted to Preventing Chronic Disease: Public Health Research, Practice, and Policy. (Data collected)

Freberg, K., Mahoney, T. Q., \& King, K. M. Meade Activity Center: An examination of communication channels in a rural recreation context. To be submitted to Journal of Health Communication. (Data collected)

\section{Guest Lectures}

Charity Sporting Events, (2013, February 25). SPAD 536 Sport Administration in Nonprofit Organizations. University of Louisville, KY.

Charity Participation Sport. (2012, October 22). SPAD 703 Sport Consumer Research. University of Louisville, Louisville, KY.

Contracts. (2012, September 4). SPAD 689 Legal Aspects of Sport. University of Louisville, Louisville, KY. 
Introduction to Doctoral Research. (2012, August 30). ELFH 710 Doctoral Seminar in Educational Leadership. University of Louisville, Louisville, KY.

Social Media as a Marketing Tool. (2012, April 10). SPAD 383 Sport Marketing. University of Louisville, Louisville, KY.

Title IX. (2012, April 2). SPAD 489 Legal Aspects of Sport. University of Louisville, Louisville, KY.

Financial Principles. (2011, November 7). SPAD 281 Principles in Sport Administration. University of Louisville, Louisville, KY.

Sexual Harassment. (2011, November 7). SPAD 489 Legal Aspects of Sport. University of Louisville, Louisville, KY.

Financial Principles. (2011, April 20). SPAD 281 Principles in Sport Administration. University of Louisville, Louisville, KY.

Social Media in Sport. (2011, April 14). SPAD 391 Sociology of Sport. University of Louisville, Louisville, KY.

Youth in Sports. (2011, April 7). SPAD 284 Issues and Ethics in Sport. University of Louisville, Louisville, KY.

iPad Case Study. (2011, March 31). SPAD 490 Senior Seminar. University of Louisville, Louisville, KY.

Feasibility Studies. (2011, March 31). SPAD 404 Financial Principles of Sport. University of Louisville, Louisville, KY.

Campus Recreation. (2011, February 22). SPAD 390 Sport Governance. University of Louisville, Louisville, KY.

Introduction to Recreation Management (2009, November). SPT 375 Sport Administration. Nazareth College of Rochester, Rochester, NY.

Wild and Wonderful West Virginia: Benefits of Outdoor Recreation (2009, February). Lunch and Learn Series. West Virginia Wesleyan College, Buckhannon, WV. 


\section{GRANT AND FUNDING ACTIVITIES}

Mahoney, T. Q. Travel to Denver, Colorado for the 2013 Sport Recreation and Law Association (SRLA) Conference. Funded by the Department of Health and Sport Sciences, University of Louisville in the amount of $\$ 175$.

Mahoney, T. Q. Travel to Austin, Texas for the Sixth Summit on Sport and Communication. Funded by the Sport Administration Club, University of Louisville in the amount of $\$ 200$.

Mahoney, T. Q. Travel to Austin, Texas for the Sixth Summit on Sport and Communication. Funded by the Graduate Student Council, University of Louisville in the amount of $\$ 250$.

Mahoney, T. Q. Subcontracted research assistant for Meade Activity Center research and evaluation. Funded by the Department of Health and Sport Sciences, University of Louisville, through the Social Innovation Fund in the amount of \$7,700.

Mahoney, T. Q. Travel to Seattle, Washington for the 2012 North American Society of Sport Management (NASSM) Conference. Funded by the Department of Health and Sport Sciences, University of Louisville in the amount of $\$ 300$.

Mahoney, T. Q. Bernard Patrick Maloy Graduate Student Research Award. Expansion of the Transformative Use Test and the Impact on Sport Video Games and Athlete Privacy Rights. Funded by the Sport Law and Recreation Association (SRLA) in the amount of $\$ 500$.

Mahoney, T. Q. Travel to London, Ontario, Canada for the 2011 North American Society of Sport Management (NASSM) Conference. Funded by the International Center, University of Louisville in the amount of $\$ 300$.

Mahoney, T. Q. Travel to London, Ontario, Canada for the 2011 North American Society of Sport Management (NASSM) Conference. Funded by the Graduate Student Council, University of Louisville in the amount of $\$ 300$.

Mahoney, T. Q. Travel to Savannah, Georgia for the 2011 Sport Recreation and Law Association (SRLA) Conference. Funded by the Graduate Student Council, University of Louisville in the amount of $\$ 300$. 


\section{SERVICE}

International Association for Communication and Sport Member

2012 - Present

North American Society for Sport Management

Member

2010 - Present

Sport, Recreation, and Law Association

Member

2010 - Present

Student Initiatives Committee

2011 - Present

Board of Directors, Student Representative

$2011-2012$

University of Louisville - Spring Research Conference

Chair, Conference Site Committee

$2011-2012$

Abstract Reviewer

$2011-2012$

New York State Recreation and Parks Society

Member

$2007-2010$

Central New York Recreation and Parks Society

Member

$2007-2010$

President-Elect

$2009-2010$

Secretary

$2008-2009$

\section{HONORS AND AWARDS}

2013 - School of Interdisciplinary and Graduate Studies - Dean's Citation

2013 - University of Louisville Red and Black Faculty Mentor

2013 - Sixth Summit on Communication and Sport - Distinguished Research Paper

2012 - Graduate Teaching Academy - Selected participant in the University-wide yearlong intensive teaching program, sponsored by the School of Interdisciplinary and Graduate Studies

2012 - Bernard Patrick Maloy Graduate Student Research Award - Sport Recreation and Law Association

2008 - Outstanding Special Event - New York State Recreation and Parks Society

2008 - Outstanding Special Event - Central New York Recreation and Parks Society

2008 - Outstanding Flyer/Brochure - Central New York Recreation and Parks Society

2005 - Sport Management Achievement Award - Nazareth College of Rochester 
2004 - Volleyball Defensive Player of the Year - Nazareth College of Rochester 2004 - Volleyball Team Captain - Nazareth College of Rochester 2003 - Volleyball Team Captain - Nazareth College of Rochester 2002 - 2005 - Sigma Beta Delta, International Honor Society in Business, Management and Administration

\section{ACTIVITIES}

\section{Volunteer}

- NCAA Volleyball Championships

- Louisville Ironman

- Kentucky Speedway NASCAR

- Kentucky Derby Festival Marathon

- Kentucky Derby Festival Parade

- US Grand Prix of Cyclocross

- University of Kentucky Market Research Team

- Leukemia and Lymphoma Society - Team in Training

- Mentor - Lake Placid Half-Marathon

- Participant - Lake Placid Marathon

- Special Events Volunteer

- Special Olympics Volleyball
November 2013

August 2011, 2012

July 2011

April 2011

April 2011

October 2010

August 2010

2009

2008

$2008-2010$

$2001-2005$

\section{Coaching}

- Bishop Grimes High School

○ Junior Varsity Women's Volleyball Coach

$2007-2010$

- Assistant Varsity Women's Volleyball Coach

$2007-2010$

- West Virginia Wesleyan College

- Volunteer Assistant Women's Volleyball Coach

$2005-2007$

- Volley FX - Rochester Volleyball Club Coach

- Head Volleyball Coach - 15 and Under Girls

$2003-2005$ 